Utah State University

DigitalCommons@USU

$5-2020$

\title{
Dramatic Play Affordances of Outdoor Settings for First and Second Grade Children With and Without Disabilities
}

Nicholas R. LeSchofs

Utah State University

Follow this and additional works at: https://digitalcommons.usu.edu/etd

Part of the Landscape Architecture Commons

\section{Recommended Citation}

LeSchofs, Nicholas R., "Dramatic Play Affordances of Outdoor Settings for First and Second Grade Children With and Without Disabilities" (2020). All Graduate Theses and Dissertations. 7769.

https://digitalcommons.usu.edu/etd/7769

This Thesis is brought to you for free and open access by the Graduate Studies at DigitalCommons@USU. It has been accepted for inclusion in All Graduate Theses and Dissertations by an authorized administrator of DigitalCommons@USU. For more information, please contact digitalcommons@usu.edu.

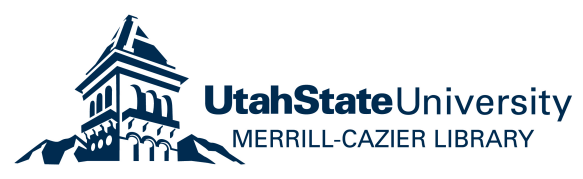




\title{
DRAMATIC PLAY AFFORDANCES OF OUTDOOR SETTINGS FOR FIRST AND SECOND GRADE CHILDREN WITH AND WITHOUT DISABILITIES
}

\author{
by \\ Nicholas R. LeSchofs \\ A thesis submitted in partial fulfillment \\ of the requirements for the degree \\ of \\ MASTER OF LANDSCAPE ARCHITECTURE
}

Approved:

Keith Christensen, Ph.D.

Major Professor

Jake Powell

Committee Member
Lisa Boyce, Ph.D.

Committee Member

UTAH STATE UNIVERSITY

Logan, Utah 
Copyright (C) Nicholas R. LeSchofs 2020

All Rights Reserved 


\begin{abstract}
Dramatic Play Affordances of Outdoor Settings for First and Second Grade Children With and Without Disabilities
\end{abstract}

by

\title{
Nicholas R. LeSchofs, Master of Landscape Architecture
}

Utah State University, 2020

\section{Major Professor: Dr. Keith Christensen}

Department: Landscape Architecture and Environmental Planning

Unstructured play is crucial for children's development. For first and second graders, dramatic play is valuable, as it advances their cognitive skills, social skills, and emotional intelligence. Interactions among children with and without disabilities are valuable opportunities to further children's development. This study compared dramatic play affordances of play settings to determine which settings afforded the most dramatic play amongst first and second graders with and without disabilities. Eighty-nine six-toeight-year-olds were observed daily during lunch recess on an inclusive playground. Behavior mapping identified settings that afforded dramatic play, imitative role-play, make-believe with objects, make-believe with actions and situations, interaction, and verbal communication. Settings with characteristics of loose parts, stage-like areas, natural props, enclosed areas, slightly-themed settings, and open-ended settings afford dramatic play. Specifically, Zip Slide, the Spiral Slide, Sensory Wave Rock N Raft, the Open Grassy Hill, and the Nature Play Areas afforded the most dramatic play. Playgrounds that include these settings or settings with these characteristics may afford 
greater dramatic play opportunities among first and second graders with and without disabilities. The study suggests that a well-designed inclusive playground reduces barriers for children with disabilties, creating an enviroment where children with diabilities can engage in similar play behaviors with their typically developing peers. 


\section{PUBLIC ABSTRACT}

Dramatic Play Affordances of Outdoor Settings for First and Second Grade Children with and without Disabilities

\section{Nicholas R. LeSchofs}

Unstructured play is crucial for children's development. Dramatic play is play involving a transformation of objects, actions, or self-identity. During dramatic play, children may operate at more advanced cognitive levels than they do in non-dramatic play, thereby furthering their cognitive, social, and emotional skills. Interactions among children with and without disabilities are valuable opportunities to further a children's development.

This study compared dramatic play behaviors among first and second grade children with and without disabilities to determine which play settings encouraged children to engage in quality dramatic play. Eighty-nine six-to-eight-year-olds were observed during lunch recess daily on an inclusive playground. Through behavior mapping of the children's play behaviors, specific settings were identified that afforded the most dramatic play,

The study suggests that a well-designed inclusive playground reduces barriers for children with disabilties, creating an enviroment where children with diabilities can engage in similar play behaviors with their typically developing peers. Settings with characteristics of loose parts, stage-like areas, natural props, enclosed areas, slightly themed settings, and open-ended settings offered children opportunities for dramatic play. Specifically, Zip Slide, the Spiral Slide, Sensory Wave Rock N Raft, Open Grassy Hill, 
and the Nature Play Areas encouraged the most dramatic play. Therefore, a welldesigned inclusive playground that includes settings designed with these characteristics may encourage children with and without disabilities in the first and second grades to engage in peer interactions and dramatic play to further their development. 


\section{ACKNOWLEDGMENTS}

I am extremely grateful to all of those with whom I have had the pleasure to work during my thesis project. I would like to thank my committee members, Dr. Keith Christensen, Prof. Jake Powell, and Dr. Lisa Boyce, for their insightful, straightforward, good-natured encouragement, and their time, knowledge, support, and valuable insight throughout this entire process. I'd also like to thank graduate researcher Lindsie Smith for her help with data collection. Nobody has been more important to me during the process of my project than my family and friends. I would like to thank my parents, whose love and guidance are with me in whatever I pursue. Then there are my friends. who are a great support in deliberating over problems and findings, as well as providing many happy distractions. Finally, my thanks goes out to the first and second grade participants that reminded me how exciting it truly is to play and make-believe.

Nicholas R. LeSchofs 
CONTENTS

Page

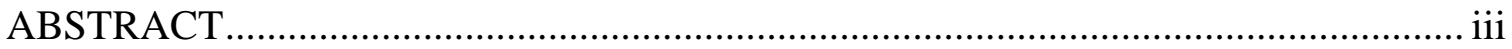

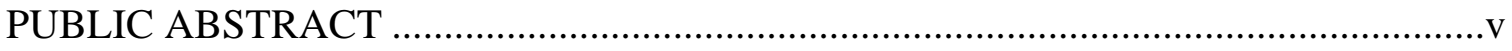

ACKNOWLEDGMENTS ....................................................................................... vii

LIST OF TABLES

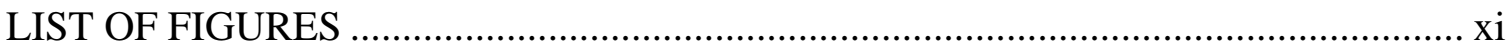

CHAPTER

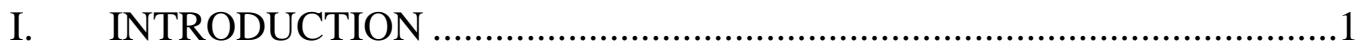

Unstructured Play is Necessary .................................................................

Dramatic Play Enhances Children's Development.....................................2

Playgrounds Afford Opportunities for Dramatic Play ..................................

Children with Disabilities Need Dramatic Play ..............................................6

Children with Disabilities have fewer Opportunities for Dramatic Play .....6

Elementary School-aged Play is Critical for those with Disabilities............7

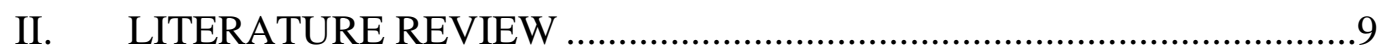

Development During the First and Second Grade Years...............................

Play: Stages and Development...........................................................13

Types of Dramatic Play ......................................................................15

Playground Features that Afford Dramatic Play .........................................16

Play in Children with Disabilities ..........................................................19

The 7 Principles of Inclusive Design .......................................................24

A Framework for the Study of Playgrounds ..............................................24

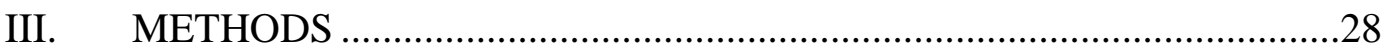

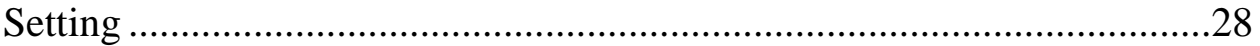

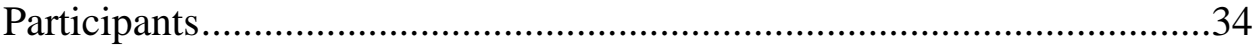

Measures - Type of Dramatic Play...........................................................35

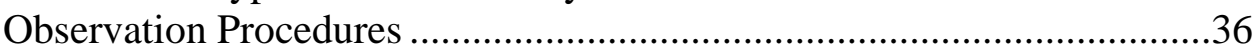

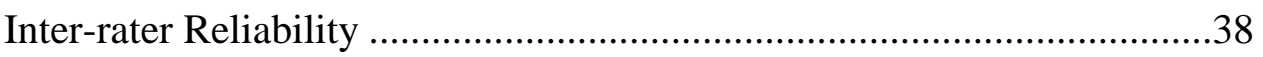


IV. RESULTS

Type of Dramatic Play and Setting .....................................................42

Playground Setting and Type of Dramatic Play .....................................55

Children with and without Disabilities and Dramatic Play ......................56

Children with and without Disabilities and Dramatic Play and Follow-up

Tests

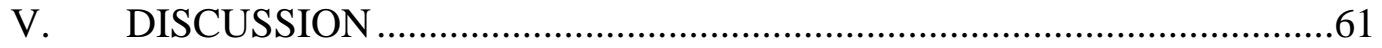

Dramatic Play in Play Episodes ........................................................66

Multiple Children ..............................................................................63

Dramatic Play in Open-ended Settings ................................................64

Dramatic Play on the Elementary School Playground............................65

Type of Dramatic Play Related to Settings ............................................65

Settings That Did Not Afford Dramatic Play .........................................68

Play of Children with and without Disabilities.....................................70

Anecdotal Observations/Playground Characteristics...............................73

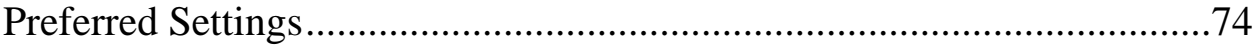

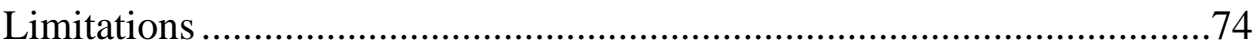

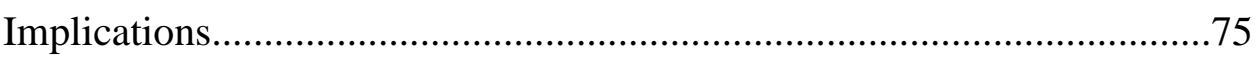

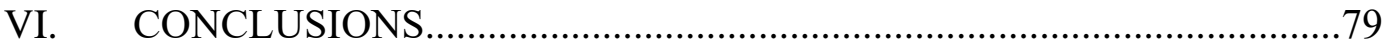

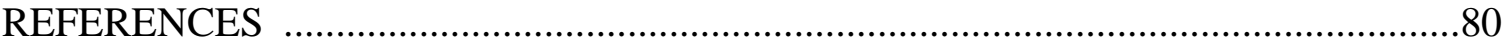

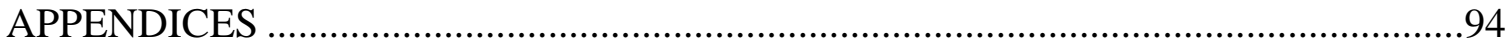

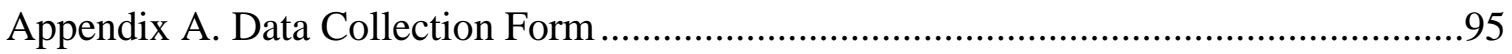

Appendix B. Data Collection Defined Measures.....................................................99

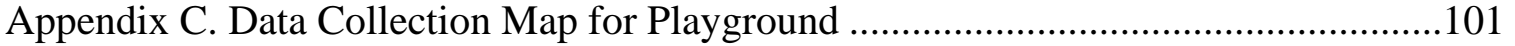

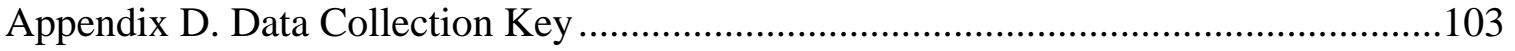

Appendix E. Parental Consent Form ...................................................................... 105 


\section{LIST OF TABLES}

Table Page

1. Settings with the Most Dramatic Play ..........................................................43

2. Settings with the Most Imitative Role-play .................................................45

3. Settings with the Most Make-believe with Objects ..........................................47

4. Settings with the Most Make-believe with Actions and Situations ......................49

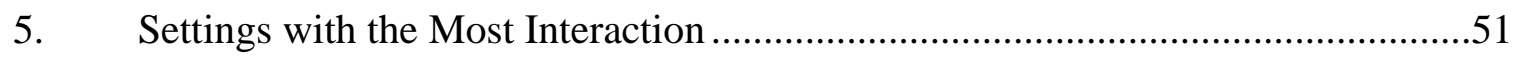

6. Settings with the Most Verbal Communication .............................................53

7. Median Test of Frequency for Type of Dramatic Play and Disability .................57

8. Descriptive Statistics of Type of Dramatic Play and Disability ..........................58 


\section{LIST OF FIGURES}

Figure

1. Aerial Image of Utah State University Campus with Playground..... .30

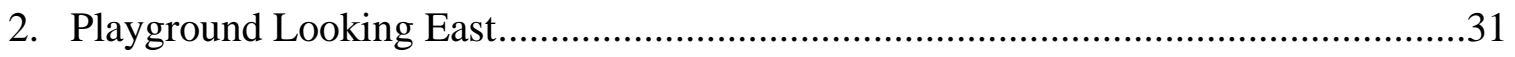

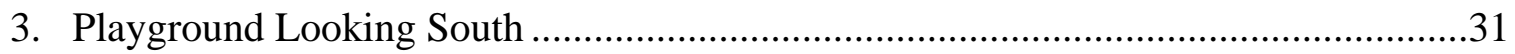

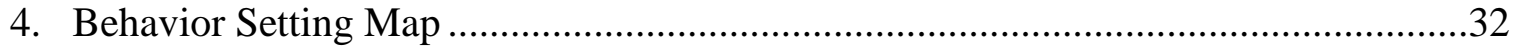

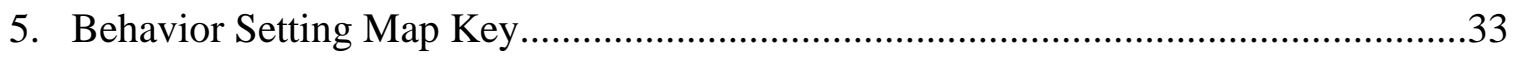

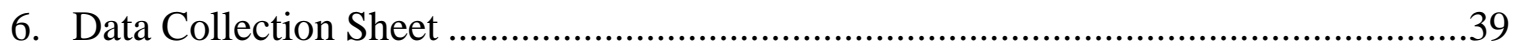

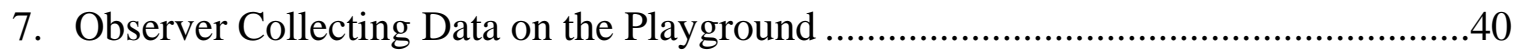

8. Distribution of Observed Children with an IEP Designation .................................41

9. Distribution of Dramatic Play Types across All Settings .......................................42

10. Settings That Afforded the Most Dramatic Play.....................................................44

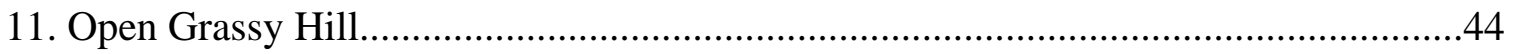

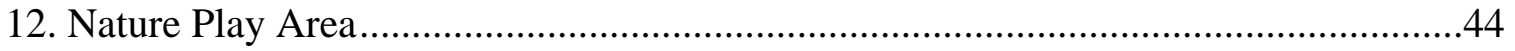

13. Settings That Afforded the Most Imitative Role-play .........................................46

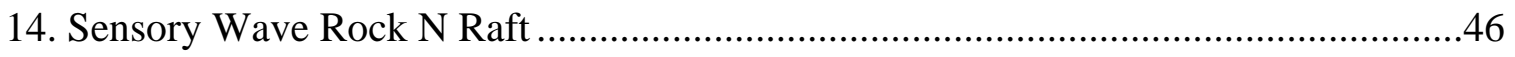

15. Settings That Afforded the Most Make-believe with Objects..................................48

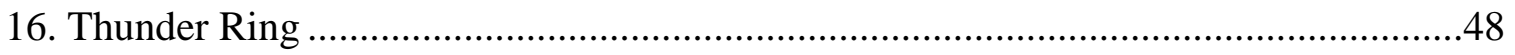

17. Settings That Afforded the Most Make-believe with Actions and Situations..............50

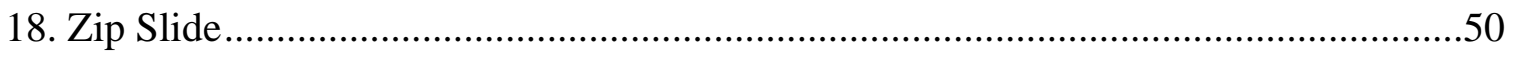

19. Settings That Afforded the Most Interaction.........................................................52

20. Settings That Afforded the Most Verbal Communication........................................54 
21. Type of Dramatic Play Distribution among Children with and without

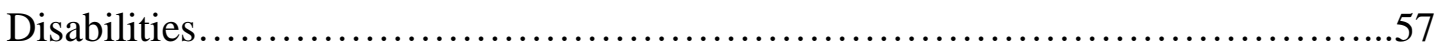

22. Settings That Children with Disabilities Were More Likely to Use..........................58

23. Sensory Wave Seat, Erractic Climber, and the Stego Climber .................................58

24. Settings That Children without Disabilities Were More Likely to Use ......................59

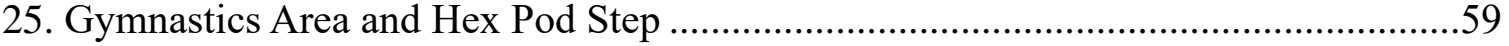




\section{CHAPTER I}

\section{INTRODUCTION}

Unstructured play is necessary for children's development. Children continue to learn and develop through dramatic play. Playgrounds provide a setting for unstructured play where children can engage in dramatic play. Children with disabilities are no different than their peers in their need to engage in dramatic play. However, children with disabilities have fewer opportunities for dramatic play than children without disabilities. Elementary school-aged play is critical for those with disabilities, as they often lack opportunities for dramatic play. Therefore, the purpose of this study is to determine whether inclusive playground design practices support increased congruent dramatic play behavior among first and second grade children with and without disabilities at Edith Bowen Elementary School in Logan, Utah.

\section{Unstructured Play is Necessary}

According to Petrie and Clarkin-Phillips (2018), unstructured play is critical for children's overall development, including development of social, cognitive, and mental/emotional skills. Play is an activity where children can amuse and occupy themselves (Burdette \& Whitaker, 2005). Play allows children the opportunity to expend their energy, use their imagination, be creative, and develop their mental and emotional competence. During play, children have a critical opportunity to interact with their peers, parents, or caregivers (Ginsburg, 2007). Through unstructured play, children optimize their brain development (Burdette \& Whitaker, 2005), decide how to play, where to play, and with what and whom to play (Houtz, 2017). Unstructured play offers children the chance to use their imaginations, solve problems, 
and work through a variety of challenges (Jacoby-Garrett, 2018). Play can also help children learn to socialize, self-regulate, and gain self-confidence (Starling \& Nelson-Zlupko, 2011). Burdette \& Whitaker (2005) believed that unstructured play helps children to regulate emotional states, including depression, anxiety, aggression, and sleep problems. Berman (2007) hypothesized that children who participate in unstructured play grow up to be adults who can be leaders in life and in the workplace. Through unstructured play, children develop strength, agility, fine and gross motor control, physical confidence, conflict resolution skills, cooperation, impulse control, literacy, and critical thinking as they practice experimentation and independent thinking. Play supports the development of the whole child (Houtz, 2017).

Every child engages in play (Jacoby-Garrett, 2018). Playgrounds are environments that afford children an opportunity to engage in play. Play is crucial for children's development (Mitchell et al., 2006). Children learn life lessons on the playground which help them overcome adversity later in life, because the playground is a microcosm of adult life. While on the playground, children learn that they cannot always get what they want. They learn how to be patient and how to let their frustrations out in ways that will not hurt other children or themselves. They also learn about their personal limits and the consequences of going too far. "If kids learn it on the playground, they're going to be able to apply it in other places in their lives" (Vaira, 2009, p. 34). Playing on the playground provides children the opportunity to develop skills to handle their emotions.

\section{Dramatic Play Enhances Children's Development}

Children continue to learn and develop through dramatic play. Dramatic play is imaginative behavior involving a transformation of objects, actions, and self-identity (Petrakos \& 
Howe, 1996). When children participate in dramatic play, they are deeply engaged in many kinds of learning (Drucker et al., 1999). Researchers have linked dramatic play to various aspects of cognitive development (Cooper \& Dever, 2001). Dramatic play provides a nonthreatening, child-centered environment where children teach, learn, and experience real-life roles. "Because pretend play allows children to construct narratives spontaneously, alone or in collaboration with others, it is an arena for the development of one of the most important intellectual capacities of the human mind" (Drucker et al., 1999, p. 11). Dramatic play promotes language and vocabulary growth, stimulates imagination and creative thinking, and fosters critical thinking and high-level cognitive processes (Johnson, 1998). Children explore materials and discover possibilities, confront problems and find solutions, and create narratives that reflect and extend their experience of themselves and the world. In this way, they learn without being directly taught (Drucker et al., 1999). "When children use one object to represent another, they practice the symbol-making process necessary to read, write, and understand math” (Brown, 2017, p. 166). During dramatic play, children organize and synthesize information, interpret ideas, create new ideas, interact cooperatively with others, and think out loud (Johnson, 1998). Therefore, during dramatic play, children may operate at more advanced cognitive levels than they do in nondramatic play (Hatcher \& Pretty, 2004). In this way, dramatic play serves as a vehicle for symbolic imagination and "as-if" thinking. It consists of the physical enactment of symbolic scenarios and is an activity that involves understanding, negotiation, and coordination of action by participants (Nicolopoulou \& Ilgaz, 2013). "Dramatic play is a particularly rich area for exploring and consolidating learnings about the social world" (Drucker et al., 1999, p. 10). Children collaborate with each other, make suggestions and decisions, and compromise. Through their interactions with each other, they exercise and enhance their social understandings and 
skills of working with others and standing up for themselves (Drucker et al., 1999).

Furthermore, dramatic play gives students a sense of ownership over their learning (Johnson, 1998). It stretches the children's imagination. It gives them a chance to feel what it is like to be an adult and provides an opportunity to interact and become aware of their boundaries. Dramatic play contributes to the child's overall development (Jelks \& Dukes, 1985).

\section{Playgrounds Afford Opportunities for Dramatic Play}

Playgrounds provide a setting for unstructured play where children can engage in dramatic play. Playgrounds provide children a variety of play environments which afford opportunities for learning skills, social development, and interaction (Hudson \& Thompson, 2001; Mitchell et al., 2006). Playgrounds were originally intended to be open public space to be used as a teaching tool to encourage play (Association, 2006; Oke \& Middle, 2016).

Playgrounds are one of the most important places to which children should be exposed during their development (Eden, 2008). They are unique in that they are some of the last remaining environments that offer children a chance to develop specific skills with physical activity (McConkey, 2018). Playing outside on playgrounds provides children with the freedom to run, shout, and manipulate the environment (White \& Stoecklin, 1998). Playgrounds provide practical spaces for children to play and are essential in their development (Mitchell et al., 2006).

Dramatic play can also occur outside on the playground ("A Staff Training Aid: Pretend Play," 2003). Props on a supervised playground can enhance children's dramatic play experience (Association, 2006). A study by Shim, Herwig, and Shelley (2001) found that children were more likely to be engaged in interactive dramatic play outdoors than in an indoor classroom. Older preschool children (aged four to five) found types of play experiences outside more readily 
than in the classroom. The older preschool children were more likely than the younger preschool children (aged two to three) to engage in dramatic play on the outdoor playground (Shim et al., 2001). These findings are consistent with the work of Henniger (1985), who found that older children were more likely to participate in dramatic play on the playground than younger children. This same study found that children were more likely to be involved in interactive dramatic play outdoors than indoors (Shim et al., 2001). Cooper \& Dever (2001) describe the dramatic play experiences of a group of first-graders in the classroom. In this study, the children demonstrated their knowledge of how written communication conveys a message through the use of an open/closed sign on a pretend card store. Children practiced their developing skills through participation of dramatic play in this pretend card store by creating, pricing, and selling greeting cards. Preparing for and engaging in dramatic play provides children with a child-centered environment where they can teach, learn, and experience real-life roles. These dramatic play experiences provide evidence of the value of dramatic play (Cooper \& Dever, 2001). Cloward-Drown (2014) observed and compared the play of 24 preschoolers on a natural and a manufactured playground. The results indicated that "the natural playground afforded more dramatic play than the manufactured playground. Specifically, $75 \%$ of the observed solitary dramatic play, $51 \%$ of the observed sociodramatic play, and $91 \%$ of the observed complex sociodramatic play occurred on the natural playground" (p. 38). In recent years, there has been an increase of playgrounds specifically designed to afford dramatic play (Eden, 2008; Oke \& Middle, 2016). 


\section{Children with Disabilities Need Dramatic Play}

Children with disabilities are no different than their peers in their need to engage in dramatic play. All children, including those with disabilities, benefit from play (Barton, 2015).

"Play is a functional goal for children with disabilities" (Martin, 2014, p. 3). The benefits of physical activity are universal for all children, including those with disabilities (Murphy \& Carbone, 2008). Play contributes to learning and development (Barton, 2015). Participation of children with disabilities in physical activity programs promotes better physical, emotional, and social well-being (Murphy \& Carbone, 2008). Prellwitz and Skär (2007) performed a study to better understand how children with different abilities use playgrounds to engage in creative play and interact socially with their peers. "The results from the present study indicate that playgrounds are important environments for all children, regardless of their abilities" (Prellwitz \& Skär, 2007, p. 153). Dramatic play behaviors are important for children with disabilities. For children with disabilities, dramatic play is a predictor of social abilities later in life, so many curriculums for children with disabilities include dramatic play, as it is a functional skill within the cognitive domain. Dramatic play is a functional goal because it provides children with skills to both access their environment and engage with peers. Dramatic play is important for children with disabilities (Barton \& Wolery, 2008).

\section{Children with Disabilities Have Fewer Opportunities for Dramatic Play}

Children with and without disabilities participate in similar types of play (Solish et al., 2010). Yet children with disabilities have fewer opportunities for dramatic play than children without disabilities. "Recent research concerning the activity participation of individuals with disabilities suggests that they do not have the same opportunities as their typically developing 
(TD) peers, although they may have similar desires" (Solish et al., 2010, p. 227). Research shows that the developmental levels of children with disabilities could be a greater influence on their play with peers than their chronological age (Hestenes \& Carroll, 2000). Children with disabilities may have fewer opportunities to engage in dramatic play because of physical (restricted mobility), cognitive (understanding the complexity of play), or socioemotional (difficulty initiating and/or maintaining appropriate social interaction) disabilities (Hestenes \& Carroll, 2000). They engage in fewer play behaviors, display less variety in their play (Barton, 2015), and have a difficult time playing creatively and actively (Brodin, 2005). Typically developing children's play progresses from simple types of play to more advanced types. However, children with disabilities may fail to progress to more advanced types of play (DiCarlo \& Reid, 2004). Children normally play without interference from adults or caretakers, but for children with disabilities, this is not always possible, as some are dependent on support from others (Brodin, 2005). Failure to progress to more advanced types of play can have detrimental effects on children, including reducing learning opportunities and overall skill development (DiCarlo \& Reid, 2004). A disability may limit the amount of success a child has in engaging in dramatic play with peers.

\section{Elementary School-aged Play is Critical for Those with Disabilities}

Elementary school-aged play is critical for those with disabilities, as they often lack opportunities for dramatic play. The type, quality, and diversity of children's play is affected by the type, quality, and diversity of the play environments (Czalczynska-Podolska, 2014). A welldesigned and organized playground provides play opportunities, stimulates a wide range of developmental skills (Wardle, 2000), and supports a variety of play types, including dramatic 
play (Shin \& Frost, 1995). Previous research shows relationships not only between children's behavior on the playground and the type of playground, but between specific activities and playground features, therefore suggesting that some playground features affect play type. However, "more research on the utilization of playgrounds and children's interactions with space and peers is needed" (Czalczynska-Podolska, 2014, p. 134). Researchers have systematically examined children's play. These examinations were often motivated by the theoretical stances of Piaget (1962) and Vygotsky (1967), both of whom saw play as serving an important role in preschoolers' social development. As such, much of the subsequent research on children's play has been confined to the preschool years. Therefore, the play of elementary school-aged children has been neglected (Pellegrini \& Perlmutter, 1989). Yet the period of elementary school is a critical period in the development of children (Fromberg \& Bergen, 2006). As the development and social needs of children with disabilities run parallel with other children, play at this time of life is especially critical for elementary school-aged children with disabilities. Dramatic play for children with disabilities is perhaps even more important at this age since they often lack opportunities for peer interactions (Overton \& Rausch, 2002). 


\section{CHAPTER II}

\section{LITERATURE REVIEW}

\section{Child Development During the First and Second Grade Years}

Children's development during the first and second grade years (ages six to eight) has been well-documented. This knowledge creates a starting point for understanding the role that age-appropriate play spaces have in supporting children's growth (Isenberg \& Quisenberry, 2002). A well-designed playground acknowledges developmental needs, influences how children play, and provides an opportunity for children to grow. While Barbour (1999) and Ünal (2009) studies on a broad range of age groups concludes that playgrounds should include a variety of options for children at all developmental stages, this study focuses on children's development during the first and second grade years, or from six to eight years of age. Understanding the basics of children's development allows landscape architects, as playground designers, to design play spaces and evaluate the effectiveness of play spaces to support age-appropriate play activities.

Copple and Bredekamp's textbook (2009), Developmentally Appropriate Practice in Early Childhood Programs, indicates that during the primary school grades (ages six to eight), children continue to develop. They further their gross motor, fine motor, social, and moral skills. From the ages of six to eight, children look for ways to apply their learned skills. They now find learning experiences that build on their interests more engaging and meaningful; their learning experiences are more complex. Children in this age group encounter tasks that are more difficult and require more precision than in earlier years. They enjoy becoming more confident and 
independent as they adapt their skills. They are now aware of how they compare with their peers and care about social approval (Copple \& Bredekamp, 2009).

Physically, elementary-age children have improved use of all body parts. Elementary-age children become more adept physically and attempt more physical challenges than preschool children. Their gross motor skills, such as balance and sequences of movements, are refined, so they have more controlled and purposeful coordination of their bodies. Fine motor skills, such as writing and drawing, are also refined and become more precise during these ages (Copple \& Bredekamp, 2009). Encouraging children to participate in physical exercise or play leads to increased metabolic rates, motor coordination and function, and relationships among peers. For example, when children play fighting warriors (dramatic play), they enhance their physical development. "Children first understand that actions (and objects on which one might act) can be separated from reality and can be based on the meaning of a given situation, rather than on the physical properties of objects" (Lillard et al., 2013, p. 3).

Socially, elementary-age children develop a more complete understanding of how their behaviors affect others and begin to better understand their roles in society. They begin to work with and care about others, respect and appreciate diversity, and develop positive approaches to learning. Children start to form interests in the opinions and abilities of their peers, and, therefore, are better able to engage in conversations. Elementary-age children can now estimate their self-worth (either by pride or shame), compare their performance to their peers, and understand limits due to their abilities. Emotionally, children in the first and second grade develop the ability to infer others' thoughts, feelings, and intentions, an ability which is integral to developing and maintaining relationships (Copple \& Bredekamp, 2009). Children's ability to regulate their own emotional states (Eisenberg et al., 1993) and infer others' emotional states is 
important to forming peer relationships (Cassidy et. al., 1992). Dramatic play provides children with an opportunity for prosocial behavior by developing emotional regulatory skills through collaborating and negotiating the direction of play with their social peers.

Cognitively, elementary-age children's vocabulary increases significantly. In this period of time, they transition from merely listening, speaking, and reading to incorporating what was read into real-life scenarios. Elementary-age children are more flexible and proficient in mental representation and acquire the ability to think in a more dimensional way (Copple \& Bredekamp, 2009). Elementary-age children learn how to reason with common sense (Eccles, 2000). Morally, they develop their ability to reflect, internalize moral rules, and act according to a conscience (Copple \& Bredekamp, 2009). There is a relationship between dramatic play and cognitive development in children. Allowing children to be involved in dramatic play activities where they perform at higher cognitive levels increases logical thinking, metacognition, problem solving, memory, and attention (Bergen, 2002).

Piaget argued that changes during the dramatic play stage of children's development follow an inverted bell curve (Piaget, 1962). According to Piaget, dramatic play begins to develop at age two, increasing over the next three or four years (Fein, 1981) as children begin to mentally form representations of objects (Rathus, 2013), and declining once a child reaches the age of seven and play becomes more realistic and logical (Fein, 1981). Piaget believed the dramatic play stage of a child's development concluded at age seven, but others have since questioned whether dramatic play concludes at seven or if it depends on the child (Oke \& Middle, 2016). Others argue that dramatic play does not disappear; it just takes place in a different context (Scarlett et al., 2005). Dramatic play is often associated with the preschool years because it is during those years that it fully emerges (Scarlett et al., 2005). During the 
primary grades, functional and constructive play decreases (Refshauge et al., 2013). In children with disabilities, one study showed that dramatic play peaked in first and second grade (Eifermann, 1971; Fein, 1981, p. 1097).

Dramatic play develops through a sequence of stages and phases of increasing levels of sophistication (Oke \& Middle, 2016). Overton \& Jackson (1973) found that when two groups of children (aged three to four and six to eight) were asked to pretend to comb their hair, most three- and four-year-old children used a body part (fingers) as a comb substitute, whereas six- to eight-year-old children imagined a comb in hand. During late childhood (ages six to 12), children rarely participate in dramatic play at school because new academic demands require greater attention and more serious behavior. However, outside of school, children engage in dramatic play with small groups of good friends (Scarlett et al., 2005). Scarlett et al. (2005) gives an example of children aged seven and nine engaging in dramatic play using play mobiles or materials to create elaborate play scenes. Children in this age range engage in dramatic play by incorporating pretense into their games via rules. They also develop fantasies and alternative scenes in their minds. This usually carries on into adolescence and even adulthood (daydreaming). It is in this age range that children begin to fantasize about alternative lives lives with adventure and romance. In this way, dramatic play is connected to reality in ways that are not common to preschoolers. Becoming a famous singer or a world-famous athlete are possible options in the elementary school child's play (Scarlett et al., 2005). During dramatic play in this age group, children continue to develop control of their emotions and more mature ways of expressing those emotions, ultimately leading to more openness, thoughtfulness, creativity, and a better understanding of relationships later in life (Scarlett et al., 2005). These children are also less aggressive, less impulsive, and better able to differentiate between fantasy 
and reality (Singer \& Singer, 1990). Given the importance of dramatic play during the primary grades, it is important to design playgrounds for dramatic play. Lillard et al. (2010) found that dramatic play is neglected in playground designs. Through surveys of government agencies, designers, and developers, Oke \& Middle (2016) found that when a playground is designed, it is unlikely that either the local government or the developer will consider dramatic play. Despite its importance, surprisingly little is known about the types of dramatic play on the playground during the first and second-grade years, as further research was motivated by the theoretical stances of Piaget (1962) and Vygotsky (1967). As a result, much of the research on children's play has been confined to the preschool years. Because of this, the play of elementary schoolaged children has been neglected (Pellegrini \& Perlmutter, 1989), even though the elementary school years are a critical period in the development of children (Fromberg \& Bergen, 2006).

Oke \& Middle (2016) concluded that dramatic play is neglected in playground design, and therefore, greater education is needed addressing the value of dramatic play in playground design.

\section{Play: Stages and Importance in Child Development}

Theorists have varying opinons and explanations for the purposes and functions of children's play, but they all concur that play occupies a central role in children's development. As children play, they refine and develop skills that allow them to feel safe, secure, and confident (Isenberg \& Quisenberry, 2002). First and second grade children have the opportunity to use their imagination, solve problems, work through challenges, and develop many skills (Jacoby-Garrett, 2018). Play affords different types of learning, and therefore, the development of different types of skills (Copple \& Bredekamp, 2009). As children develop, their play 
becomes more complex (Isenberg \& Quisenberry, 2002). Smilansky (1968), while using psychologist Jean Piaget's theories of cognitive development, developed the four stages of play: functional play, constructive play, dramatic play, and games with rules. These reflect a child's increasing cognitive development. The focus of this study was dramatic play.

Dramatic play is a higher level of play behavior and provides a connection to children's performance on cognitive tasks, including language and academic achievement (McClintic \& Petty, 2015). It allows children to understand themselves and others while developing in critical ways (Wilson, 2007, 25). Dramatic play means adopting roles and pretending to be something or someone else (Copple \& Bredekamp, 2009). It includes house/family play, superhero play, protect/rescue play, chase games, and nurture/care play (Logue \& Harvey, 2009). Children discover new situations and emotions (Wardle, 2000) through transformations by acting out stories (Christie, 1990). Dramatic play also includes using a prop to represent a mental picture. For example, if a child picks up a banana and uses it like a telephone by talking into it, then the child has "transformed" the object (a banana) into another object (a telephone). The child has a mental picture of a telephone (Strickland \& Morrow, 2000). Dramatic play invites creativity and social interaction (Wilson, 2007) with involvement and cooperation. It also provides a window into the thoughts and cooperation of their peers (Copple \& Bredekamp, 2009). Dramatic play allows children an opportunity to practice language skills as well (Copple \& Bredekamp, 2009). When children actively engage in dramatic play with peers, they must communicate clearly to be understood. This results in many clarifications and negotiations between peers (Strickland \& Morrow, 2000). Dramatic play provides a large "scope for movement, and the play can be on a larger scale and involve the whole child" (Wilson, 2007, p. 25). "High-level dramatic play produces documented cognitive, social, and emotional benefits" (Copple \& Bredekamp, 2009, p. 
15). Thus, opportunites for dramatic play should be available to children everyday (Wilson, 2007).

\section{Types of Dramatic Play}

A modification of the Smilansky Scale, similar to that used by Elias \& Berk (2002), was used to code children's dramatic play, as it assesses the maturity of a child's drama and play through identifying play elements. The types of dramatic play are listed in increasing levels of cognitive and social development, and the maturity of the children's play depends on the presence of these elements and the extent to which dramatic play is sustained. The scale uses five behaviors and persistence of a play episode to indicate the presence and maturity of dramatic play (Elias \& Berk, 2002, Smilansky \& Shefatya, 1990)

1. Imitative role-play. A child engages in self-referenced role-play using imitative vocalizations or actions; he/she becomes a character other than himself/herself in another context.

2. Make-believe with objects. A child uses verbal declaration, movements, and/or a substitute object (which is not a replica of the actual object) to represent a real object in a play episode.

3. Make-believe with actions and situations. A child uses verbal declarations to substitute for action or to describe a situation to further the play episode.

4. Interaction. There are at least two children collaborating to develop or maintain a play scene. This is other-referenced role-play, in which a child commands, explains, offers play props, or gestures to a peer(s) with the intent that the peer(s) will listen and use his/her suggestions to build the play episode. 
5. Verbal communication. There is verbal dialogue between play partners within a play scene. Either a child speaks as a role-played character or speaks for an auxiliary character represented by an object.

6. Persistence of play episode. A child remains in an imaginary framework to support continuance of a play episode. The child may undertake multiple roles, but continues to follow a definite theme. There is some elaboration or repetition. Interruption may take place as long as the child returns to the original theme.

Social participation may increase with development and age, but by first and second grade, children can play in collaboration and are fully capable of engaging in higher levels of play behaviors. "As a child progresses in play development, the rules become less attached to roles and begin to refer to the child him/herself, which means, they become a tool of awareness of the child's own behavior"' (Savina, 2014, p. 1697). Through play, children learn life lessons, develop habits, build character, and shape and refine their personalities (Vaira, 2009). They connect with peers, experiment with their identities, and learn about human relationships. Play helps to expand children's views and improve their ability to include other people, so they can better function in society.

\section{Playground Features that Afford Dramatic Play}

Studies have shown specific playground features afford children the possibility to engage in dramatic play. Dramatic play is influenced by facilitators such as loose moveable parts (props) (Drown \& Christensen, 2014, Refshauge et al., 2013, Woolley, 2008), plants (and the space 
between them) (Fjortoft, 2000, Refshauge et al., 2013), and platforms/stages (Drown \& Christensen, 2014, Maxwell et al., 2008, Refshauge et al., 2013).

Facilitators are items that have been shown to encourage dramatic play among children (Eden, 2008). Moveable parts (props) are materials in the environment that children can move and manipulate in the way they desire; such materials add complexity and variety to playgrounds (Wilson, 2007) and range from natural materials, such as leaves, sticks from vegetation, (Refshauge et al., 2013), wood, water, sand, and stones/rocks, (Zahra \& Moore, 2013) to construction materials, such as wire, plastic, and lumber (Wilson, 2007), and even manufactured materials, such as toys, blocks, cloth, and tools (McClintic \& Petty, 2015). Moveable parts (props) create personal places which afford children opportunities to interact with the environment (Refshauge et al., 2013). They also offer educational benefits and creative stimulation for children (Zahra \& Moore, 2013). Moveable parts (props) encourage children's imagination to transform (McClintic \& Petty, 2015), alter, interact with, and better understand their environment (Woolley \& Lowe, 2013, Zahra \& Moore, 2013), and should be strategically placed throughout the playground to afford the most dramatic play, while still allowing children to move freely (Wilson, 2007).

Plants are flexible and afford possibilities for children to hide without being excluded from nearby activities (Fjortoft, 2000). Children can hide in or walk through the vegetation (Zahra \& Moore, 2013), and trees and vegetation can afford opportunities for climbing and hanging, all of which are great opportunities for dramatic play, such as rescue play. A bush can become a house, with walls that embrace an entire group for house/family play (Fjortoft, 2000).

Refshauge et al. (2013) integrated a playground into a park. This playground included behavior settings (a play structure and a swing for functional play, a sand play area for dramatic 
and constructive play, and an open space consisting of turf, topography, and asphalt for games (with rules), in order to allow for all types of play. After observations, it was determined that dramatic play occurred most often in the playhouse in the sand area. The playhouse resembled a watchtower with stairs and a hollow space underneath (Refshauge et al., 2013). Drown \& Christensen (2014) found that some specific playground features afford more dramatic play than others. The specific playground features that afforded more dramatic play were a rectangular brick structure, a rectangular brick structure with a stage, and a play castle. Structures with low overhead ceilings, walls, or vegetation to form implied ceilings and walls are spatially distinct behavior settings that impact dramatic play (Drown \& Christensen, 2014). Moore \& Wong (1997) found that less-constructed structures, such as a sandbox, also afforded dramatic play. This emphasizes the importance of an enclosure for dramatic play (Drown \& Christensen, 2014). Mason (1982) argued that playground equipment designed to afford dramatic play should be flexible and adaptable. He believed, a cubby can be a house for one play episode and a fort for the next is far better than one which looks very much like a castle. This would not inspire the children to treat it as anything but a castle (Mason, 1982). In recent years, additional items, including climbing domes, pirate ships, cars, and ride-on-toys have been added to playgrounds to help facilitate dramatic play (Eden, 2008, Oke \& Middle, 2016). Playground features that can be broken down and remodeled, such as construction or scrounge materials, and natural materials (plants, water, and sand) are effective in encouraging dramatic play in children (Brett, Moore, \& Jr, 1993, Oke \& Middle, 2016). 


\section{Play for Children with Disabilities}

Children with disabilities are no different than their peers in their need for peer interaction (Locke et al., 2016). However, "children with intellectual disability and specific language impairments participate in less conversation and social interactions with peers on the playground" (Stanton-Chapman \& Schmidt, 2016, p. 91). Through research interviews, Yantzi et al. (2010) also found that children with disabilities experience many barriers and do not feel included on the playground, yet they have similar developmental needs. "All children do not need to access play spaces in the same way, but they are all fundamentally entitled to go out and play," he wrote (Yantzi et al., 2010, p. 68).

Ethical, empirical, and theoretical rationales emphasize the benefits that children with disabilities receive from interactions with typically developing peers (Hestenes \& Carroll, 2000). Interactions with typically developing peers are important (Fernelius, 2017, Prellwitz \& Skär, 2007). Peer interactions could lead to more friendships among children with disabilities, which promotes the development of social competence (Frankel et al., 2011). Bauminger, Finzi-Dottan, Chason, \& Har-Even (2008) suggest that children with disabilities would benefit socially from friendships with typically developing children. Friendships that include both children with and without disabilities were "found to be more durable and stable and to exhibit higher levels of goal-oriented social behaviors and positive affect" (Frankel et al., 2011, p. 571).

Through play on the playground, children develop an awareness for the environment, learn social norms and values, and develop skills. For children with disabilities, these skills are important for their development (Prellwitz \& Skär, 2007) because they help increase their ability to relate with others, thereby facilitating their transition into adulthood (Stanton-Chapman \& Schmidt, 2017). However, children with disabilities may not interact with their typically 
developing peers because of social and physical/environmental barriers (Loy \& Dattilo, 2000), as well as personal barriers (Stanton-Chapman \& Schmidt, 2017) and sensory issues (Prellwitz \& Skär, 2007).

The physical attributes of the playground can also be difficult for children with disabilities to master, and, therefore, an obstacle for participating in play (Prellwitz \& Skär, 2007). Ensuring that children with disabilities take advantage and fully benefit from these opportunities still remains a challenge and is not often considered when playgrounds are designed (Stanton-Chapman \& Schmidt, 2016).

Children with disabilities may experience social barriers from peers and staff. According to Taub \& Greer (2000), even teachers have stereotypes about what children with disabilities are capable of doing. Taub \& Greer (2000) also found that typically developing children assume that children with disabilities are not capable of engaging in play. Because of this misconception, children with disabilities are usually given the role of spectator, rather than an active role in games. Taub and Greer (2000) continued, "Instead of a child with a disability being viewed as just another child, the child's disability can become the master status or salient social identity" (p. 396). The schedules of children with disabilities can also act as a social barrier. Many children with disabilities have set daily schedules for playtime which are different than their typically developing peers. This puts them at a distinct disadvantage when it comes to joining in games (Mejeur et al., 2012, Woolley With et al., 2006). Other social barriers may include, but are not limited to, children's fears of being teased by their peers (Prellwitz \& Skär, 2007), parental fears that a child may experience bullying (Woolley With et al., 2006), and the fact that children with disabilities are rarely alone on playgrounds, as they are often accompanied by an 
adult who disturbs the normal play patterns between children with and without disabilities (Prellwitz et al., 2001).

Children with disabilities may also experience physical or environmental barriers on the playground which may lead to reduced social participation (Rimmer, 2005, Stanton-Chapman \& Schmidt, 2017). Physical/environmental barriers include, but are not limited to, inaccessible routes, poorly maintained and crowded playgrounds (Prellwitz et al., 2001), playgrounds located in areas of high traffic (Pereira, 2004), and the physical design of some playgrounds, including the arrangement of playground settings (Taub \& Greer, 2000). Skär (2002) found that children with disabilities had difficulties accessing the playground equipment, including the slides, swings, and climbing structures. The children in the study described the difficulties they faced getting on and off the playground equipment without an adult, because of their need for a mobility aid (Skär, 2002). Prellwitz (2007) surveyed 41 municipalities in Northern Sweden regarding the number of playgrounds built to be accessible for children with mobility disabilities. The results showed that of the 2,266 playgrounds surveyed, only two were built to be accessible for children with mobility disabilities. Also, 46 of the playgrounds surveyed had only one piece of playground equipment that could be accessed by a child with a mobility disability. Other physical or environmental barriers could include architectural barriers and practices, social attitudes, discrimination, and organizational policies (Stanton-Chapman \& Schmidt, 2017).

Two other barriers that children with disabilities experience are personal and sensory. According to Stanton and Schmidt (2017), personal barriers include a limited number of instances for peer interaction, deficits in motor skills which impact overall mobility, cognitive delays, and social-emotional delays, all of which may influence processing abilities (StantonChapman \& Schmidt, 2017). Children with sensory disabilities in the first and second grade 
typically have trouble paying attention, interacting with peers, and learning. In fact, "the child may present with poor motor coordination for more refined gross motor skills (jump rope, ball skills) as well as fine motor skills (handwriting) and overall motor endurance" (Critz, Blake, \& Nogueira, 2015, p. 712). Difficulties in motor planning (dyspraxia) causes poor performance of coordinated actions and new motor activities on the playground, which may lead to feelings of inadequacy, social isolation, or behavioral outbursts (Critz et al., 2015). Prellwitz \& Skär (2007) suggested playing with sand, water, and noisemakers to help children with sensory issues on the playground.

Mejeur et al. (2012) performed a systematic literature review of best practices for fullinclusive playgrounds. The results yielded four articles that discuss the difference in play among children with and without disabilities (Mejeur et al., 2012). These articles include "The Play of Children with Special Needs in Mainstream and Special Education settings" (Bray \& Cooper, 2007), "Playground Interactions for Preschool-Age Children with Special Needs" (Nabors \& Badawi, 1997), "Relations Between Activities and Cooperative Playground Interactions for Preschool-Age Children with Special Needs" (Nabors et al., 1999), and "Playground Accessibility and Usability for Children with Disabilities: Experiences of Children, Parents and Professionals" (Prellwitz, 2007).

Bray \& Cooper (2007) found that children with disabilities had substantial delays in their play, meaning they played well below their chronological age. The chronological age of the children in the study was 60 months, yet the play age among the children with disabilities was only 34.3 months (Bray \& Cooper, 2007).

Results of Nabor \& Badawi's (1997) study indicate that children with disabilities engage in less cooperative play than typically developing peers. In the course of the study, they engaged 
in solitary play or were with a teacher more often than they interacted with their typically developing peers. They often arrived on the playground at a different time than their typically developing peers, and therefore had fewer chances to be involved in play with peers (Nabors \& Badawi, 1997).

Nabors et al. (1999) found that children with and without disabilities engage in similar types of play. When children (with and without disabilities) were engaged in group play, the children with disabilities engaged in fewer activities that required complex skills and were more likely to engage in play with low demands (Nabors et al., 1999).

Prellwitz (2007) suggested that children with disabilities engaged in less play than their typically developing peers. After interviewing the children, it was discovered that the playgrounds were too complicated (the children with disabilities were afraid that they would be teased for using the play equipment incorrectly) and inaccessible to the children with disabilities. Sometimes they were not even able to get into the playground because the gates were too narrow, sand began too close to the entrance, or a ditch surrounded the entire playground. Surveys revealed that several playground designers had insufficient knowledge of how to design playgrounds for children with disabilities or had not even thought about it. "For example, when building a playground near the county hospital, a special slide for children with disabilities was ordered by the landscape architect, but no instruction had been given to the builder regarding the stairs leading to the slide" (Prellwitz, 2007, p. 28). Children with disabilities have different experiences on the playground than children without disabilities, even though they receive the same developmental benefits while playing on the playground. 


\section{The 7 Principles of Inclusive Playground Design}

The 7 Principles of Inclusive Playground Design were created by the Center for Universal Design at North Carolina State University and adapted by the Utah State University Center for Persons with Disabilities and PlayCore to address playgrounds and what children want to feel and experience during play on the playgorund. A thoughtfully designed inclusive playground can create opportunities to ensure that children of all ages and abilities can be active, both physically and socially, through play, while also enhancing skill development. However, removing physical barriers guarantees neither social inclusion among children nor the opportunity for all children to actively participate. Thus, the aforementioned principles provide 7 guidelines of inclusive playground design to create a truly inclusive and embracing play experience that will meet the developmental needs of all children through intentionally providing opportunities for physical, cognitive, communicative, social/emotional, and sensory development. The principles focus on individual play activities and the context of the environmental design. The principles are: Be Fair, Be Included, Be Smart, Be Independent, Be Safe, Be Active, and Be Comfortable.

\section{A Framework for the Study of Playgrounds}

To study the interaction between human behavior and designed playgrounds, this study uses two theories from environmental and ecological psychology: Gibson's (1977) Theory of Affordances and Barker's (1968) behavior settings.

Gibson's Theory of Affordances allows for a closer examination of playgrounds by identifying clusters of elements that support desired play outcomes (Fjortoft, 2000). Affordances are the physical opportunities and dangers that the environments offer the user while the user is 
acting in a specific environment (Gibson, 1977). An environment may offer multiple affordances with hierarchical differences among them. Affordances also include the emotional, social, and cultural opportunities that the individual perceives in the environment (Kyttä, 2004). The concept of affordance allows children to interact with their peers and the environment. However, providing affordances and opportunities for certain behaviors in an environment does not guarantee they will be utilized. Yet without designing the physical environment to support the desired behaviors, it will be unlikely for them to occur (Lang, 1987). All that being said, understanding the concept of affordances and how they relate to playgrounds can assist the playground designer in creating better spaces for children to play (Moore et al., 2007).

The two variables that lead to the creation of affordances are the characteristics of the user and the characteristics of the environment. Because of this, affordances will change with time (Heft, 1988). Affordances can be seen in varying levels: potential, perceived, and actualized. Potential affordances exist in the environment, which allows for a possible action. Perceived affordances are a subset of affordances determined by the user, and actualized affordances are a smaller subset of affordances that are revealed through actions of the user (Kyttä, 2004, Nye \& Silverman, 2012). Kyttä's (2004) Bullerby-model, which is the ideal representation of a child-friendly setting, includes many affordances that are perceived and actualized because the children can explore. Environmental features guide the children's behavior and can either be taught or independently discovered. Therefore, variation and exploration are "an integral part of the perception of affordances, and developmental appropriateness is essential for an affordance to be actualized" (Cloward Drown, 2014, p. 26). As children discover affordances, they continue to explore the environment (Kyttä, 2004). A 
playground with difficult and exciting situations (Ünal, 2009) that keep and arouse children's interest (Eriken, 1985) will provide opportunities for play and development in children.

The Theory of Affordances implies that the child involved is "capable" of actualizing and then utilizing the associated affordance. But how "capable" does the child need to be for an affordance to apply? Some children with disabilities may not be "capable" of actualizing the affordance. Others might actualize an affordance ineffectively at first, but in due time, with training and further development, the skill level will increase.

Barker's (1968) behavior settings are subsections of geographical areas where behavior and the physical environment are linked in time and space (Barker, 1968). Through directly observing and recording children's activities, Barker realized that some behavioral settings or activities have specific and identifiable features that afford certain behavioral actions. For example, on a playground, a behavior setting might be a sidewalk used for riding tricycles or a grass hill used for tag. Behavior settings include the environment and the integrated activity, as well as the features and the behavioral possibilities. Landscape architect Kevin Lynch proposed that knowledge of behavior settings could be used as a basis for designing places that would better suit people's behavior (Lynch \& Hack, 1984). Following this reasoning, linking setting, type, and peer interactions is essential for both understanding the impact of design on a child's social inclusion on a playground and guiding design interventions (Cosco \& Moore, 2009). According to Refshauge et al. (2013), the affordances to be designed for the primary grades include "climb-able, jump-on-able, run-able, balance-able, imagine-able, move-able, construction-able, hide-behind-able, swing-on-able, spin-on-able, roll-downable" (pp. 233 - 234). Behavior settings provide a medium for identifying the potential affordances of different types of areas within a playground (Moore et al., 2007). Furthermore, understanding a playground 
according to its behavior settings and affordances and how the playground supports distinct behavioral possibilities for children's play would help professionals design playgrounds that effectively include all children (Drown \& Christensen, 2014). 


\section{CHAPTER III}

\section{METHODS}

The purpose of this study was to determine whether inclusive playground design practices support increased congruent dramatic play behavior between first and second-grade children with and without disabilities. The main research questions for this study were "Is dramatic play among first and second-grade elementary school students supported by the individual behavior settings of the play environment at Edith Bowen Laboratory School?" and "To what extent is there a difference between the dramatic play behaviors of first and secondgrade elementary school students with and without disabilities across the behavior settings of the play environment at Edith Bowen Laboratory School?"

These questions were investigated using the concept of affordances (Gibson, 1977), behavior settings (Barker, 1968), and the degree to which inclusively-designed behavior settings increase children with disabilities' access to the affordances of the same.

\section{Setting}

The setting for this research was the Edith Bowen Laboratory School at Utah State University in Logan, Utah, as this school possesses a playground designed using The 7 Principles of Inclusive Design. Edith Bowen Laboratory School is a kindergarten through sixth-grade charter school located on the campus of Utah State University which partners with the Emma Eccles Jones College of Education and Human Services. Admission to Edith Bowen Laboratory School is determined through random selection. This process ensures that the population of the school is culturally, socially, and economically diverse. The school is a Title I 
school, meaning $35 \%$ of the students receive free or reduced lunch. In addition, $16 \%$ of the students at the school qualify for and receive special education services.

The Edith Bowen Laboratory School was chosen as it possesses a recently installed playground designed according to The 7 Principles of Inclusive Design. The playground (Figures $1-5)$ was built in 2018 and designed with several specific behavior settings in mind. Within the playground, behavior settings were defined by dividing the playgrounds into specific, distinct spatial areas based on intended behavior affordances/settings. These spatial areas included paths for traveling and nature play areas which were landscaped with numerous accommodations to support play, such as enclosed areas with vegetation, rock platforms, benches, and tables. 


\section{Figure 1}

Aerial Image of Utah State University Campus (Playground Highlighted)

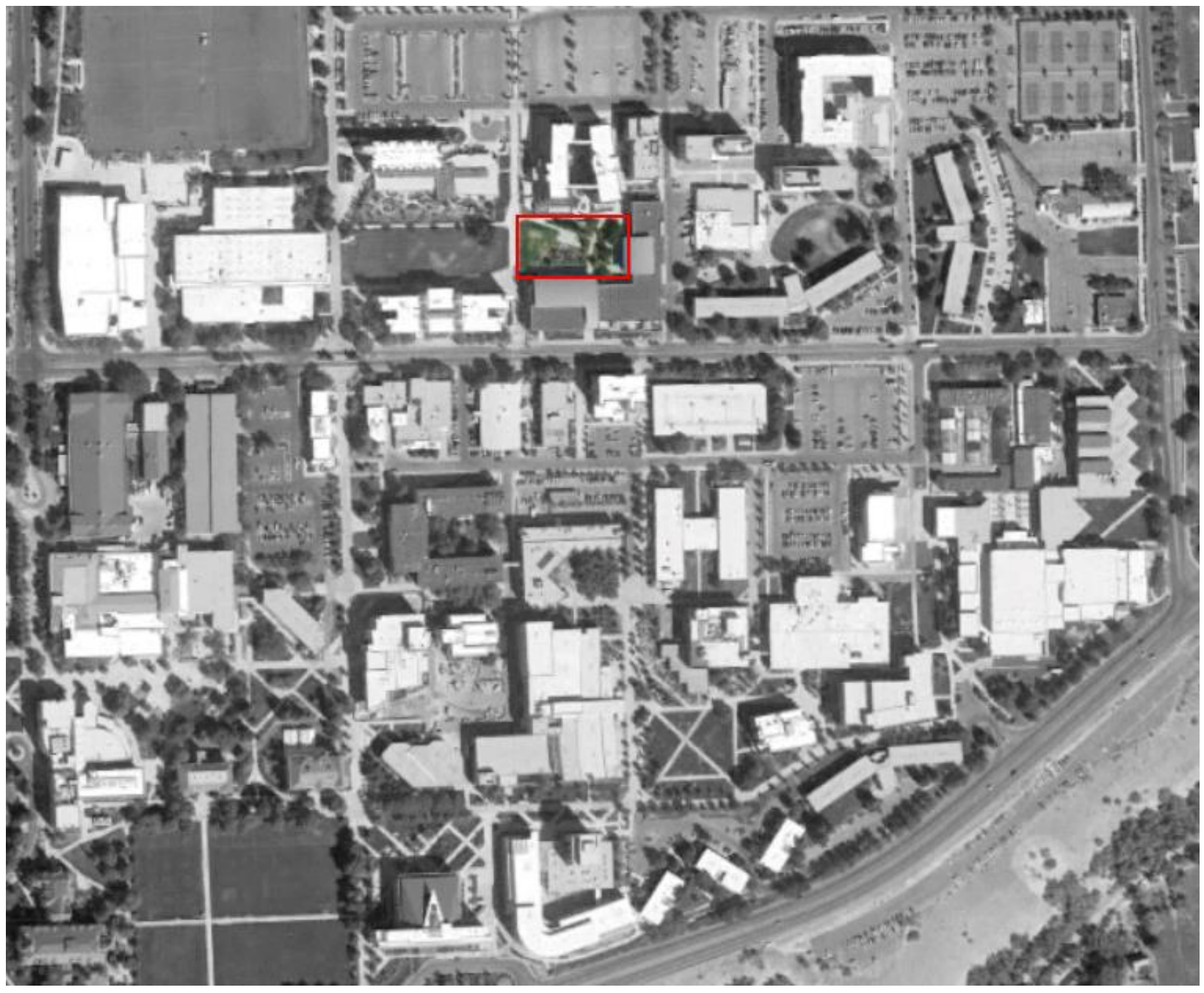


Figure 2

Playground Looking East

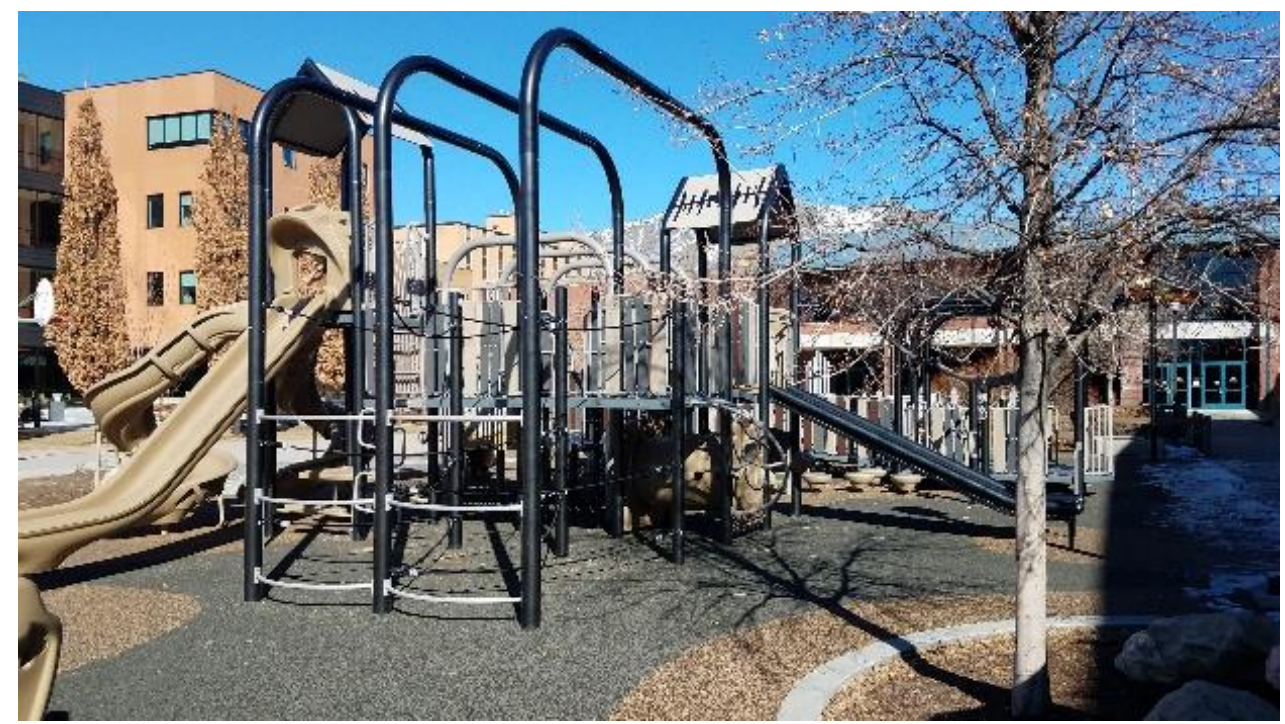

Figure 3

Playground Looking South

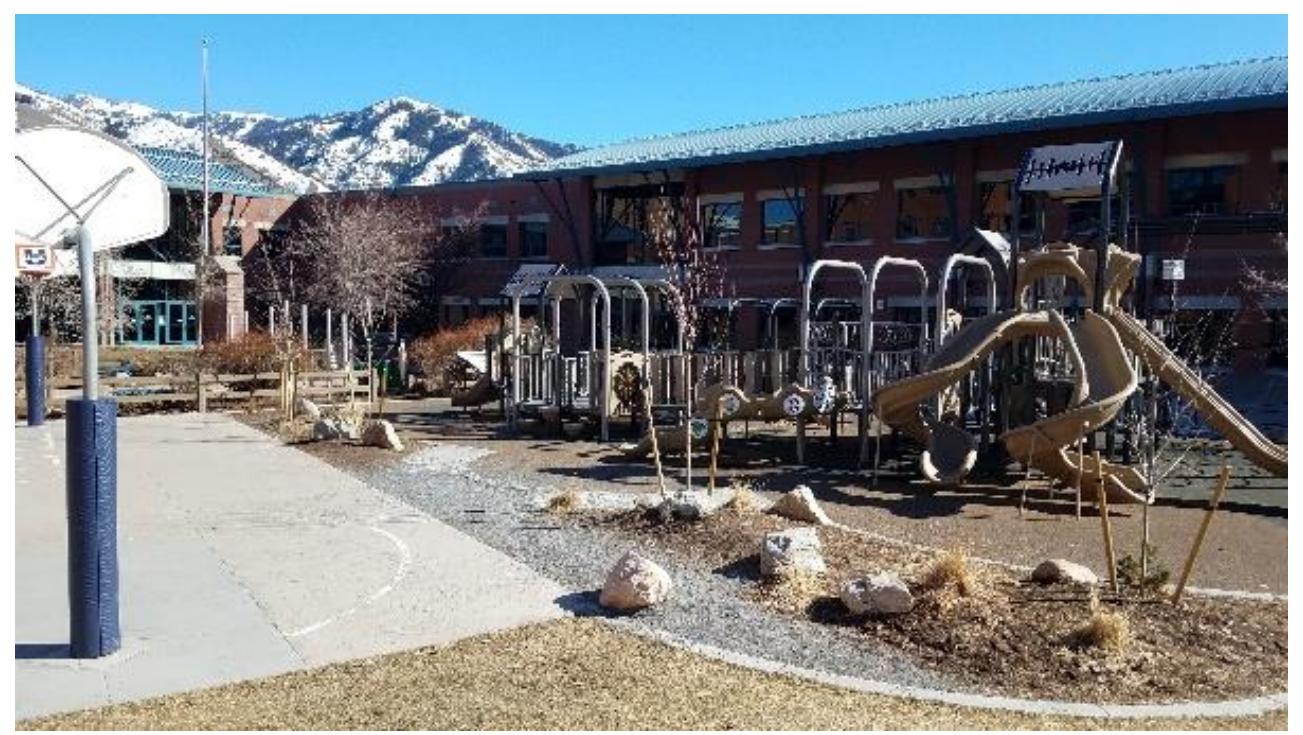




\section{Figure 4}

Behavior Setting Map

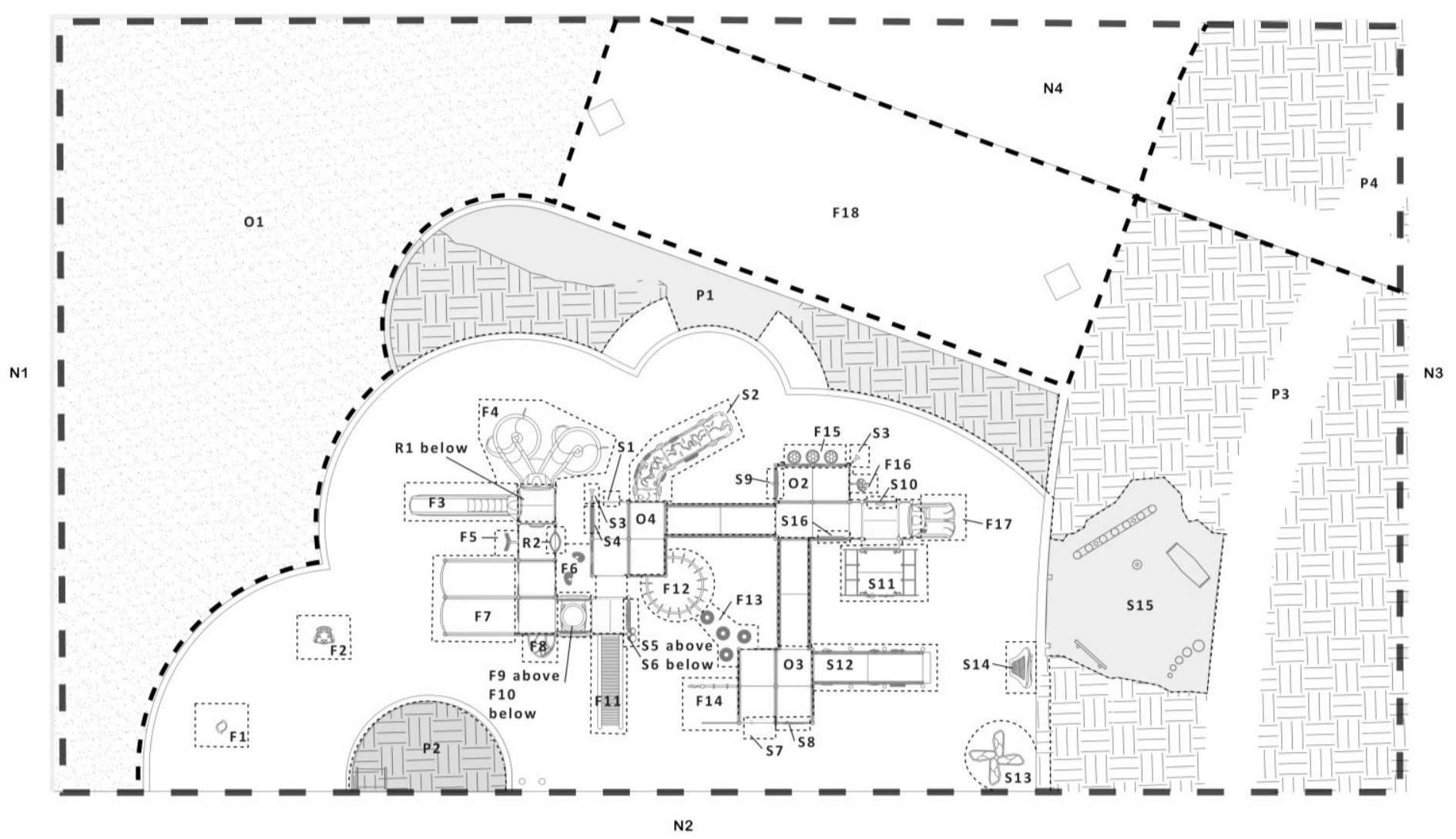




\section{Figure 5}

\section{Behavior Settings Map Key}

Sensory Play (S)

1 Telescope

2 Sensory Climber Up \& Down

3 Talk Tube

4 Frog Slide Puzzle

5 Kinetic Spinner

6 Bongos

7 Gizmo Panel

8 Sensory Wave Panel

9 Sun Blossom Double

10 Thunder Ring

11 Sensory Wave Rock

N Raft

12 Sensory Wave Ramp

13 Shadow Play Area

14 Cantata Chimes

15 Music Area

16 Music Panel

Rest/Activity Areas (R)

1 Decorated Table and Benches

2 Seat Panel

Plantings (P)

1 Landscape Divider

2 Tree Planter

3 Nature Play South

4 Nature Play North

Open Areas (O)
Functional Play (F)

1 Tilted Whirlwind Seat

2 Sensory Wave Seat

3 Zip Slide

4 Spiral Slide

5 Stego Climber

6 Sprout Climber

7 Ropes Course

8 Erratic Climber

9 Arch Bridge

10 Straight Crawl Tube

11 Roller Slide

12 Loop Ladder

13 X-pod Step

14 Gymnastics Area

15 Hex Pod Step

16 Spiral Climber

17 Rumble \& Roller Zip Slide

18 Basketball Court

Other

N1 Area west of the playground

N2 Area south of the playground

N3 Area east of the playground

N4 Area north of the playground

ARD Around the playground, multiple settings used

\footnotetext{
1 Open Grassy Hill

2-4 Play Structure Surface
} 


\section{Participants}

Prior to the data collection, research methods and parental consent forms were reviewed and approved by the Institutional Review Board (IRB). Parental consent forms were given to each child and parent, in order to allow the researcher to observe the children.

This study focused on first and second-graders ranging in age from six to eight years at Edith Bowen Laboratory School. The study included 8 children with disabilities and 81 children without disabilities. As any first or second-grade student may have been observed, informed consent was acquired from the parents of all children with and without disabilities willing to participate. However, as the direct observation took place according to random selection from informed consent, it is likely that no data was collected for some children in the school's first and second-grade population. The identification of disability status was made in collaboration with the school's Special Education Program Coordinator and was based on whether a child had an Individualized Educational Plan (IEP) and the designation category of said plan. By working with the school and with the consent of the parents, the observer obtained the class pictures of the children with disabilities to identify those children on the playground. The children were observed during their lunch recess. It was assumed that there were various grade levels overlapping during the recess time. Thus, for this study, the data was collected for children aged six to eight years (first and second-graders) during their specified lunch recess. The only personal data collected for each student observed was gender, grade level, and IEP designation, if any. 


\section{Measures - Types of Dramatic Play}

Dramatic play was selected for this study. Dramatic play is imaginative behavior involving a transformation of objects, actions, and self-identity (Petrakos \& Howe, 1996). It is when children pretend to be someone else or to be somewhere else. Through representational skills and imaginative expression, dramatic play provides a foray into abstract thought and more complex cooperation with peers (Drown \& Christensen, 2014). A modification of the Smilansky Scale similar to that used by Elias \& Berk (2002) was used to code children's dramatic play. The scale uses five behaviors and persistence of a play episode to indicate the presence and maturity of dramatic play (Drown \& Christensen, 2014, Smilansky \& Shefatya, 1990).

1. Imitative role-play. A child engages in self-referenced role-play using imitative vocalizations or actions; he/she becomes a character other than himself/herself in another context.

2. Make-believe with objects. A child uses verbal declaration, movements, and/or a substitute object (not a replica of the actual object) to represent a real object in a play episode.

3. Make-believe with actions and situations. A child uses verbal declarations to substitute for action or to describe a situation to further the play episode.

4. Interaction. There are at least two children collaborating to develop or maintain a play scene. This is other-referenced role-play, in which a child commands, explains, offers play props, or gestures to peer(s) with the intent that the peer(s) will listen and use his/her suggestions to build the play episode. 
5. Verbal communication. There is verbal dialogue between play partners within a play scene. Either a child speaks as a role-played character or speaks for an auxiliary character represented by an object.

6. Persistence of play episode. A child remains in an imaginary framework to support continuance of a play episode. The child may undertake multiple roles, but follows a definite theme. There is some elaboration or repetition. Interruption may take place as long as the child returns to the original theme.

Based on these behaviors, solitary dramatic play occurs when a child pretends independently. Solitary dramatic play contains at least one of the first three dramatic play behaviors $(1,2$, or 3$)$. In contrast, sociodramatic play, or organized group play, exhibits interaction (4) plus one of the other four dramatic play behaviors $(1,2,3$, or 5). Complex sociodramatic play, a truly cooperative endeavor that requires higher cognitive and social skills, displays interaction (4), at least three of the five dramatic play behaviors $(1,2,3$, or 5), and persistence (6). In this study, all other types of play were categorized as "other." Routine tasks, such as sunscreen application, bathroom breaks, or intervention by elementary staff (such as reprimanding), were coded as non-play behaviors and excluded from analysis.

\section{Observation Procedures}

Type of play, mode of play, gender, and weather were collected but not used in this study. Children were observed during their lunch recess. To minimize the observer effect on the children being observed, an acclimation phase prior to the start of actual observations allowed the children to become accustomed to the presence of the observer. To identify those children with IEP disability designations, the observer worked with the Edith Bowen Laboratory School 
staff and the Special Education Director to distribute a survey to the parents requesting consent to participate in this study. A data collection sheet, which included the behavior settings map, was used to simultaneously record the location of the participants on the playground and the type and mode of play that they exhibited (see Figure 6). The behavior setting map shows "densities" of behaviors over time, which helped to identify which behavior settings afforded the greatest behavioral opportunities, in particular for children with disabilities. Prior to data collection, children with disabilities whose parents gave consent to participate in this study were identified. The children were observed in a continuous, 20 -second interval system during the seven-minute periods. For this study, the children's behaviors were recorded as follows: during the 20-second interval that a child was observed engaging in play, an alphabetic code representing the type and mode of play was written on the data collection sheet, based on the behavior he/she exhibited. The children with disabilities whose parents gave consent to participate in the study were randomly identified and assigned to the observers the week before observations. The first week, each observer observed two children with a disability and one without a disability. The second week, each observer observed two children without a disability and one with a disability. At the end of a two-week period, 15 children with disabilities and 15 children without disabilities were observed. This procedure was performed so that half the children observed had a disability. Results indicate that of the children observed, 50.17\% had an IEP designation.

At the beginning of the interval for Child One, the researcher noted on the data collection sheet the type of play, whether that type of play was dramatic play, the specific type of dramatic play, the mode of play, the number of children he/she interacted with, and the corresponding location on the playground (behavior setting). This process continued until the seven-minute interval had 
ended or the child went inside. The process was then repeated, beginning again with another child. This procedure continued until the recess period concluded or three children had been observed. An example of an observer collecting data is shown in Figure 7. Since the variables being observed required some interpretation, observers added notes as needed. The results were recorded as they were observed on the playground, with each behavior being interpreted as defined above. These observations occurred daily for eight weeks. An example of observercollected data on the playground is shown in Figure Five. This method of study was approved by USU's Institutional Review Board (IRB General \# 10424).

\section{Interobserver Reliability Analysis}

\section{Type of Dramatic Play}

A Kruskal-Wallis statistical test was conducted to evaluate the differences among the three observers with regards to median change of the type of dramatic play, in order to assess interobserver reliability. The type of dramatic scores of the three observers showed virtually no differences between Observer $3(M d n=701.83)$, Observer $2(M d n=738.45)$, and Observer 1 $(M d n=699.56)$. 
Figure 6

\section{Data Collection Sheet}

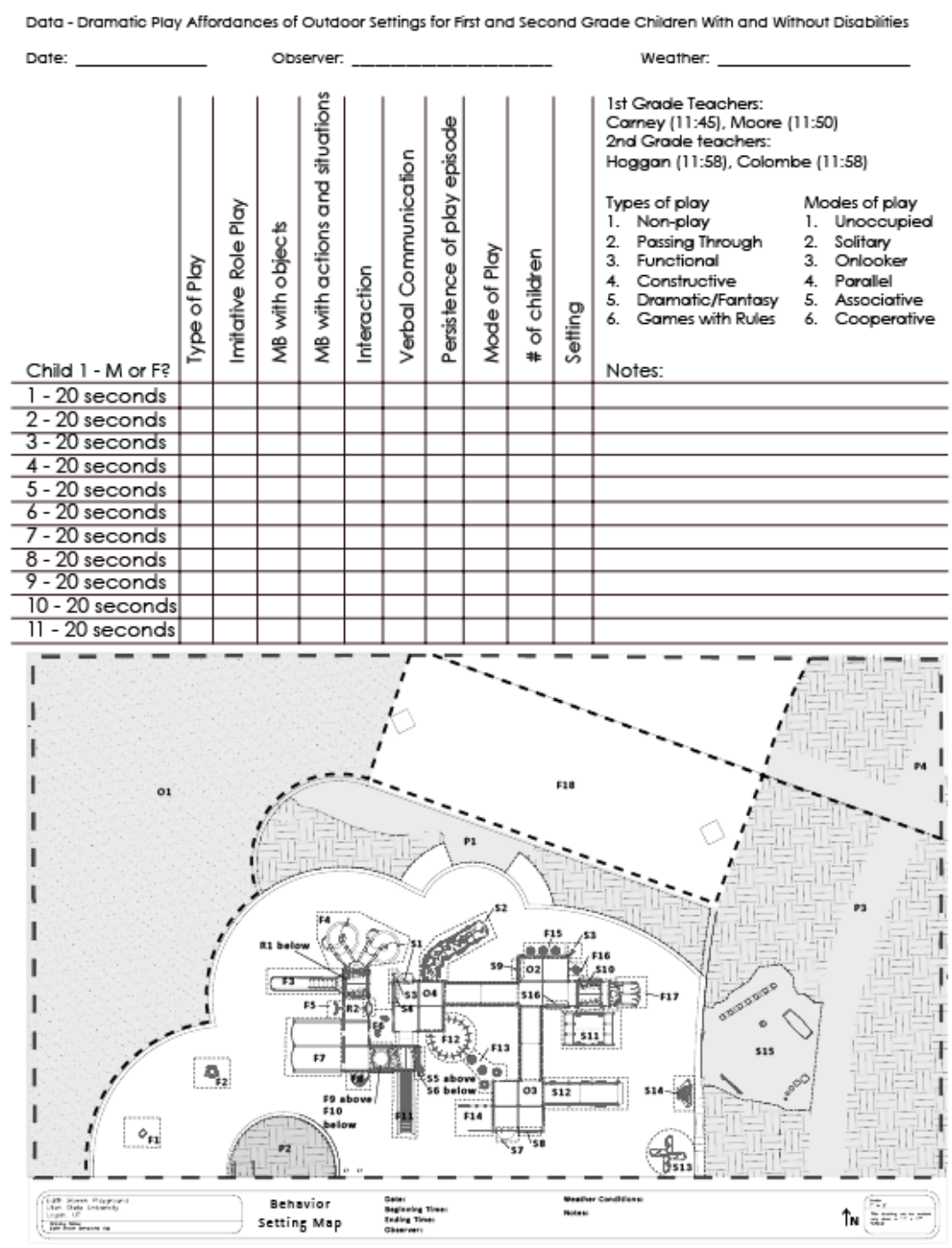


Figure 7

Observer Collecting Data on the Playground

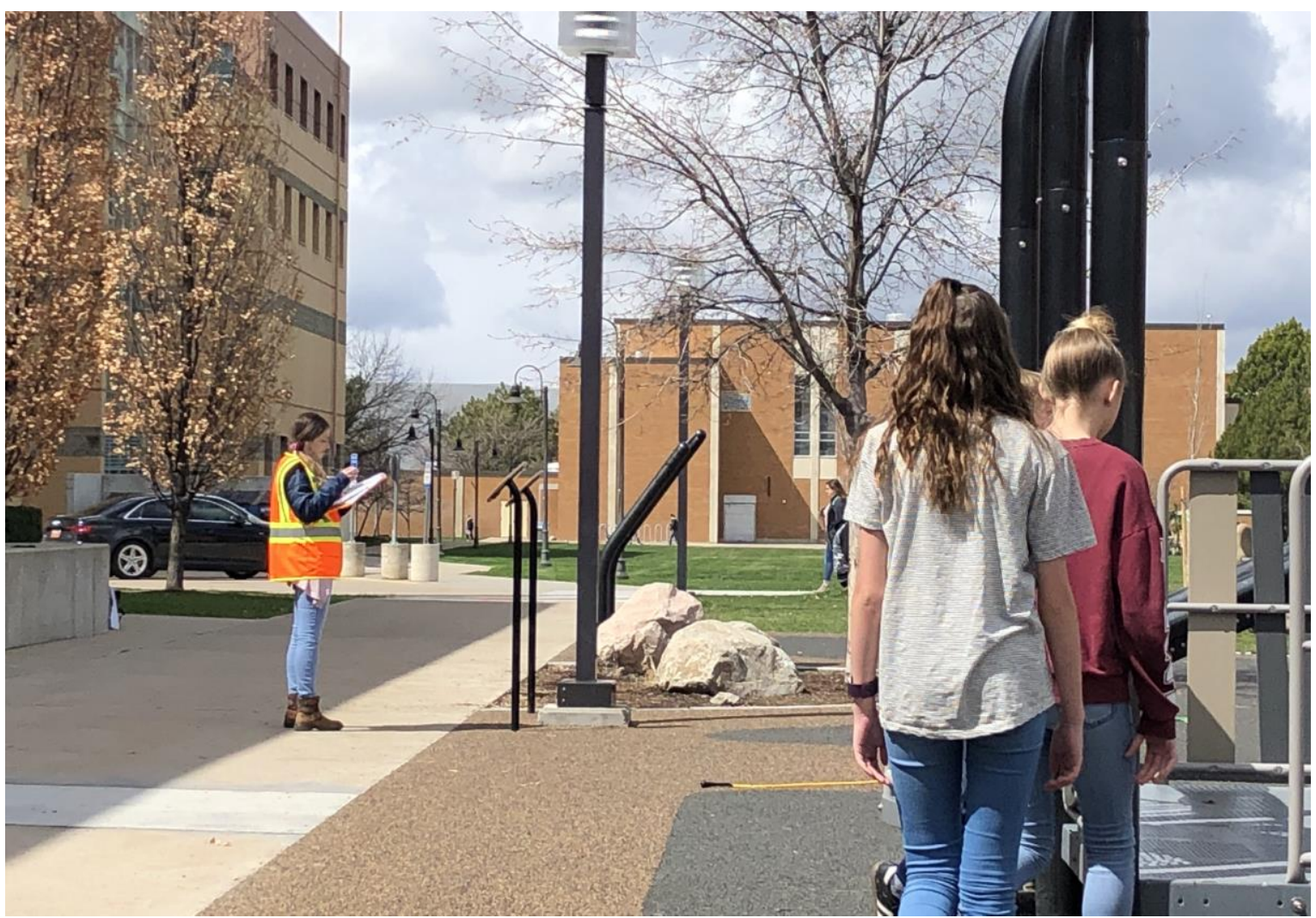




\section{CHAPTER V}

\section{RESULTS}

The play settings were observed 1,437 times during the study. There were three IEP designations in this study: Specific Learning Impairment (SLI) (37\%), Speech/Language Impairment (SLD) (4.8\%), and Developmental Delay (DD) (8.4\%), as depicted in Figure Six. The remaining $49.8 \%$ of children did not have a disability.

\section{Figure 8}

Distribution of Observed Children with an IEP Designation

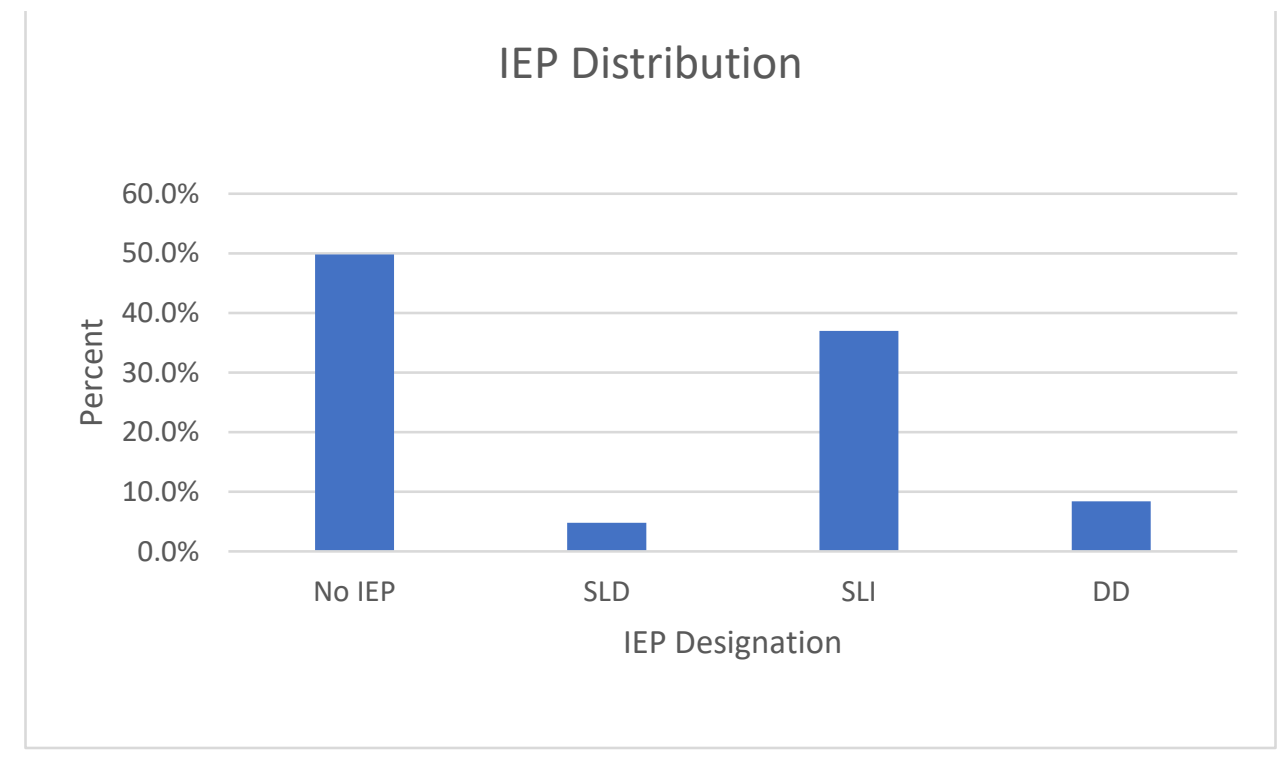

Dramatic play accounted for $30.7 \%$ of the overall play. Of the observed dramatic play, imitative role play occurred $3.1 \%$ of the time, make-believe with objects occurred $6.3 \%$ of the time, make-believe with actions and situations occurred $10.6 \%$ of the time, interactions occurred $5.8 \%$ of the time, verbal communication occurred $3.5 \%$ of the time, and persistence of play episode occurred $1.3 \%$ of the time (see Figure Eight for distribution of dramatic play types). 


\section{Type of Dramatic Play and Setting}

In order to better study the question "Is dramatic play among first and second-grade elementary school students supported by the indiviual behavior settings of the play enviroment at Edith Bowen Laboratory School?," SPSS Statistics software was used to analyze the data. A crosstabulation was used to display the distribution of the two variables, playground settings and dramatic play. For each type of dramatic play, a table summarizing the data (Tables 1 through 6) and a figure (Figures 10,13, 15, 17, 19, and 20) illustrating the location on the playground will follow. Images of common settings will also be included (Figures 11, 12, 14, 16, and 18).

Another crosstabulation was used to display the distribution of playground settings and specific type of dramatic play (imitative role play, make-believe with objects, make-believe with actions and situations, interaction, verbal communication, and persistence of play episode). Make-believe with actions and situations was the most common form of dramatic play, accounting for $10.6 \%$ of all dramatic play.

\section{Figure 9}

Distribution of Dramatic Play Types Across All Settings

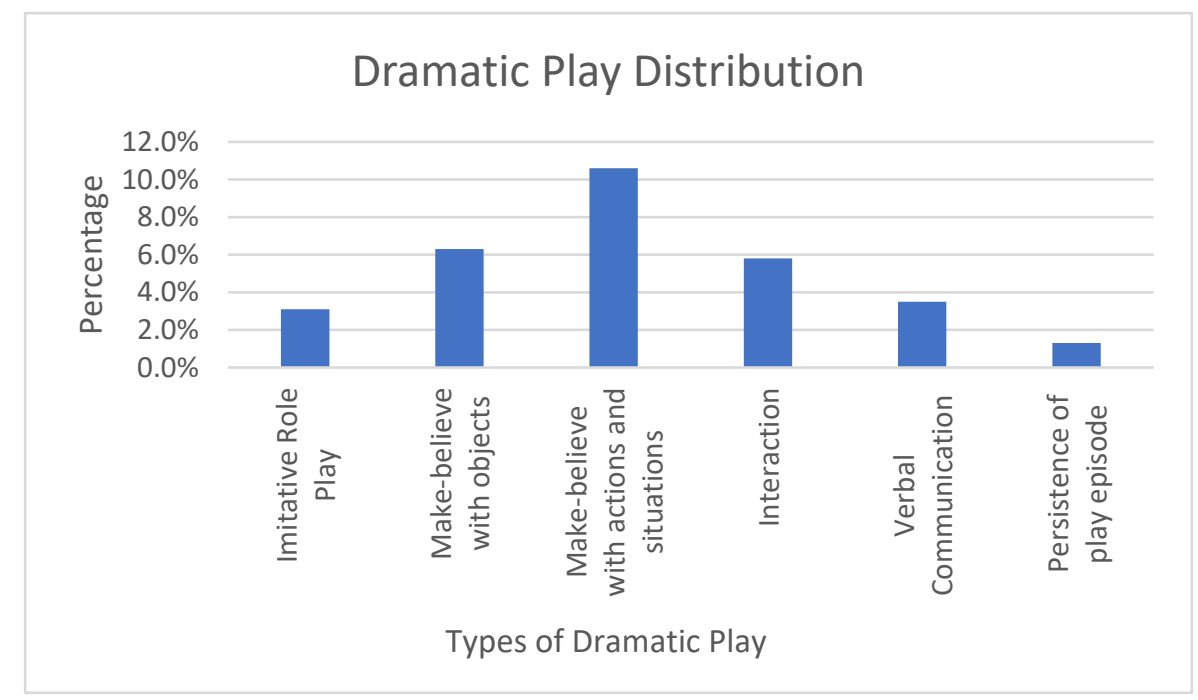


Table 1

Specific settings with the Most Dramatic Play

\begin{tabular}{lll}
\hline Setting Code & Setting Name & $\begin{array}{l}\text { Percent of } \\
\text { Dramatic Play }\end{array}$ \\
\hline P4 & Nature Play North & $20.2 \%$ \\
P3 & Nature Play South & $17.0 \%$ \\
O1 & Open Area, Grassy Hill & $13.6 \%$ \\
S11 & Sensory Wave Rock N Raft & $10.2 \%$ \\
ARD & Around Playground & $5.7 \%$ \\
S10 & Thunder Ring & $3.9 \%$ \\
N1 & Area West of Playground - open grassy area, mound, and \\
& trees & $3.2 \%$ \\
N3 & Area East of Playground - concrete area, next to building, \\
& with tables and small planted areas & $3.2 \%$ \\
F7 & Ropes Course & $2.7 \%$ \\
N2 & Area South of Playground - concrete area with four-square & $2.7 \%$ \\
& and concrete dividers, next to building & \\
F3 & Zip Slide & $2.5 \%$ \\
F4 & Spiral Slide & $2.5 \%$ \\
N4 & Area north of playground - concrete slab with statues and & $2.0 \%$ \\
& an open grassy area surrounding & $89.4 \%$ \\
\hline
\end{tabular}

Note. All other settings accounted for under $2 \%$ of nearly $90 \%$ of all dramatic play occurrences.

The settings that afforded the most dramatic play were the Nature Play Areas, Open Grassy Hill, and the Sensory Wave Rock N Raft, accounting for $61 \%$ of all dramatic play. 


\section{Figure 10}

Settings highlighted in green are the settings that afforded the most dramatic play.

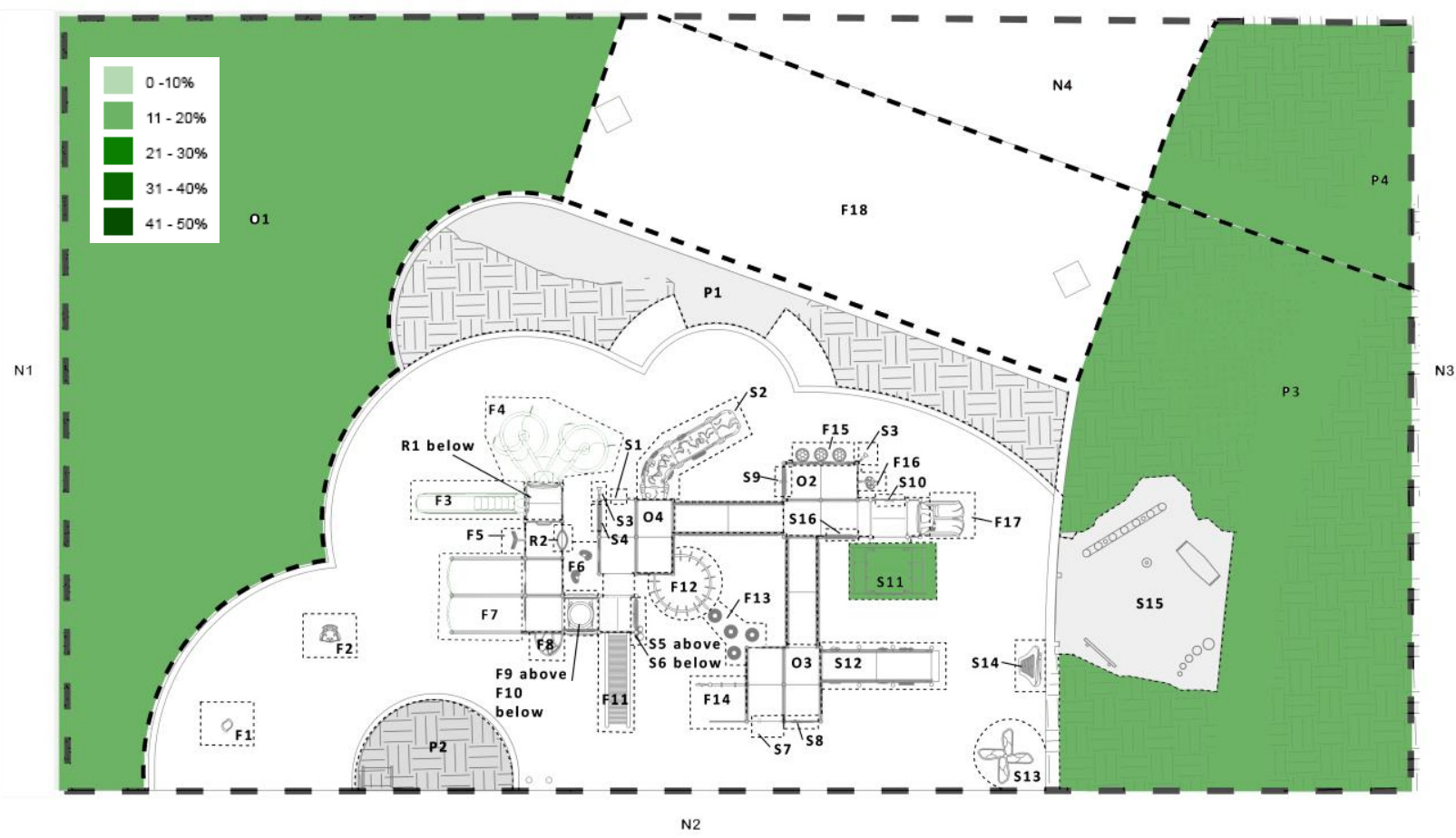

Note. The darker the shade of green, the higher the percentage of dramatic play.

\section{Figure 11}

\section{Open Grassy Hill}

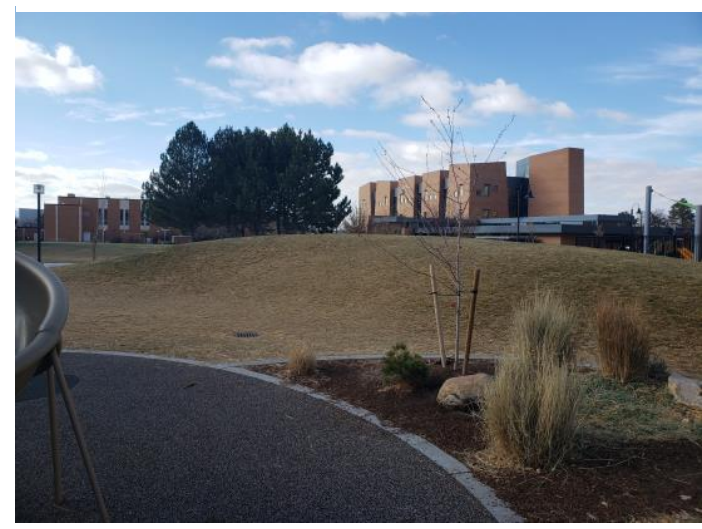

Figure 12

Nature Play Areas

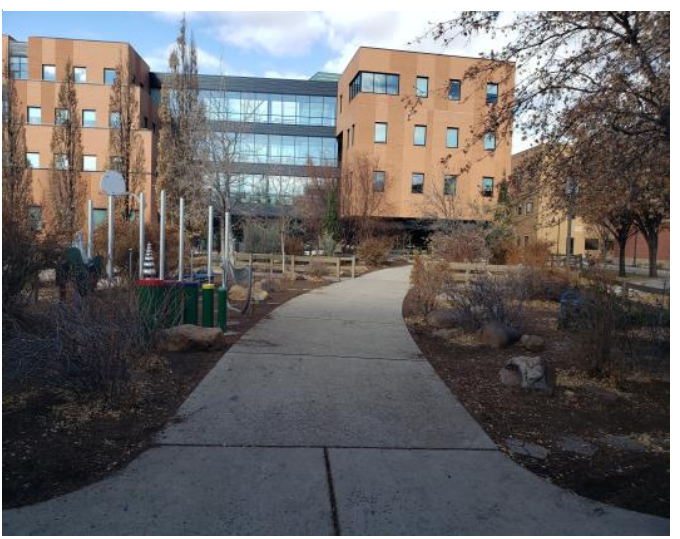


Table 2

Specific Settings that Afforded the Most Imitative Role-play

\begin{tabular}{lll}
\hline Setting Code & Setting Name & $\begin{array}{l}\text { Percent of Imitative } \\
\text { Role-play }\end{array}$ \\
\hline P3 & Nature Play South & $31.8 \%$ \\
F4 & Spiral Slide & $22.7 \%$ \\
S11 & Sensory Wave Rock N Raft & $11.4 \%$ \\
O1 & Open Area, Grassy Hill & $9.1 \%$ \\
ARD & Around Playground & $6.8 \%$ \\
P4 & Naure Play North & $6.8 \%$ \\
S15 & Music Area & $4.5 \%$ \\
F16 & Spiral Climber & $2.3 \%$ \\
N4 & Area North of Playground & $2.3 \%$ \\
P1 & Landscape Divider & $2.3 \%$ \\
Total & & $100.0 \%$ \\
\hline
\end{tabular}

Note. All other settings did not see any imitative role-play.

The settings that afforded the most imitative role-play were the Naturally Planted Beds, Spiral Slide, Sensory Wave Rock N Raft, and the Open Grassy Hill, accounting for $75 \%$ of all imitative role-play. 


\section{Figure 13}

Settings highlighted in green are the settings that afforded the most imitative role play.

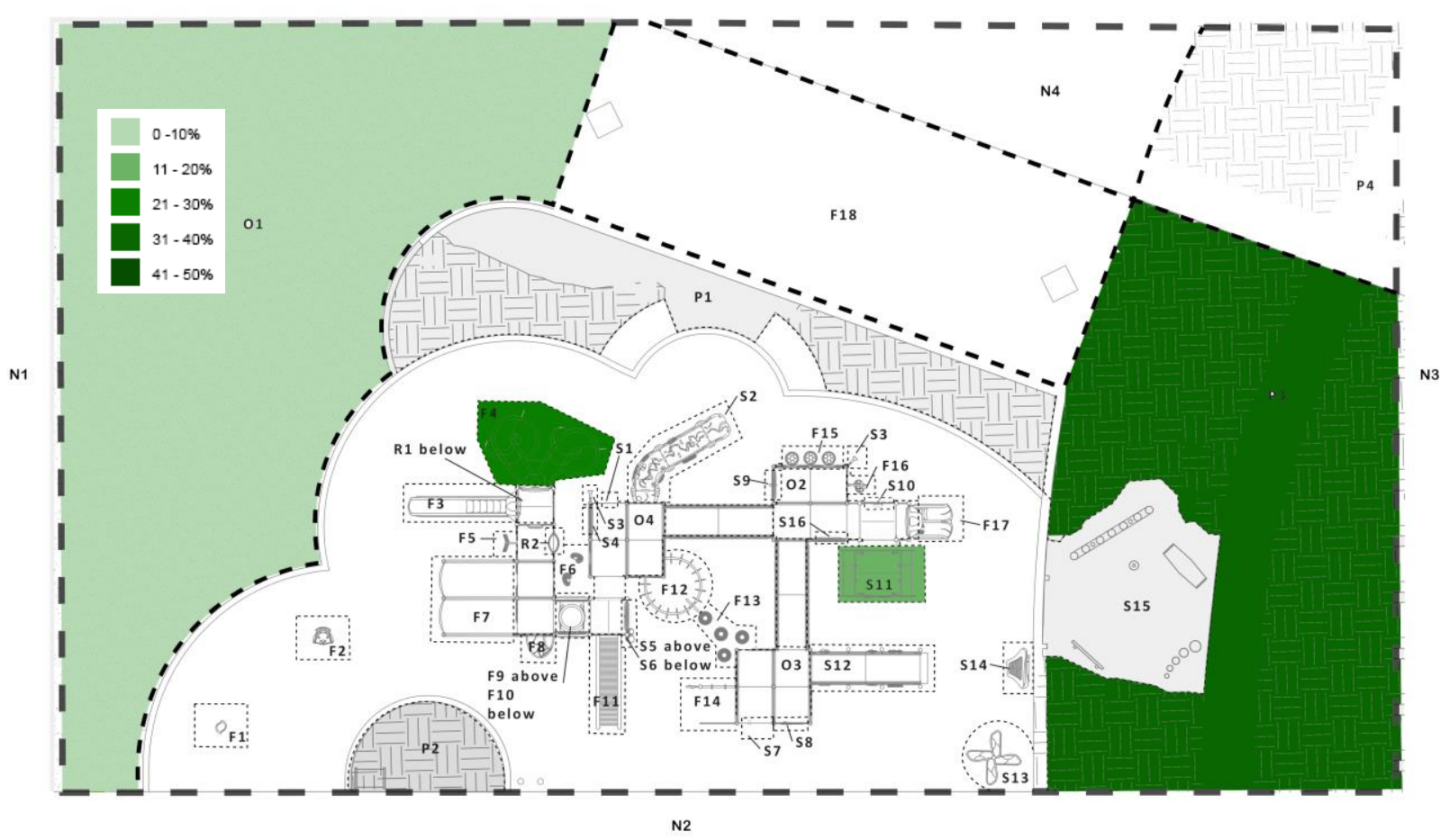

Note. The darker the shade of green, the higher the percentage of imitative role-play.

\section{Figure 14}

Sensory Wave Rock N Raft

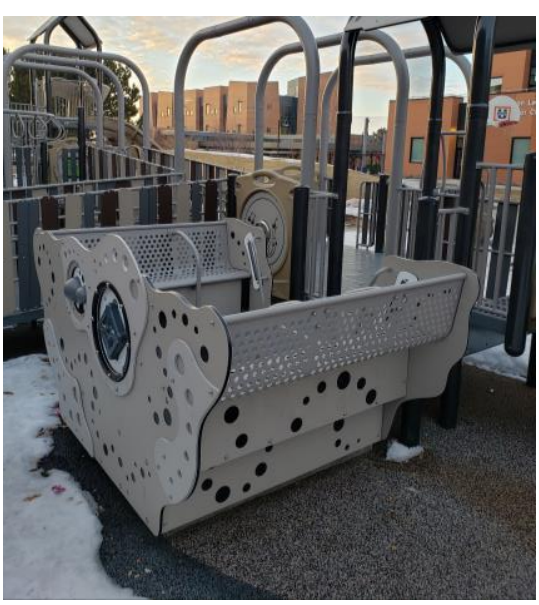


Table 3

Specific Settings that Afforded the Most Make-believe with Objects

\begin{tabular}{lll}
\hline Setting Code & Setting Name & $\begin{array}{l}\text { Percent of Make-believe } \\
\text { with Objects }\end{array}$ \\
\hline P3 & Nature Play South & $22.0 \%$ \\
O1 & Open Area, Grassy Hill & $17.6 \%$ \\
P4 & Nature Play North & $16.5 \%$ \\
S10 & Thunder Ring & $12.1 \%$ \\
S11 & Sensory Wave Rock N Raft & $12.1 \%$ \\
N3 & Area East of Playground & $8.8 \%$ \\
N2 & Area South of Playground & $3.3 \%$ \\
N4 & Area North of Playground & $3.3 \%$ \\
F11 & Roller Slide & $1.1 \%$ \\
N1 & Area West of Playground & $1.1 \%$ \\
P1 & Landscape Divider & $1.1 \%$ \\
S13 & Shadow Play Area & $1.1 \%$ \\
Total & & $100.0 \%$ \\
\hline
\end{tabular}

Note. All other settings did not see any make-believe with objects.

The settings that afforded the most make-believe with objects were the Naturally Planted Beds, the Open Grassy Hill, the Thunder Ring, and the Sensory Wave Rock N Raft, accounting for $80.3 \%$ of all make-believe with objects. 


\section{Figure 15}

Settings highlighted in green are the settings that afforded the most make-believe with objects.

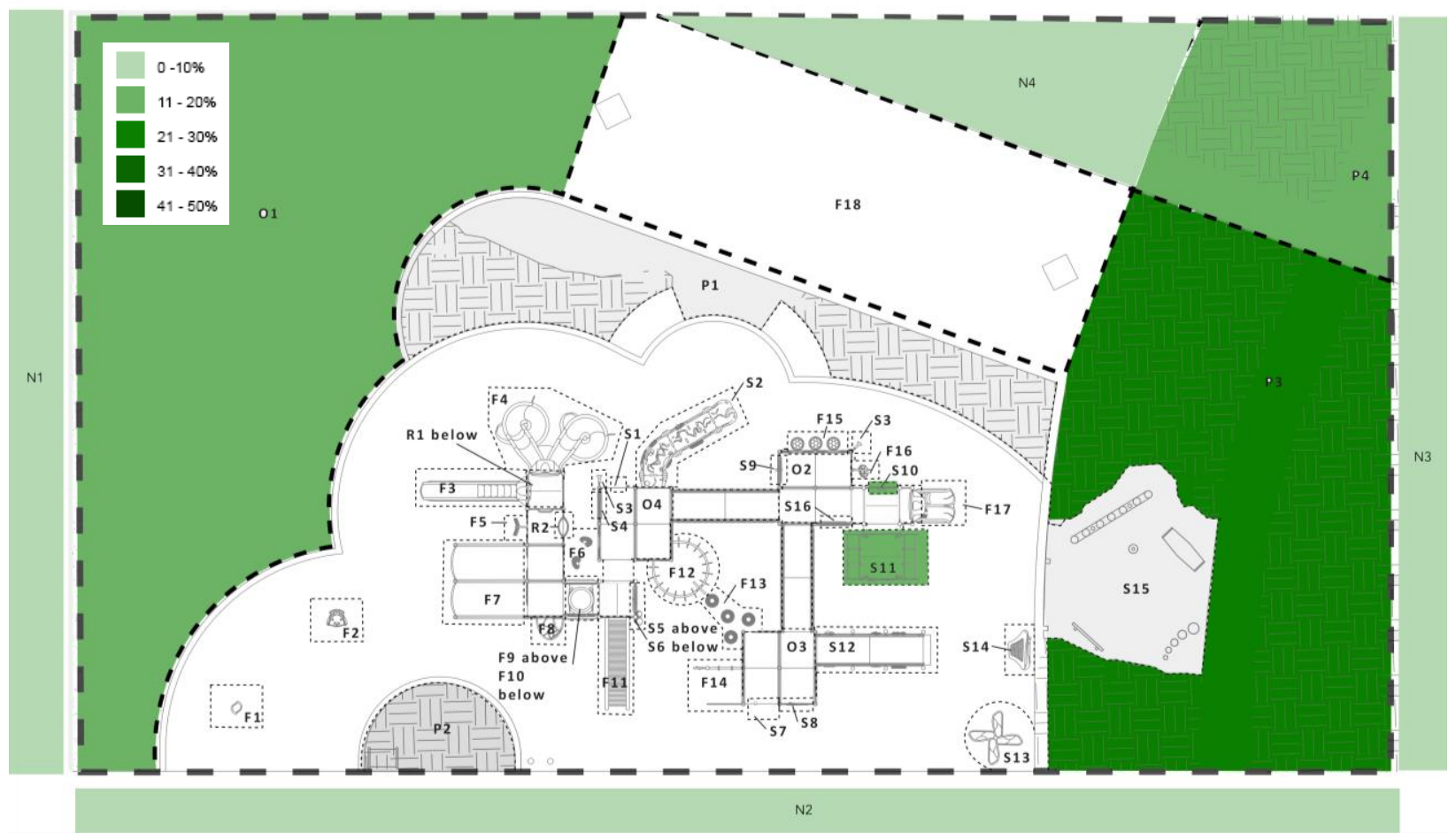

Note. The darker the shade of green, the higher the percentage of make-believe with objects.

\section{Figure 16}

Thunder Ring

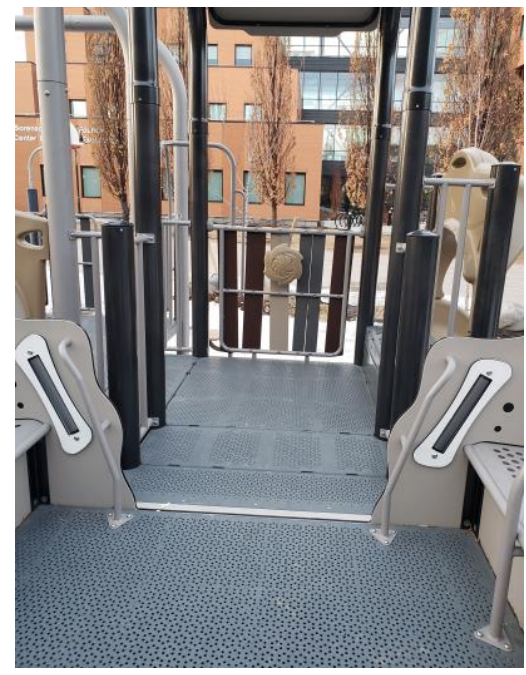


Table 4

Specific Settings that Afforded the Most Make-believe with Actions and Situations

\begin{tabular}{lll}
\hline Setting Code & Setting Name & $\begin{array}{l}\text { Percent of Make- } \\
\text { believe with Actions } \\
\text { and Situations }\end{array}$ \\
\hline P3 & Nature Play South & $15.7 \%$ \\
O1 & Open Area, Grassy Hill & $13.7 \%$ \\
P4 & Nature Play North & $13.1 \%$ \\
ARD & Around Playground & $9.2 \%$ \\
S11 & Sensory Wave Rock N Raft & $7.2 \%$ \\
F3 & Zip Slide & $6.5 \%$ \\
F7 & Ropes Course & $6.5 \%$ \\
N1 & Area West of Playground & $5.9 \%$ \\
S10 & Straight Crawl Tube & $3.3 \%$ \\
N2 & Area South of Playground & $2.6 \%$ \\
F18 & Basketball Court & $2.0 \%$ \\
N3 & Area East of Playground & $2.0 \%$ \\
F5 & Stego Climber & $1.3 \%$ \\
N4 & Area North of Playground & $1.3 \%$ \\
P1 & Landscape Divider & $1.3 \%$ \\
Total & & $91.6 \%$ \\
\hline
\end{tabular}

Note. All other settings accounted for under $1 \%$ make-believe with actions and situations.

The settings that afforded the most make-believe with actions and situations were the Naturally Planted Beds, the Open Grassy Hill, around the playground using multiple settings, the Sensory Wave Rock N Raft, and the Zip Slide, accounting for $65.4 \%$ of all make-believe with actions and situations. 
Figure 17

Settings highlighted in green are the settings that afforded most the make-believe with actions and situations.

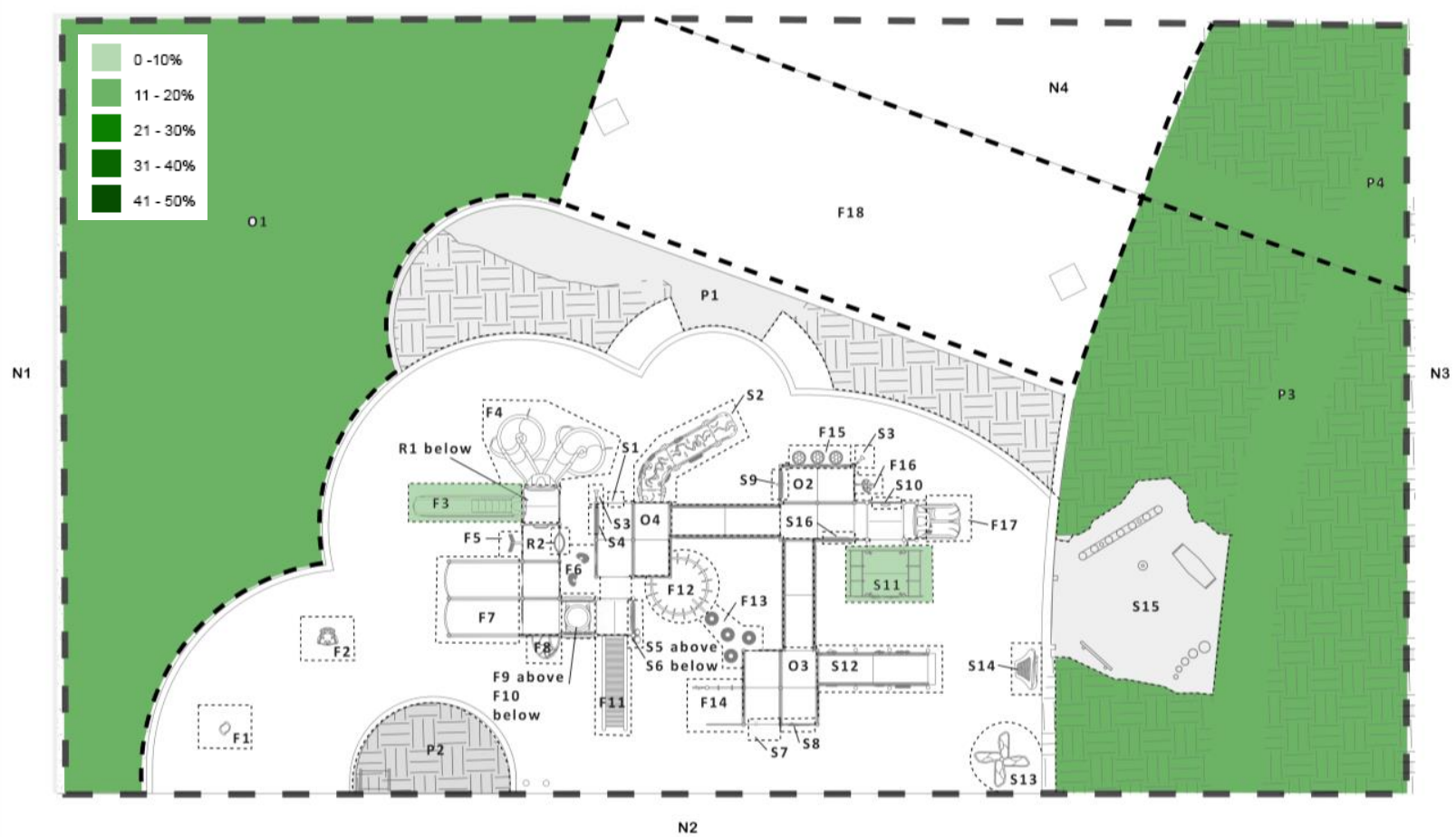

Figure 18

Zip Slide

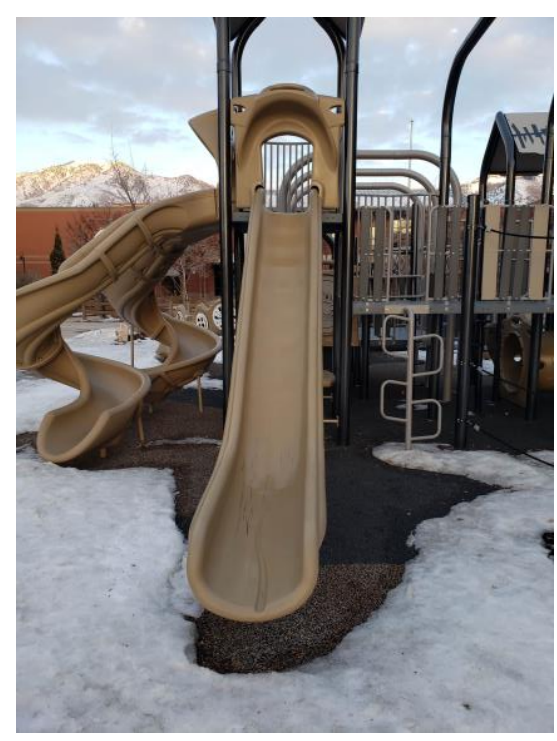


Table 5

Specific Settings that Afforded the Most Interaction

\begin{tabular}{lll}
\hline Setting Code & Setting Name & Percent of Interaction \\
\hline P4 & Nature Play North & $31.3 \%$ \\
P3 & Nature Play South & $15.7 \%$ \\
S11 & Sensory Wave Rock N Raft & $13.3 \%$ \\
O1 & Open Area, Grassy Hill & $12.0 \%$ \\
N1 & Area West of Playground & $4.8 \%$ \\
N3 & Area East of Playground & $3.6 \%$ \\
ARD & Around Playground & $2.4 \%$ \\
F12 & Loop Ladder & $2.4 \%$ \\
F17 & Rumble \& Roller Zip Slide & $2.4 \%$ \\
N2 & Area South of Playground & $2.4 \%$ \\
N4 & Area North of Playground & $2.4 \%$ \\
P2 & Tree Planter & $2.4 \%$ \\
F18 & Basketball Court & $1.2 \%$ \\
O2 & Play Structure Surface & $1.2 \%$ \\
S10 & Thunder Ring & $1.2 \%$ \\
S12 & Sensory Wave Ramp & $1.2 \%$ \\
Total & & $100.0 \%$ \\
\hline
\end{tabular}

Note. All other settings did not see any Interaction.

The settings that afforded the most interactoins were the Naturally Planted Beds, the

Sensory Wave Rock N Raft, and the Open Grassy Hill, accounting for $72.3 \%$ of all interaction. 


\section{Figure 19}

Settings highlighted in green are the settings that afforded the most interaction.

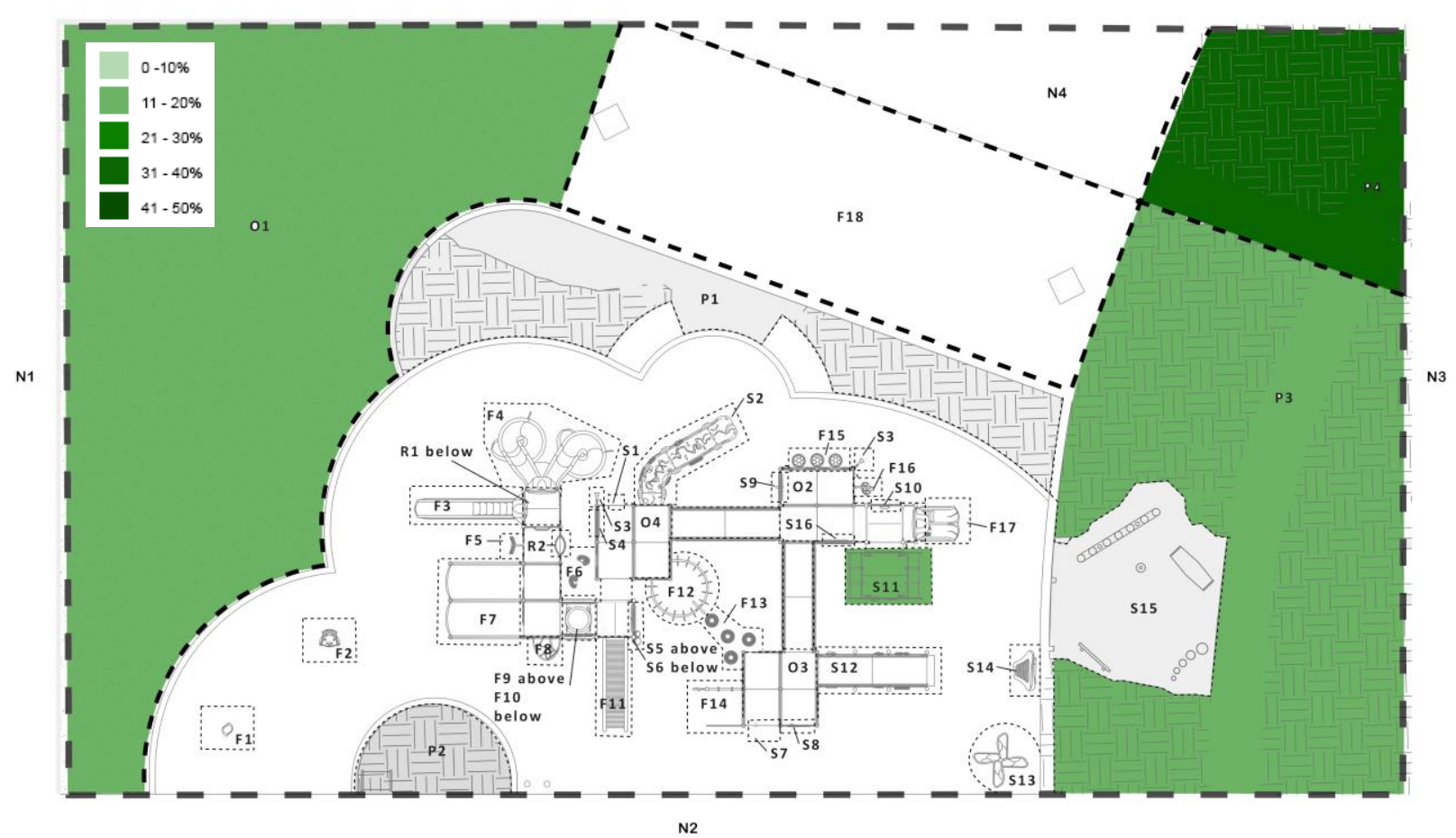

Note. The darker the shade of green, the higher the percentage of interaction. 
Table 6

Specific Settings that Afforded the Most Verbal Communication, as all other settings did not see any verbal communication.

\begin{tabular}{lll}
\hline Setting Code & Setting Name & $\begin{array}{l}\text { Percent of Verbal } \\
\text { Communication }\end{array}$ \\
\hline P4 & Nature Play North & $49.0 \%$ \\
O1 & Open Area, Grassy Hill & $11.8 \%$ \\
P3 & Nature Play South & $9.8 \%$ \\
N2 & Area South of Playground & $5.9 \%$ \\
F1 & Tilted Whirlwind Seat & $3.9 \%$ \\
F7 & Ropes Course & $3.9 \%$ \\
F10 & Straight Crawl Tube & $2.0 \%$ \\
F11 & Roller Slide & $2.0 \%$ \\
F3 & Zip Slide & $2.0 \%$ \\
N4 & Area North of Playground & $2.0 \%$ \\
P2 & Tree Planter & $2.0 \%$ \\
S11 & Sensory Wave Rock N Raft & $2.0 \%$ \\
S15 & Music Area & $2.0 \%$ \\
S3 & Talk Tube & $2.0 \%$ \\
Total & & $100.0 \%$ \\
\hline
\end{tabular}

Finally, the settings that afforded the most verbal communication were were the Naturally Planted Beds and the Open Grassy Hill, accounting for $70.6 \%$ of all verbal communication. 
Figure 20

Settings highlighted in green are the settings that afforded the most verbal communication.

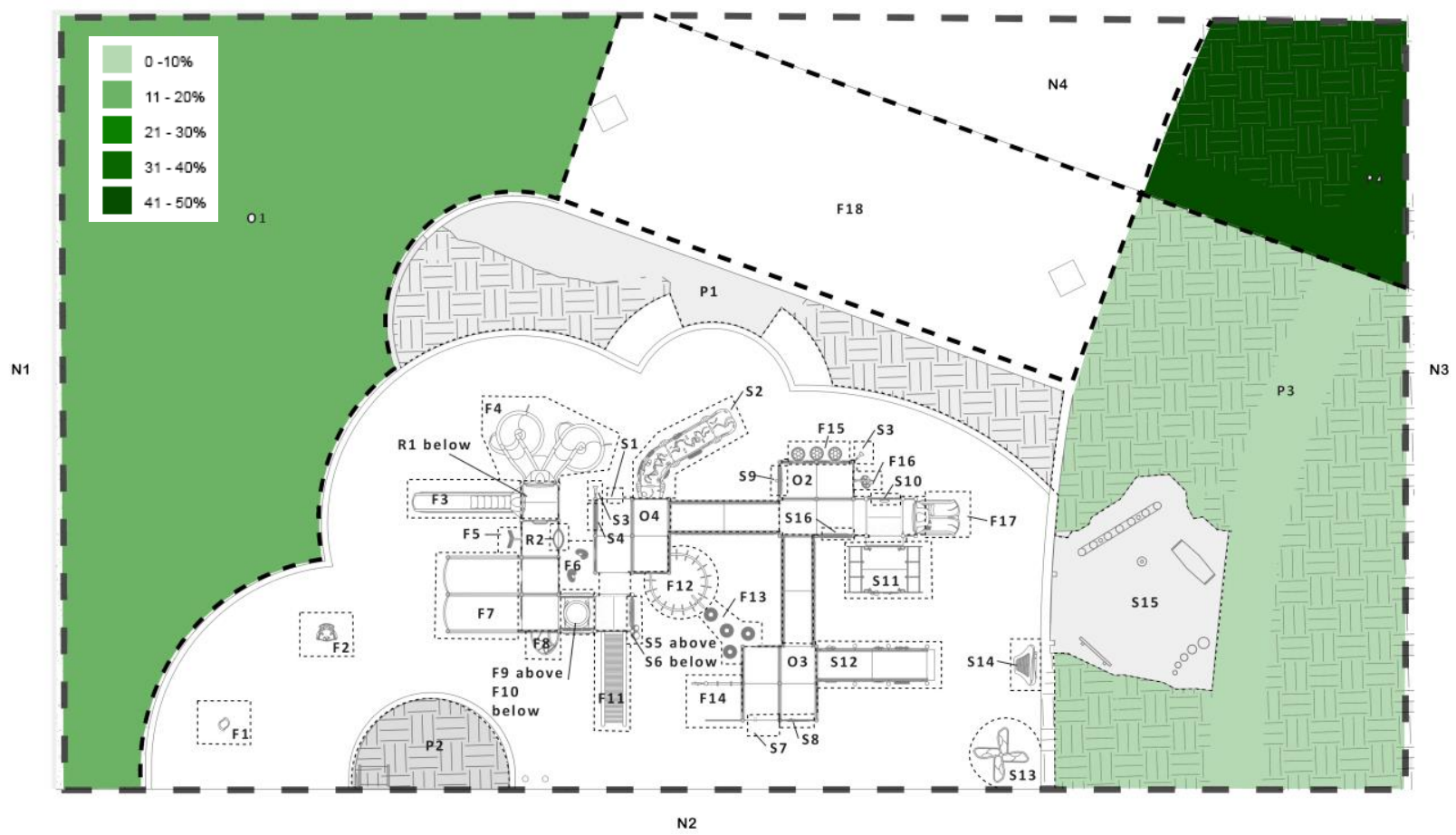

Note. The darker the shade of green, the higher the percentage of verbal communication. 


\section{Playground Setting and Type of Dramatic Play}

A two-way chi-square analysis was conducted to evaluate whether play settings were correlated with dramatic play type. The two variables were type of dramatic of play, including imitative role play, make-believe with objects, make-believe with actions and situations, interaction, and verbal communication, and the 49 play settings on the playground. Type of dramatic play and play setting were found to be related: Pearson $\chi^{2}=250,1437=595.899, p$ $<.001$. A follow-up examination of the results was conducted to identify in which settings the types of dramatic play observed occurred at least two times the expected rate if each type of dramatic play were equally likely in each play setting.

The results for type of dramatic play indicated that the Spiral Slide (F4) was 9.09 times more likely, the Natural Planted Area (P3) was 2.69 times more likely, the Sensory Wave Rock N Raft (S11) was 2.63 times more likely, and the Musical Play Area (S15) was 2.2 times more likely to be used for imitative role-play than expected. Expected values are from the statistical test.

The open concrete area with tables, east of the playground (N3) was 2.28 times more likely, the Thunder Ring (S10) was 6.87 times more likely, and the Sensory Wave Rock N Raft (S11) was 2.75 times more likely to be used for make-believe with objects than expected.

Results indicate the Loop Ladder (F12) was 2.5 times more likely, the Hex Pod Step (F15) was 2.5 times more likely, the Zip Slide (F3) was 5.5 times more likely, the Ropes Course (F7) was 2.54 times more likely, the open grass area with a mound and trees (N1) was 2.57 times more likely, and the Sensory Wave Rock N Raft (S11) was 2.1 times more likely to be used for make-believe with actions and situations than expected. 
The Natural Planted Area (P4) was 2.76 times more likely and the Sensory Wave Rock N Raft (S11) was 3.05 times more likely to be used for interaction than expected.

The results of the study indicate that the Natural Planted Area (P4) was 4.31 times more likely and the Talk Tube (S3) was 10 times more likely to be used for verbal communication than expected.

\section{Children with and without Disabilites and Types of Dramatic Play}

To what extent is there a difference between the dramatic play behaviors of first and second-grade elementary school students with and without disabilities across the behavior settings of the play environment at Edith Bowen Laboratory School, as this is an inclusive playground? To answer this question, a chi-square two-way test was performed to determine whether there were a difference in dramatic play types among children with and without disabilites. The two variables were children (with or without disabilities) and type of dramatic play (imitative role play, make-believe with objects, make-believe with actions and situations, interaction, verbal communication, and persistence of play episode). There was a significant difference between dramatic play types among children with and without disabilites: Pearson $\chi^{2}$ $(5,1418)=36.005, p<.001$. Children without disabilites engaged in higher levels of dramatic play than children with disabilities. 


\section{Figure 21}

Type of Dramatic Play distribution among children with and without disabilities.

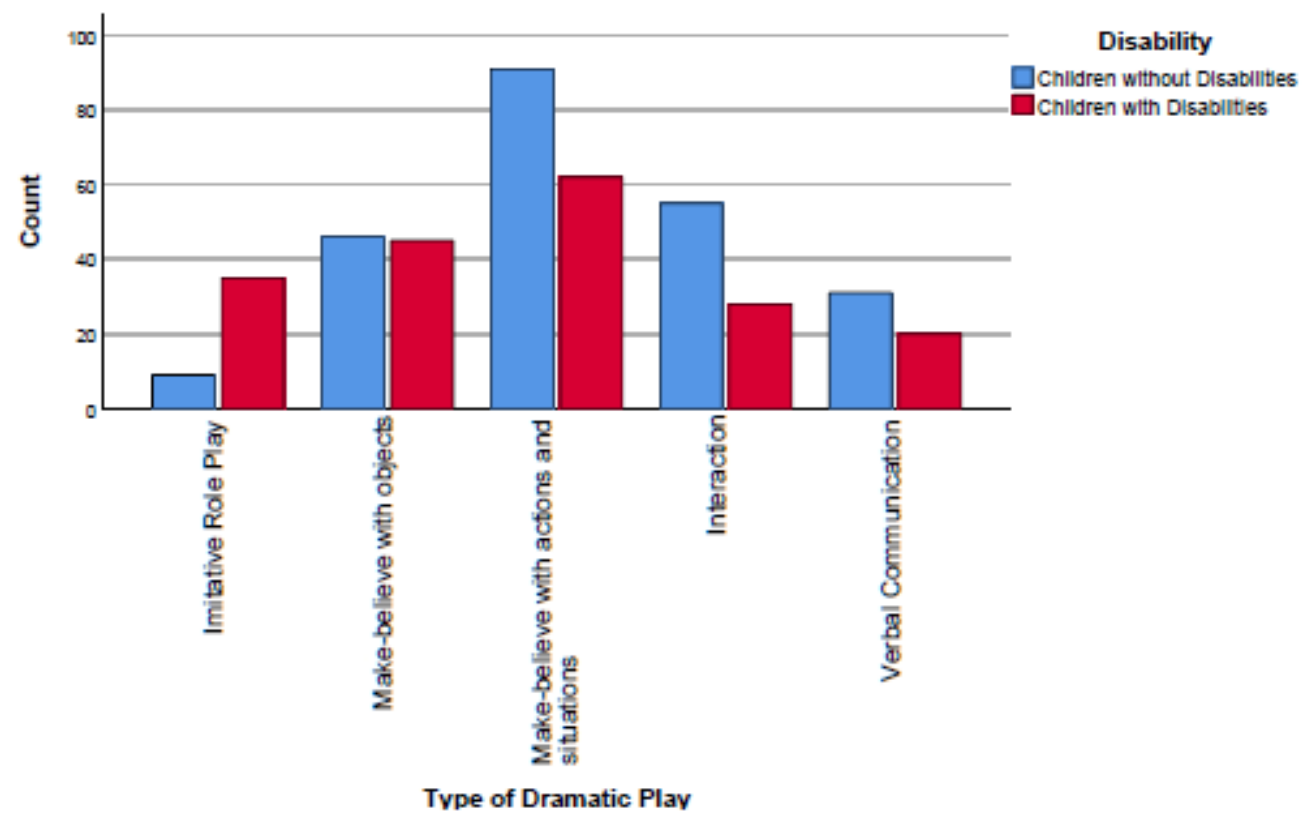

\section{Children with and without Disabilites and Dramatic Play Follow-up Tests}

A $49 \times 2$ ANOVA test was conducted to evaluate the effects of the settings and disabilities (the independent variables) on the types of dramatic play (the dependent variable). The results for the ANOVA indicated a significant interaction. The main effect for setting and disability yielded an $\mathrm{F}$ ratio of $\mathrm{F}(18,368)=2.159, \mathrm{p}<.001$, indicating a significant difference between dramatic play types and whether or not the child had a disability.

An ANOVA test was conducted to evaluate the effects of disabilities on the types of dramatic play. Results yielded an $\mathrm{F}$ ratio of $\mathrm{F}(1,422)=17.388, \mathrm{p}<.001$. Another ANOVA test was conducted to evaluate the effects of behavior settings on the types of dramatic play. Results yielded an $\mathrm{F}$ ratio of $\mathrm{F}(34,422)=3.230, \mathrm{p}<.001$, indicating a difference between type of dramatic play for children with and without disabilities. 
Figure 22

Settings that children with disabilities were more likely to use.

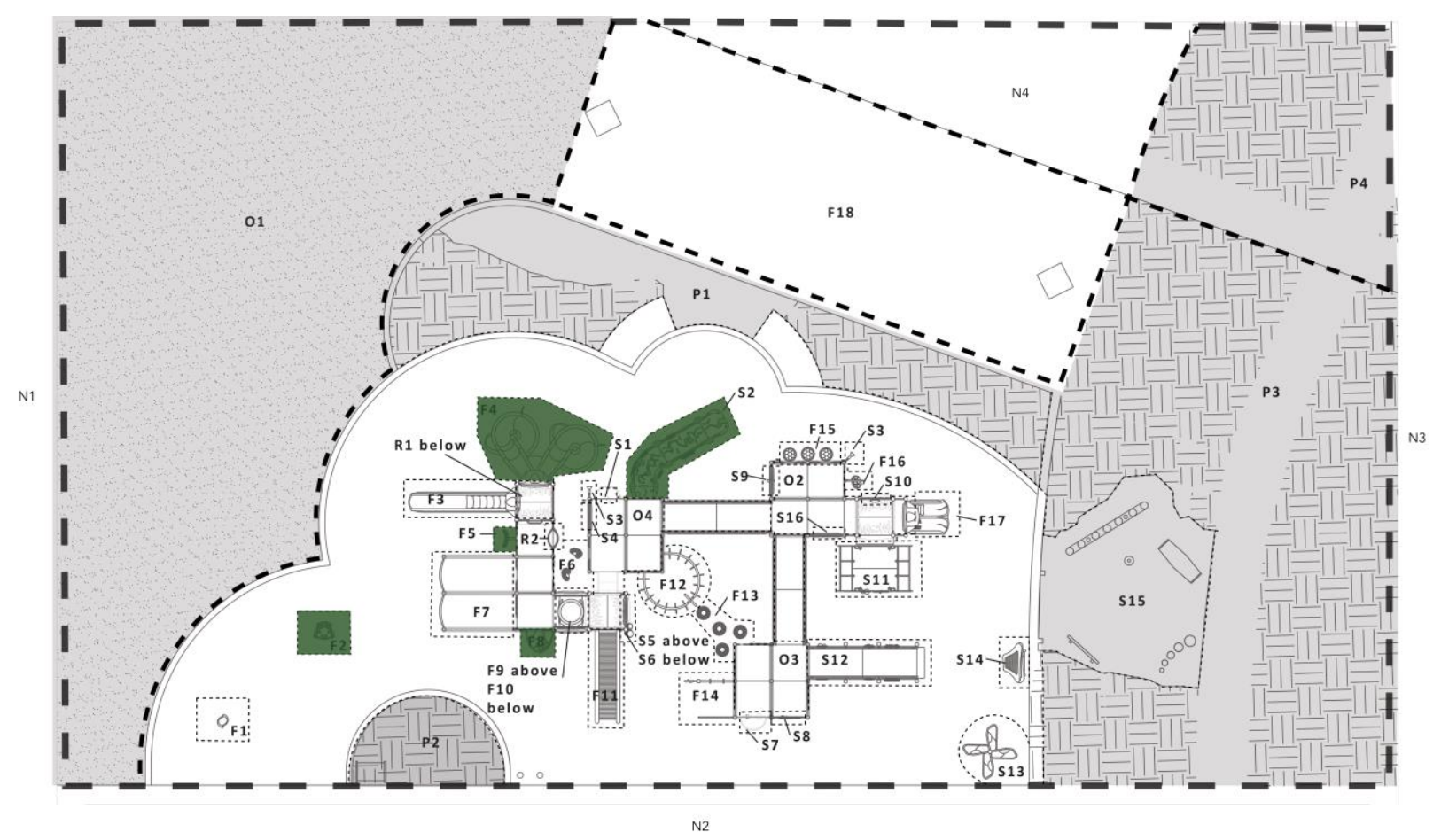

The following settings were more likely to afford dramatic play opportunities for children

with disabilities: Spiral Climber, Sensory Wave Seat, Spiral Slide, Erratic Climber, and the Stego Climber.

\section{Figure 23}

Settings that Children with Disabilities Are More Likely to Use, from left to right: Sensory Wave Seat, Erratic Climber, and the Stego Climber.
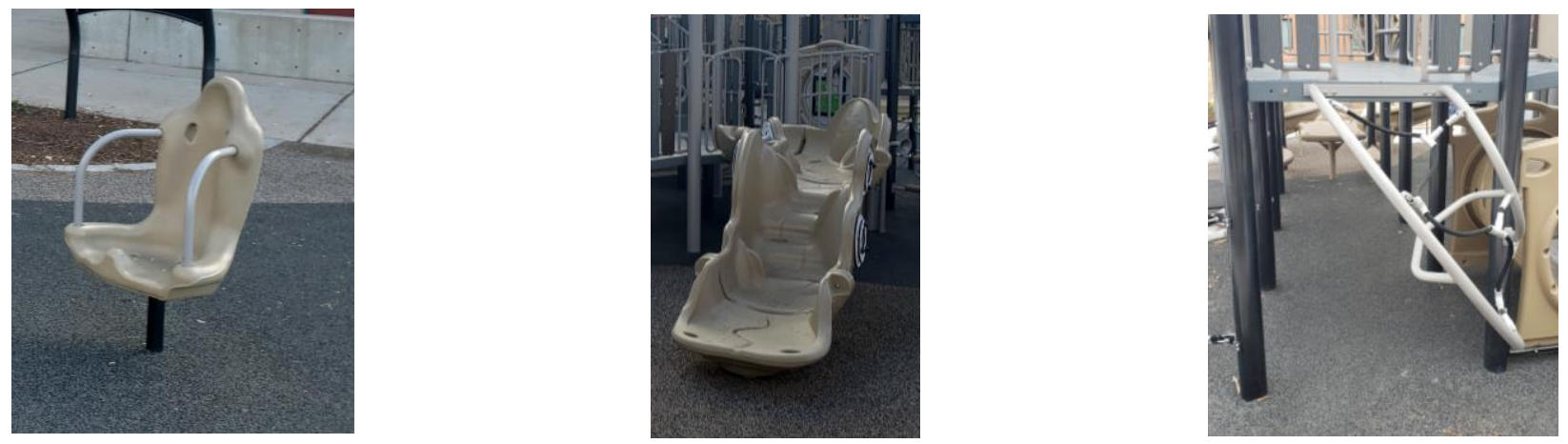


\section{Figure 24}

Settings that Children without Disabilities Were More Likely to Use.

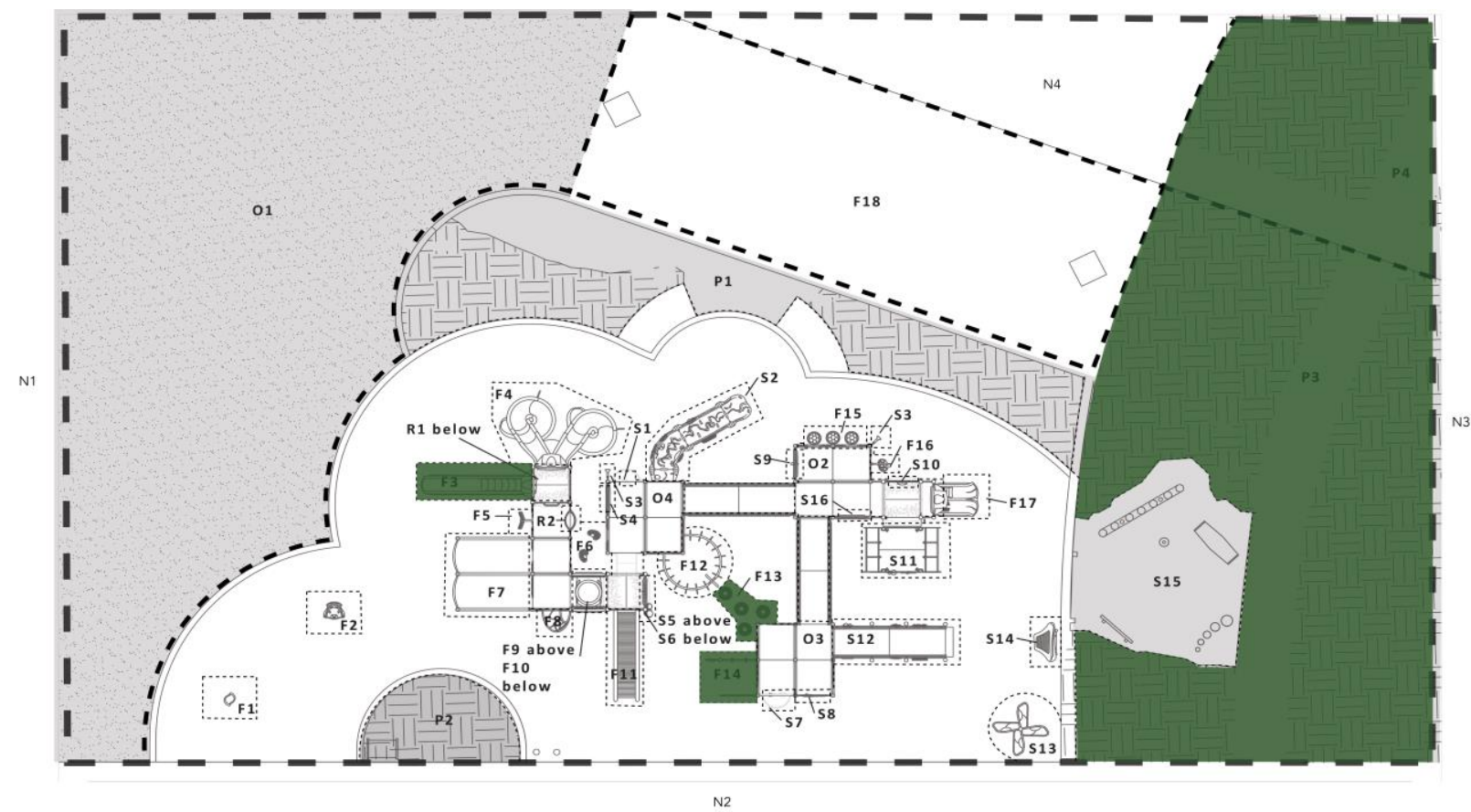

The following settings were more likey to afford dramatic play opportunities for children without disabilites: Gymnastics Area, Hex Pod Step, Rumble \& Roller Zip Slide, Play Structure Surface, Talk Tube, and the Nature Play South.

\section{Figure 25}

Gymnastics Area with Hex Pod Step in the Background

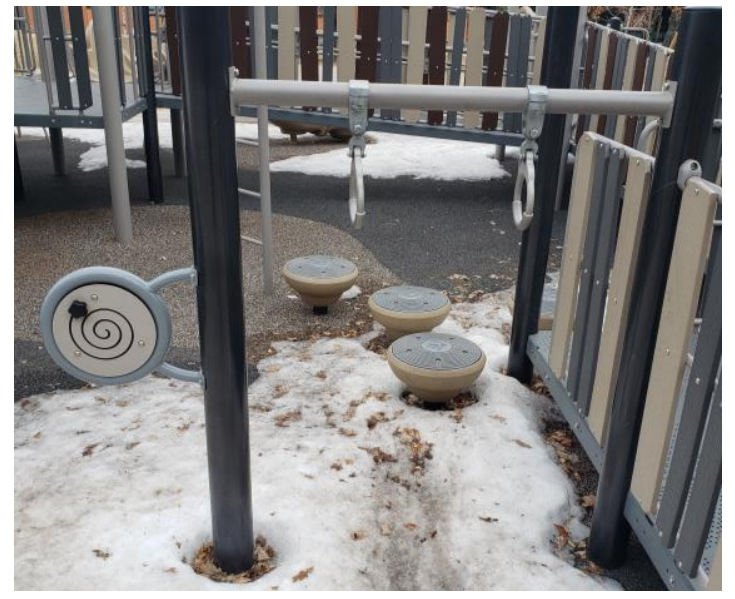


Follow-up tests were performed by comparing means, with 0.0 being the lowest level of dramatic play and 6.0 the highest level of dramatic play. The results indicate that the mean score (type of dramatic play) for all children (with and without disabilities) was 3.01 (makebelieve with actions and situations). The mean score (type of dramatic play) for children with disabilities was 2.765 (the equivalent of make-believe with objects), whereas the mean score (type of dramatic play) for children without disabilites was 3.446 (the equivalent of make-believe with actions and situations). 


\section{CHAPTER V}

\section{DISCUSSION}

This study compared the dramatic play affordances of behavior settings among children with and without disabilities in the first and second grades to answer the following research questions: To what extent do children in the first and second grades engage in dramatic play on the playground? Is dramatic play among first and second-grade elementary school students supported by the individual behavior settings of the play environment at Edith Bowen Laboratory School? What settings supported (and did not support) dramatic play behaviors at Edith Bowen Laboratory School? What settings were more likely to afford dramatic play behaviors? Does a well-designed inclusive playground reduce the differences between play behaviors of children with and without disabilities? Direct observations indicated that certain behavior settings afford more dramatic play among all children (both children with and without disabilities). Children's dramatic play developed more frequently in settings that allowed the children the opportunity to manipulate the materials in their environment as desired, similar to the findings of Droege \& Howes (1991) and as cited in Petrakos \& Howe (1996). Children's dramatic play developed in settings where children had stage-like areas and open-ended/enclosed settings, similar to the findings of Maxwell et al. (2008), which claimed that enclosed spaces, nodes and connector spaces, and stage-like places afforded dramatic play.

\section{Dramatic Play Occurred in Play Episodes}

Children in the first and second grade need a wide variety of equipment so they can choose how and where their play will occur. They also need opportunities to engage in group 
play to further their social-emotional skills. As children participate in dramatic play, these skills are refined. As shown in this study, dramatic play is typically influenced by facilitators such as open-ended settings with loose movable parts (props), plants (and the space between them), or platforms/stages. This study found that children with and without disabilities in the first and second grades used the Nature Play North and Nature Play South, Open Grassy Hill area, Sensory Wave Rock N Raft, Ropes Course, Zip Slide, and the Spiral Slide. These behavior settings were those that afforded the children the opportunity to manipulate their environment. The Nature Play North and South areas are flexible and offer children several opportunities to promote their play through using leaves, rocks, flowers, etc., as these are loose, movable props. It appears that loose parts provide an opportunity for children to think, be creative, and further the exploration of their environment. A flexible play environment adds more affordances for dramatic play than play equipment and settings. The Ropes Course, for example, was flexible and allowed children to be imaginative and manipulate it to a point. The ropes are connected and not directly loose; however, they are also flexible and movable, which allowed the children to be creative.

Natural play props played a role in the children's dramatic play when the children visited the naturally planted areas during their play episode. Children incorporated wood chips, gravel, sand, and plant material into their play. Plant material includes loose movable parts, such as leaves, flowers, and stems, which are removable from the plant itself. They create enclosed spaces with loose "walls." The placement and design of these settings make an impact on dramatic play. Of course, plant materials could be limited in their play opportunities. Certain plants contain toxins that are harmful if ingested and/or attract animals that may be a nuisance. However, using plant materials and other natural play props can enhance a child's dramatic play 
experience, and the inclusion of such should be carefully considered in order to eliminate hazards.

Children play based on what they know, what they have, and what they want to better understand. It appears that children may use plant materials and natural play props to act out animals, plants, and non-living elements to help them better understand the world.

\section{Multiple Children}

Settings that allowed multiple children to interact with the environment were often spaces that afforded dramatic play. A common aspect of the spaces where multiple children interacted was a sense of enclosure. Enclosed settings, such as the Sensory Wave Rock N Raft, provided children with a space where they could play without being disrupted, thereby allowing them to engage in uninterrupted dramatic play. While the girls anecdotally preferred to play 'house' and the boys preferred a version of pirates or cops and robbers, both used the Sensory Wave Rock N Raft as a scaffold to support their play—as a house for the girls or a boat for the boys. For example, a common theme for one specific girl who often engaged in dramatic play was to pretend the bench in the Sensory Wave Rock N Raft was a bed and to put her "children" to bed. It was also often used as a boat, wherein the boys would "jump ship." The Sensory Wave Rock N Raft functioned as an enclosed, inclusive motion playground feature that the children could use in multiple play scenarios. It appears that children's dramatic play would benefit from play settings that are not strongly themed, in order to better allow for flexibility regarding the dramatic play opportunities. For example, the Sensory Wave Rock N Raft does not have a direct theme, so it can be used as a boat, a house, or anything else the children want it to be for their play episode. Slides are also open-ended play settings. Children hid underneath the slide, which 
created a ceiling and, therefore, an enclosed space, or the children climbed on the top and bent over, creating a "cave" for their peers to slide through. The frequency of dramatic play in areas with enclosed settings corresponds with previous research in young children's play behaviors (Brown \& Burger, 1984, Maxwell et al., 2008).

\section{Dramatic Play in Open-ended Settings}

All of the settings that afforded the most dramatic play were open-ended areas. When dramatic play occurred on the playground, it took place in specific settings: in places that were enclosed (for example, the Sensory Wave Rock N Raft and in-between plants), stage-like places (the open grassy hill), node or connector places (the open grassy hill and areas between the playground and buildings), and natural areas (nature play areas). These areas seemed to allow for group interaction, which afforded children the opportunity for dramatic play. Loose parts are also supported throughout these areas. Loose parts help facilitate dramatic play on the playground. There were play settings, such as the two Play Structure platforms (O2 and O4), that were open areas that did not support dramatic play in this study. These open areas on the play structure were surrounded by other play settings that afforded play opportunities. Though these settings were infrequently used, when they were used, it was often as a platform on which to observe other children playing (non-play) or as a bridge to pass through during their play episode, such as in a game of tag. It appears that open areas also afford children the opportunity to watch their peers or pass through to other settings in their play episodes. The first and second-grade children who were engaged in non-play on the Play Structure Surfaces (open-ended areas) were children with disabilities. While children without disabilities may have assumed that the children with 
disabilities were not capable of engaging in the play scenarios, they were, in fact, merely observing.

\section{Dramatic Play on the Elementary School Play Playground}

Despite the importance of dramatic play in the development of children (Singer et al., 1973), surprisingly little is known about the types of dramatic play on the playground during the first and second-grade years. Instead, the types of dramatic play are listed in increasing levels of cognitive and social development. Previous studies examining preschoolers' dramatic play indicate that self-initiated dramatic play may only account for between $0.2 \%$ and $25 \%$ of overall play (Maxwell et al., 2008, Sanders \& Harper, 1976). Since the types of play and types of dramatic play correspond with increasing levels of cognitive and social development, dramatic play in first and second-grade children should be more common than among preschool-age children. Results of this study indicate that dramatic play accounted for $30.7 \%$ of the overall play, which supports this reasoning.

\section{Type of Dramatic Play Related to Settings}

This study determined that certain settings are more likely to facilitate higher levels of dramatic play. Settings that offer children the opportunity to engage in social interactions with other children were the settings that afforded dramatic play. It appears that specific playground settings facilitate social interaction because materials become facilitators in the play. This indicates that the older the child is, the more he or she plays with other children in groups. It is also an indication of verbal fluency and may indicate topics children are learning in the classroom. These social playground settings easily accommodate groups of children, making 
them great places for social interaction. Play themes stem from topics of relevance to the child. Dramatic play episodes, and, therefore, social interaction, are built on themes that shift according to the child's interest and are facilitated through specific settings and materials provided by adults. Such features of the play environment afford and facilitate play forms, roles, and interactions.

During imitative role-play episodes, the child assumes a pretend role and signals the transformation with a verbal declaration. The settings that were more likely to afford imitative role-play were the Spiral Slide, the Nature Play North and South areas, the Sensory Wave Rock N Raft, and the Musical Play Area. These settings allowed the children to pretend to be something or someone else from their personal experiences. Vygotsky (1998) says that children use settings in a way that is imitative of their personal lives, rather than changing their form and function. This reflects the child's developing ability to separate sensory and motor functions, or episodes that are repetitive or driven by the physical form and function of play settings. Smilansky \& Shefatya (1990) found that the presence of imitative role-play is the defining element for dramatic play to exist within play episodes because it provides children with an imaginary context to fuel their interactions, actions, and movements. A low presence of imitative role-play may affect the development of higher levels of dramatic play, as children may not be as prepared with an imaginative context to carry out supporting events and actions; therefore, a low level of imitative role-play demonstrated by children may affect the development of their actions and situations within a play episode, as children are less-equipped with an imaginative context to carry out supporting events and actions. The low levels of imitative role play in this study may indicate that the children studied, as first and second-graders, may also have been functioning at 
a higher cognitive/social level, as they may have been more engaged in imitative role-play in previous years.

In make-believe with objects play episodes, children are more concerned with the meaning associated with the object instead of its physical properties. When children engage in make-believe with objects, the object becomes the focus of the play episode, which allows the children to act in a form of abstract thought so they can separate the object from its original meaning. The children in this study engaged in some make-believe with objects, indicating that they were involved in some play episodes in which they substituted the form and function of an object for something else, but there may have been more make-believe with objects play episodes if the play settings throughout the playground included more loose, moveable objects to stimulate their play. Many children within the study displayed a dependency on physical objects to stimulate their play. The Nature Play Area and the Open Grassy Hill were more likely to afford make-believe with objects because these settings had open spaces, loose, moveable objects, or objects that could be used in many different ways.

Make-believe with actions and situations is a more mature form of dramatic play. It requires that children have knowledge of how to creatively use setting in their play episode. The Nature Play Area and the Open Grassy Hill afforded make-believe with actions and situations, as these settings were manipulative, whether that be physically or mentally and open-ended. In this study, the children took on and sustained specific roles by consistently engaging in actions, speech, and interactions with peers and themes that were often similar to topics studied in the classroom or experiences in their personal lives. These settings offered children the ability to engage in actions and interactions with their peers while using the play settings as they wanted. Research consistently shows that the more mature the play is, the more mature the roles and 
relationships between peers. Results indicated that children in the first and second-grade years engage most often in make-believe with actions and situations.

Group interactions indicate when a child directs another child's actions or words within the context of the play episode. The complexity of the play episodes was reflective of the children's highly collaborative interactions during play episodes. The settings where children could plan and negotiate roles, events, and sequences, were the settings that were more likely to inspire interaction. For example, the Nature Play Areas allowed the children to facilitate group interactions. During these interactions, the children often used the plants as facilitators in their play episode to direct their play.

The setting that was more likely to afford verbal communication was the Nature Play North area. Children are more likely to engage in verbal communication in settings that allow children to freely communicate with one another. When it comes to verbal communication, children need to share knowledge of similar conceptual ideas and the situation being played. In this study, such play episodes indicated that the children's skills were developing, whereas children took on roles and carried them out cooperatively.

\section{Settings that Did Not Afford Dramatic Play}

As noted, there are behavior settings that afforded dramatic play; however, it is important to note that there were settings that did not afford dramatic play. Much of the play structure did not encourage dramatic play, although it did support other types of play. Some of the stage-like areas on the playground afforded little or no dramatic play (O2 and O4, the Play Structure Surfaces). The Roller Slide, interestingly, did not afford the same level of dramatic play as the Zip or the Spiral Slide. The Talk Tube saw almost no dramatic play, which is surprising because 
a child can talk into one end of the tube while another child hears their "secret message" at the other end of the tube. Another surprising result was that the Straight Crawl Tube afforded little dramatic play. This tube allows children the opportunity to crawl through while pretending they are in a submarine or spaceship, among other things. Thus, both settings have the potential to fuel a child's imagination, yet the data suggests that though these settings may afford and were designed to afford dramatic play, the children in this study rarely used them for their intended purpose. The Straight Crawl Tube may have been too small for multiple children to use in their play setting, so even though it is an enclosed setting, it did not fully afford children the opportunity to engage in dramatic play.

Some of the settings are static, stationary, or only had one main purpose. These settings afforded children few opportunities to alter or change them, and as a result, offered children few opportunities to be creative and imaginary and to engage in dramatic play. The Cantata Chimes are static. The children who used this setting were unable to change it to their play episode. Play using the Cantata Chimes is therefore prescribed to allow children to produce rich, smooth tunes. The Spiral Climber is stationary, or anchored to the environment, so the children were unable to move it in their dramatic play episode, although the children were still able to use it for other play types. The Sensory Wave Seat was mainly designed for functional play, as a place where children can sit and spin. This setting had only one main purpose. Thus, it may have been difficult for first and second-grade children to be creative in their dramatic play using only a setting with one main purpose of functional play. There were eight settings that observed zero dramatic play. Some of the settings only had one way in or out, while other settings were designed for sensory play, functional play, or seating. This may suggest that if settings are not visible, easily accessible, or designed for dramatic play, children may not use these settings for 
dramatic play. It is also possible that children may perceive settings with only one way in or out as dead-end spaces, uncomfortable, or unsafe. Once the children's primary need to feel safe is met, then the children will engage in play more freely.

\section{Play of Children with and without Disabilities}

Does a well-designed inclusive playground create a smaller difference of play behaviors between children with and without disabilities? There was a small difference in the dramatic play types among children with and without disabilities, as expected. It was hypothsized that a welldesigned inclusive playgroud would move outdoor play environments beyond minimum accessibility requirements, recognize everyone's right to fully participate and contribute to meaningful play, and reap the lifelong developmental, physical, and social benefits of inclusion for children of all ages and abilities who engage in play.

A previous study found that teachers reported that about $75 \%$ of children with disabilities need assistance with social skills (Odom et al., 1993). However, Casby (1997) performed a review of research on the dramatic play skills of children with disabilities (language), and found that the actual differences in dramatic play abilities of children with disabilities when compared to children without disabilities are quite small; they have "a symbolic performance deficit more so than a symbolic competence deficit" (p. 477). The children with disabilities participated in all types of play on the playground, suggesting that these children are integrated into the environment, even if interactions are not at the exact same level as the children without disabilities. Children with disabilities spent the largest portion of their time engaging in functional play; whereas, children without disabilities spent the largest portion of their time engaged in dramatic play. This suggests that children with disabilities' social competence and 
performance are not quite on par with those of the children without disabilities. The dramatic play patterns of children with disabilities differed from those children without disabilities, with children with disabilities engaging in dramatic play $24.6 \%$ of the time, compared to $30.7 \%$ of the time for children without disabilities, which is consistent with previous research. The small differnences between children with and without disabilties may have been larger in a noninclusive playground, as it is quite possible that the children with disabilities may have benefited from the inclusive playground because it offers them additional opportunities to engage in dramatic play episodes with chidlren without disabilties. The mean type of dramatic play among children with disabilities was make-believe with objects; for children without disabilities the mean type of dramatic play was make-believe with actions and situations. Again, a small difference, but one which suggests children with disabilities' social competence may be slightly delayed, thus impairing their ability to generate ideas for dramatic play. This indication supports Jarrold, Boucher, \& Smith's (1996) findings.

The children without disabilities were at a slightly higher cognitive and social level, and the settings they were more likely to use were those that required more interaction and cognitive abilities. For example, the Talk Tube helps build imagination in a play episode, whereby children make plans, play games, and more. But the children who use the Talk Tube will also need to be able to function and sustain the play episode from a physical distance, which requires a higher level of ability. Settings that were more likely to afford dramatic play opportunities for both children with and without disabilities included settings geared to a combination of ability levels and typical settings that afford dramatic play. These settings allow children with and without disabilities to interact with each other in the same setting. Children with disabilities displayed less-sophisticated play abilities than children without disabilities, which may persist throughout 
their lives, despite improvements in overall development and functioning. Children with disabilities engaged in dramatic play but tended to use more direct and disruptive strategies to enter play scenarios, whereas, children without disabilities used more indirect strategies. The children began engaging in dramatic play without discussing roles in advance, and they maintained the play scenario through short play dialogues. In this regard, the children with disabilities used similar settings as those children without disabilities. For example, the children without disabilties were more likey to use the zip slide, whereas the children without disabilties were more likely to use the spirial slide. Creating settings with slightly more structure may reduce the barriers for better interaction between children with and without disabilites.

It is important to recognize that the playground this study focused on was designed to be inclusive and reduce environmental barriers to allow both children with and without disabilities to play. Children with disabilities may have benefited from the inclusive playground as it offers them additional opportunities to engage in play episodes with their peers. As a result, the small differences between children with and without disabilities may have been larger in an unsupportive environment. A well-designed inclusive playground reduces barriers for children with disabilties, creating an enviroment where children with diabilities can engage in similar play behaviors with their typically developing peers. This playground afforded children of all abilities to play together more independently, and because of this, the children felt nurtured, encouraged, respected, and active during play, both physically and socially, thus creating a sense of community among all the children.

Perhaps a higher level of social and cognitive development and competency for children with disabilities and greater education and awareness of various disabilities children with disabilities face are needed for better interactions between children with and without disabilities. 
A playground that challenges children should also push them to further their development of critical skills. Children's play behavior is differentially affected by playground design (Pellegrini, 1990).

As children grow older, skills are refined and integrated into a higher-level thought process. "Piaget presented the significant developmental accomplishments of children in terms of periods and stages. Again, he emphasized the sequence of changes more than the specific ages at which they occur. This explains why we frequently find children with disabilities experiencing a period of cognitive development associated with much younger children" (Hooper \& Umansky, 2013, p. 311). In the present study, the results indicate that even though children with disabilities interact and engage in similar levels of play and social interaction, they are at a lower cognitive and social developmental level than many children without disabilities.

\section{Anecdotal Observations/Playground Characteristics}

It was made clear through the children's actions on the playground that there were different interaction styles between boys, girls, and friends. Boys seemed to prefer competitive activities, such as cops and robbers. In contrast, girls engaged in more harmonious interactions, such as playing house. More dominate children were more vocal, as their social skills were at a higher developmental level. They often had their way on the playground by directing the play. These were also the children who often engaged in more social interaction through play. It seemed that the children who were at a lower social developmental level spent less time participating in prosocial or relationship-enhancing interactions and spent more time alone. There also seemed to be a correlation between the less dominant children and the children with disabilities. This suggests that social dominance may be related to play maturity. Social 
dominance may be less about interaction group size and more about cognitive age, persistence, and experience within the playground environment (Hawley, 2015). Further research may be needed for follow-up examinations of these playground characteristics.

\section{Preferred Settings}

Children frequented certain behavior settings more than others during formal observation. Four out of the top five most frequented settings were designed for dramatic play. For example, the top three most frequently-used settings were the open grassy hill, which accounted for $12.7 \%$ of the observed play, and the two naturally planted beds, which, when combined, accounted for $22.9 \%$ of the observed play. This corresponds with findings from Maxwell et al. (2008), who found that stage-like places help facilitate dramatic play and allow children to perform for their peers. Stage-like places easily accommodate groups of children, making them ideal places for the social interaction necessary for dramatic play. These findings are also consistent with those of Fjørtoft (2004), who stated, "the variety of woodland vegetation and the physiognomy of trees and shrubs in the area afforded multiple choices for play" (p. 30). The shrubs afforded children the opportunity to engage in building dens, playing hide-and seek, and role-playing games like house or cops and robbers.

\section{Limitations}

This study identified behavior settings that afford children with and without disabilities the opportunity to engage in dramatic play; however, some limitations should be noted. First, only one playground was observed in the fall for eight weeks in northern Utah. Second, the sample population may lack diversity, even though the school attempts to keep the population 
diverse. In addition, only eight parents of children with IEP designations responded to the survey. The disabilities that the children had were primarily non-physical disabilities, so differences in observations might be magnified if there were more children with physical or more physically obvious disabilities. As a result, these results may be limited in their generality. Lastly, misjudgements may have occurred because human observers had difficulties determining each type of dramatic play when watching and listening without distrupting the children's play behaviors. Because of this, the observed frequency of dramatic play may differ from the actual occurrence of dramatic play. However, the observation process and observers did not change throughout the study.

\section{Implications}

This study's findings suggest that specific behavior playground settings afford children the opportunity to engage in the most dramatic play. These settings include the natural planted areas, open grassy areas, Sensory Wave Rock N Raft, Thunder Ring, the Ropes Course, the Zip Slide, and the Spirial Slide. The underlying principles of playground features that afford dramatic play are found in these settings. All of these settings are open-ended areas that can be used by children as they please. In the natural planted beds, there are loose parts and enclosures. The grassy hill can become a stage. The Sensory Wave Rock N Raft, the Thunder Ring, and the Ropes Course are movable, and the slides are open-ended with opportunities to be enclosed through the children's play episodes. To create developmentally appropriate outdoor playground settings for dramatic play, play professionals should provide several options for children, including settings that are or can be enclosed, have natural play props, and include a stage-like area. 


\section{Future Research, Improved Methods}

Initially, during trial observations, a clustering system was used. Settings were clustered together, and observers monitored the children who used the settings in a cluster. This system made it difficult to observe the children and their play types accurately. Observing one child proved more effective for data collection, even though the children ran rapidly around the playground and often used more than one setting or ran out of the observer's sight. Children often thought the observers were playground aides, as observers wore the same playground vest to avoid changing the children's play behaviors. However, this often caused the observers to slip in their concentration on the observed child while assisting another child.

\section{Future Research, Continued Study}

This investigation of dramatic play affordances might be continued with a larger or more diverse group of children with and without disabilities on a different playground or within various settings that afford dramatic play. For example, future studies could compare more children with disabilities or 'a larger range of IEP designations. Future study on a different population could give greater insights as to dramatic play tendencies in older grades. Future studies may also include a comparison study of an inclusive playground and a typical playground to see if the difference is smaller on the inclusive playground, as small differences in this study between children with and without disabilities may have been larger in an unsupportive environment. A well-designed inclusive playground may also reduce barriers for children with disabilties, thereby creating an enviroment where children with disabilities can engage in similar play behaviors with their typically developing peers.

This study focused on one charter school playground and settings for dramatic play among children with and without disabilities. This also begs the questions "How can these 
settings and materials be provided in a community setting?" and "How does dramatic play change the learning experience of children with and without disabilities?"

\section{For Design}

If results from this study and existing literature were combined, guidelines could be determined to design for increased dramatic play. For playgrounds to support dramatic play, design professionals should include settings that afford dramatic play, such as the Zip Slide, the Spiral Slide, the Sensory Wave Rock N Raft, the Open Grassy Hill, and the Nature Play. Settings with characteristics of loose parts, stage-like areas, natural props, enclosed areas, slightly themed elements, and open-ended settings afford dramatic play. To provide for social interaction, play professionals should design playgrounds or characteristics of playgrounds with settings that are more likely to encourage social interaction in dramatic play. These settings may have similar characteristics, including areas large enough to easily accommodate groups of children, props to help facilitate play, and themed objects of the children's interest. For playgrounds to support dramatic play among children with and without disabilities, playground designers should also include a variety of settings that children can use at different developmental stages.

In the field of landscape architecture, collaboration is critical for the success of a project. Early childhood professionals are experts in children's needs, especially the children of the local area or school. Since the use of a playground is governed by the school, it is important that the design meets the needs and social context of the school. Playground designers or landscape architects would also benefit from the view of early childhood professionals and children themselves. For example, landscapes are often perceived at adult height, but the same landscape would be experienced differently at a child's height (Herrington \& Lesmeister, 2006). A participatory design process with practitioners, researchers, teachers, parents, and children can 
ensure a developmentally appropriate playground that emphasizes dramatic play to benefit children. 


\section{CHAPTER VI}

\section{CONCLUSION}

In summary, incorporating behavior settings that afford children the opportunity to engage in dramatic play is a good way to facilitate dramatic play in children with and without disabilities. The play behaviors of children with and without disabilities in first and second grade were found to be consistent with previous research suggesting that children with disabilities play at lower cognitive and social levels than do children without disabilities. They do, however, use similar settings, suggesting that slightly more structured settings may reduce barriers, thus allowing for better interaction between children with and without disabilites. In terms of dramatic play after preschool, this study shows that dramatic play is a significant component of the play of first and second graders, which is consistent with previous research. In terms of characteristics of settings that afford dramatic play, settings with characteristics of loose parts, stage-like areas, natural props, enclosed areas, slightly themed elements, and open-ended settings afford more dramatic play. Dramatic play themes, and, therefore, the quality of play, is dependent on the child's interest and facilitated through settings and materials as they relate to the use of outdoor spaces and playgrounds. A well-designed inclusive playground reduces barriers for children with disabilties, thereby creating an enviroment where children with diabilities can engage in similar play behaviors with their typically developing peers. A better understanding of how to provide children with these physical and social settings will allow professionals to better design play spaces that facilitate dramatic play in children with and without disabilities. 


\section{REFERENCES}

A. P. Association. (2006). Planning and urban design standards. John Wiley \& Sons.

Barbour, A. C. (1999). The impact of playground design on the play behaviors of children with differing levels of physical competence. Early Childhood Research Quarterly, 14(1), 7598.

Barker, R. (1968). Ecological psychology: Concepts and methods for studying the environment of human behavior. Stanford University Press.

Barton, E. E. (2015). Teaching generalized pretend play and related behaviors to young children with disabilities. Exceptional Children, 81(4), 489-506.

https://doi.org/10.1177/0014402914563694

Barton, E. E., \& Wolery, M. (2008). Teaching pretend play to children with disabilities: A review of the literature. Topics in Early Childhood. Special Education, 109-125.

Bauminger, N., Finzi-Dottan, R., Chason, S., \& Har-Even, D. (2008). Intimacy in adolescent friendship: The roles of attachment, coherence, and self-disclosure. Journal of Social and Personal Relationships, 25(3), 409-428. https://doi.org/10.1177/0265407508090866

Bergen, D. (2002). The role of pretend play in children's cognitive development. Early Childhood Research \& Practice, 4(1). 1-13

Berman, L. (2007). The power of play—What children learn by unstructured play. EzineArticles. https://ezinearticles.com/?The-Power-of-Play---What-Children-Learn-by-UnstructuredPlay\&id=420404 
Bray, P., \& Cooper, R. (2007). The play of children with special needs in mainstream and special education settings. Australasian Journal of Early Childhood, 32(2), 37-42. https://doi.org/10.1177/183693910703200207

Brett, A., Moore, R. C., \& Jr., E. F. P. (1993). The complete playground book. Syracuse University Press.

Brodin, J. (2005). Diversity of aspects on play in children with profound multiple disabilities. Early Child Development and Care, 175(7-8), 635-646. https://doi.org/10.1080/0300443042000266222

Brown, V. (2017). Drama as a valuable learning medium in early childhood. Arts Education Policy Review, 118(3), 164-171. https://doi.org/10.1080/10632913.2016.1244780

Burdette, H. L., \& Whitaker, R. C. (2005). Resurrecting free play in young children: Looking beyond fitness and fatness to attention, affiliation, and affect. Archives of Pediatrics \& Adolescent Medicine, 159(1), 46-50. https://doi.org/10.1001/archpedi.159.1.46

Cassidy, J., Parke, R. D., Butkovsky, L., \& Braungart, J. M. (1992). Family-peer connections: The roles of emotional expressiveness within the family and children's understanding of emotions. Child Development, 63(3), 603-618. https://doi.org/10.1111/j.14678624.1992.tb01649.x

Christie, J. F. (1990). Dramatic play: A context for meaningful engagements. The Reading Teacher, 43(8), 542-545.

Cloward Drown, K. K. (2014). Dramatic play affordances of natural and manufactured outdoor settings for preschool-aged children. Utah State University.

Cooper, J., \& Dever, M. (2001). Socio-dramatic play as a vehicle for curriculum integration in first grade. Young Children, 58-63. 
Copple, C., \& Bredekamp, S. (2009). Developmentally appropriate practice in early childhood programs serving children from birth through age 8 (Third Edition). National Association for the Education of Young Children.

Cosco, N., \& Moore, R. (2009). Sensory integration and contact with nature: Designing outdoor inclusive environments. https://naturalearning.org/sensory-integration-and-contact-withnature-designing-outdoor-inclusive-environments/

Critz, C., Blake, K., \& Nogueira, E. (2015). Sensory processing challenges in children. The Journal for Nurse Practitioners, 11(7), 710-716. https://doi.org/10.1016/j.nurpra.2015.04.016

Czalczynska-Podolska, M. (2014). The impact of playground spatial features on children's play and activity forms: An evaluation of contemporary playgrounds' play and social value. Journal of Environmental Psychology, 38, 132-142. https://doi.org/10.1016/j.jenvp.2014.01.006

DiCarlo, C. F., \& Reid, D. H. (2004). Increasing pretend toy play of toddlers with disabilities in an inclusive setting. Journal of Applied Behavior Analysis, 37(2), 197-207. https://doi.org/10.1901/jaba.2004.37-197

Drown, K. K. C., \& Christensen, K. M. (2014). Dramatic play affordances of natural and manufactured outdoor settings for preschool-aged children. Children, Youth and Environments, 24(2), 53-77. https://doi.org/10.7721/chilyoutenvi.24.2.0053

Drucker, J., Franklin, M. B., \& Wilford, S. (1999). Understanding pretend play: A guide for parents and teachers to accompany the documentary video "When a Child Pretends." https://eric.ed.gov/?id=ED441554

Eccles, J. S. (2000). The development of children ages 6 to 14. The Future of Children, 30-42. 
Eden, S. T. (2008). Play works: Helping children learn through play. AuthorHouse.

Eiermann, R. R. (1971). Social play in childhood. Child's Play. https://ci.nii.ac.jp/naid/10015051516/

Eisenberg, N., Fabes, R. A., Bernzweig, J., Karbon, M., Poulin, R., \& Hanish, L. (1993). The relations of emotionality and regulation to preschoolers' social skills and sociometric status. Child Development, 64(5), 1418-1438. https://doi.org/10.1111/j.14678624.1993.tb02961.x

Elias, C. L., \& Berk, L. E. (2002). Self-regulation in young children: Is there a role for sociodramatic play? Early Childhood Research Quarterly, 17(2), 216-238. https://doi.org/10.1016/S0885-2006(02)00146-1

Eriken, A. (1985). Playground design: Outdoor environments for learning and development. Van Nostrand Reinhold.

Fein, G. G. (1981). Pretend play in childhood: An integrative review. Child Development, 52(4), 1095-1118. JSTOR. https://doi.org/10.2307/1129497

Fernelius, C. (2017). Evidence-based practices for the design of inclusive playgrounds that support peer interactions among children with all abilities. All Graduate Theses and Dissertations. https://digitalcommons.usu.edu/etd/6809

Fjortoft, I. (2000). Landscape as playscape: Learning effects from playing in a natural environment on motor development in children.

Fjørtoft, I. (2004). Landscape as playscape: The effects of natural environments on children's play and motor development. Children, Youth and Environments, 14(2), 21-44.

Frankel, F. D., Gorospe, C. M., Chang, Y.-C., \& Sugar, C. A. (2011). Mothers' reports of play dates and observation of school playground behavior of children having high-functioning 
autism spectrum disorders: Play dates and school observation. Journal of Child

Psychology and Psychiatry, 52(5), 571-579. https://doi.org/10.1111/j.1469-

7610.2010.02318.x

Fromberg, D. P., \& Bergen, D. (2006). Play from birth to twelve: Contexts, perspectives, and meanings. Taylor \& Francis.

Gibson, J. (1977). The theory of affordances. In R.E. Shaw \& J. Bransford (Eds.), Perceiving, acting, and knowing. Hillsdale, NJ: Erlbaum.

Ginsburg, K. R. (2007). The importance of play in promoting healthy child development and maintaining strong parent-child bonds. Pediatrics, 119(1), 182-191. https://doi.org/10.1542/peds.2006-2697

Hatcher, B., \& Pretty, K. (2004). Visible through in dramatic play. Young Children, 59(6), 7982.

Hawley, P. H. (2015). Social dominance in childhood and its evolutionary underpinnings: Why it matters and what we can do. Pediatrics, 135(Supplement 2), S31. https://doi.org/10.1542/peds.2014-3549D

Heft, H. (1988). Affordances of children's environments: A functional approach to environmental description. Children's Environments Quarterly, 5(3), 29-37.

Henniger, M. L. (1985). Preschool children's play behavior in indoor and outdoor environment. Association for Childhood Education International.

Herrington, S., \& Lesmeister, C. (2006). The design of landscapes at child-care centres: Seven Cs. Landscape Research, 31(1), 63-82. https://doi.org/10.1080/01426390500448575 
Hestenes, L. L., \& Carroll, D. E. (2000a). The play interactions of young children with and without disabilities: Individual and environmental influences. Early Childhood Research Quarterly, 15(2), 229-246. https://doi.org/10.1016/S0885-2006(00)00052-1

Hestenes, L. L., \& Carroll, D. E. (2000b). The play interactions of young children with and without disabilities: Individual and environmental influences. Early Childhood Research Quarterly, 15(2), 229-246. https://doi.org/10.1016/S0885-2006(00)00052-1

Houtz, E. (2017, August 7). The importance of unstructured free play. http://www.carolinaparent.com/CP/The-Importance-of-Unstructured-Free-Play/

Hudson, S. D., \& Thompson, D. (2001). Are playgrounds still viable in the 21 st century? Parks \&amp; Recreation (Ashburn), 36(4), 54-117.

Isenberg, J. P., \& Quisenberry, N. (2002). A position paper of the Association for Childhood Education International PLAY: Essential for all children. Childhood Education, 79(1), 33-39. https://doi.org/10.1080/00094056.2002.10522763

Jacoby-Garrett, P. (2018). Developing and expanding learning through play. Parks \& Recreation, 53(5), 24-28.

Jelks, P., \& Dukes, L. (1985). Promising props for outdoor play. Day Care and Early Eduaction, 13(1), 18-20.

Johnson, A. P. (1998). How to use creative dramatics in the classroom. Childhood Education, $75(1), 2-6$.

Kyttä, M. (2004). The extent of children's independent mobility and the number of actualized affordances as criteria for child-friendly environments. Journal of Environmental Psychology, 24(2), 179-198. https://doi.org/10.1016/S0272-4944(03)00073-2 
Lang, J. (1987). Creating architectural theory: The role of the behavioral sciences in environmental design. Van Nostrand Reinhold.

Lillard, A., Pinkham, A. M., \& Smith, E. (2010). The Wiley-Blackwell handbook of childhood cognitive development (1st ed.). John Wiley \& Sons, Ltd. https://doi.org/10.1002/9781444325485

Lillard, A. S., Lerner, M. D., Hopkins, E. J., \& Smith, E. D. (2013). The impact of pretend play on children's development: A review of the evidence. Psychological Bulletin, 139(1), 134. http://dx.doi.org.dist.lib.usu.edu/10.1037/a0029321

Locke, J., Shih, W., Kretzmann, M., \& Kasari, C. (2016). Examining playground engagement between elementary school children with and without autism spectrum disorder. Autism: The International Journal of Research \& Practice, 20(6), 653-662. https://doi.org/10.1177/1362361315599468

Logue, M. E., \& Harvey, H. (2009). Preschool teachers' views of active play. Journal of Research in Childhood Education, 24(1), 32-49. https://doi.org/10.1080/02568540903439375

Loy, D. P., \& Dattilo, J. (2000). Effects of different play structures on social interactions between a boy with Asperger's Syndrome and his peers-ProQuest. Therapeutic Recreation Journal, 34(3), 190-210.

Lynch, K., \& Hack, G. (1984). Site planning. MIT press.

Martin, S. (2014). Play in children with motor disabilities.

Mason, J. (1982). The environment of play. Leisure Press. 
Maxwell, L. E., Mitchell, M. R., \& Evans, G. W. (2008). Effects of play equipment and loose parts on preschool children's outdoor play behavior: An observational study and design intervention. Children, Youth and Environments, 18(2), 36-63.

McClintic, S., \& Petty, K. (2015). Exploring early childhood teachers' beliefs and practices about preschool outdoor play: A qualitative study. Journal of Early Childhood Teacher Education, 36(1), 24-43. https://doi.org/10.1080/10901027.2014.997844

McConkey, J. (2018). Well-designed playgrounds develop important skills that contribute to successful adult life. District Administration, 54(2), 6-6.

Mejeur, M., Schmitt, G., \& Wolcott, H. (2012). A systematic review of the best practices for playground inclusion. Occupational Therapy Graduate Research.

Mitchell, R., Cavanagh, M., \& Eager, D. (2006). Not all risk is bad, playgrounds as a learning environment for children. International Journal of Injury Control \& Safety Promotion, 13(2), 122-124. https://doi.org/10.1080/17457300500310269

Moore, R. C., Cosco, N. G., \& Cosco, N. G. (2007). What makes a park inclusive and universally designed?: A multi-method approach. Open Space: People Space. https://doi.org/10.4324/9780203961827-16

Moore, R. C., \& Wong, H. H. (1997). Natural learning: The life history of an environmental schoolyard: Creating environments for rediscovering nature's way of teaching. MIG Communications.

Murphy, N. A., \& Carbone, P. S. (2008). Promoting the participation of children with disabilities in sports, recreation, and physical activities. Pediatrics, 121(5), 1057-1061. https://doi.org/10.1542/peds.2008-0566 
Nabors, L., \& Badawi, M. (1997). Playground interactions for preschool-age children with special needs. Physical \& Occupational Therapy In Pediatrics, 17(3), 21-31. https://doi.org/10.1080/J006v17n03_02

Nabors, L., Willoughby, J., \& Badawi, M. A. (1999). Relations between activities and cooperative playground interactions for preschool-age children with special needs. Journal of Developmental and Physical Disabilities, 11(4), 339-352. https://doi.org/10.1023/A:1021818908388

Nicolopoulou, A., \& Ilgaz, H. (2013). What do we know about pretend play and narrative development? A response to Lillard, Lerner, Hopkins, Dore, Smith, and Palmquist on “The impact of pretend play on children's development: A review of the evidence." American Journal of Play, 6(1), 55-81.

Nye, B. D., \& Silverman, B. G. (2012). Affordance. In N. M. Seel (Ed.), Encyclopedia of the Sciences of Learning (pp. 179-183). Springer US. https://doi.org/10.1007/978-1-44191428-6_369

Oke, A., \& Middle, G. J. (2016). Planning playgrounds to facilitate children's pretend play: A case study of new suburbs in Perth Western Australia. Planning Practice \& Research, 31(1), 99-117. https://doi.org/10.1080/02697459.2015.1081336

Overton, S., \& Rausch, J. L. (2002). Peer relationships as support for children with disabilities: An analysis of mothers' goals and indicators for friendship. Focus on Autism and Other Developmental Disabilities, 17(1), 11-29. https://doi.org/10.1177/108835760201700102

Overton, W. F., \& Jackson, J. P. (1973). The representation of imagined objects in action sequences: A developmental study. Child Development, 44(2), 309-314. JSTOR. https://doi.org/10.2307/1128052 
Pellegrini, A. D. (1990). Elementary school children's playground behavior: Implications for children's social-cognitive development. Children's Environments Quarterly, 7(2), 8-16. JSTOR.

Pellegrini, A. D., \& Perlmutter, J. C. (1989). Classroom contextual effects on children's play. Developmental Psychology, 25(2), 289-296. https://doi.org/10.1037/0012-1649.25.2.289

Pereira, B. (2004). Children's playground accessibility in the North of Portugal. World Leisure Journal, 46(1), 38-45. https://doi.org/10.1080/04419057.2004.9674347

Petrakos, H., \& Howe, N. (1996). The influence of the physical design of the dramatic play center on children's play. Early Childhood Research Quarterly, 11(1), 63-77.

Petrie, K., \& Clarkin-Phillips, J. (2018). 'Physical education' in early childhood education. European Physical Education Review, 24(4), 503-519.

Piaget, J. (1962). Play dreams \& imitation in childhood (Reprint edition). W. W. Norton and Company, Inc.

Prellwitz, M. (2007). Playground accessibility and usability for children with disabilities: Experiences of children, parents and professionals. http://urn.kb.se/resolve?urn=urn:nbn:se:ltu:diva-62215

Prellwitz, M., \& Skär, L. (2007). Usability of playgrounds for children with different abilities. Occupational Therapy International, 14(3), 144-155.

Prellwitz, M., Tamm, M., \& Lindqvist, R. (2001). Are playgrounds in Norrland (Northern Sweden) accessible to children with restricted mobility? Scandinavian Journal of Disability Research, 3(1), 56-68. https://doi.org/10.1080/15017410109510768

Rathus, S. A. (2013). Childhood and adolescence: Voyages in development. Cengage Learning. 
Refshauge, A., Stigsdotter, U., Lamm, B., \& Thorleifsdottir, K. (2013). Evidence-based playground design: Lessons learned from theory to practice. Landscape Research. https://doi.org/10.1080/01426397.2013.824073

Rimmer, J. H. (2005). The conspicuous absence of people with disabilities in public fitness and recreation facilities: Lack of interest or lack of access? American Journal of Health Promotion, 19(5), 327-329. https://doi.org/10.4278/0890-1171-19.5.327

Savina, E. (2014). Does play promote self-regulation in children? Early Child Development and Care, 184(11), 1692-1705. https://doi.org/10.1080/03004430.2013.875541

Scarlett, W. G., Al-Solaim, L., Naudeau, S., Salonius-Pasternak, D., \& Ponte, I. (2005). Children's play. SAGE.

Schmidt, E. L., \& Stanton-Chapman, T. L. (2017). Creating an inclusive playground for children of all abilities: West Fork Playground in Cincinnati, Ohio. Children, Youth and Environments, 27(3), 124. https://doi.org/10.7721/chilyoutenvi.27.3.0124

Shim, S.-Y., Herwig, J. E., \& Shelley, M. (2001). Preschoolers' play behaviors with peers in classroom and playground settings. Journal of Research in Childhood Education, 15(2), $149-163$.

Shin, D., \& Frost, J. L. (1995). Preschool children's symbolic play indoors and outdoors. International Play Journal, 3(2), 83-96.

Singer, D. G., \& Singer, J. L. (1990). The house of make-believe: Children's play and the developing imagination. Harvard University Press.

Skär, L. (2002). Disabled children's perceptions of technical aids, assistance, and peers in play situations. Scandinavian Journal of Caring Sciences, 16(1), 27-33. https://doi.org/10.1046/j.1471-6712.2002.00047.x 
Smilansky, S. (1968). The effects of sociodramatic play on disadvantaged preschool children. Wiley.

Smilansky, S., \& Shefatya, L. (1990). Facilitating play: A medium for promoting cognitive, socio-emotional, and academic development in young children. Psychological \& Educational Publications.

Solish, A., Perry, A., \& Minnes, P. (2010). Participation of children with and without disabilities in social, recreational and leisure activities. Journal of Applied Research in Intellectual Disabilities, 23(3), 226-236. https://doi.org/10.1111/j.1468-3148.2009.00525.x

Stanton-Chapman, T. L., \& Schmidt, E. L. (2016). Special education professionals' perceptions toward accessible playgrounds. Research \& Practice for Persons with Severe Disabilities, 41(2), 90-100. https://doi.org/10.1177/1540796916638499

Starling, P. E., \& Nelson-Zlupko, L. (2011). An investigation of unstructured play in nature and its effect on children's self-efficacy. Doctorate in Social Work (DSW) Dissertations, 105.

Strickland, D. S., \& Morrow, L. M. (Eds.). (2000). Beginning reading and writing. International Reading Association; Teachers College Press.

Taub, D. E., \& Greer, K. R. (2000). Physical activity as a normalizing experience for school-age children with physical disabilities: Implications for legitimation of social identity and enhancement of social ties. Journal of Sport and Social Issues, 24(4), 395-414. https://doi.org/10.1177/0193723500244007

Ünal, M. (2009). The place and importance of playgrounds in child development. Inonu University Journal of the Faculty Education, 10(2), 95-109.

Vaira, D. (2009). More than just a place to play. Parks \& Recreation, 44(4), 32.

Wardle, F. (2000). Supporting constructive play in the wild. Child Care Information Exchange. 
White, R., \& Stoecklin, V. (1998). Children's outdoor play \& learning environments: Returning to nature. ResearchGate. https://www.researchgate.net/publication/267374472_Children's_Outdoor_Play_Learnin g_Environments_Returning_to_Nature

Wilson, R. (2007). Nature and young children: Encouraging creative play and learning in natural environments. Routledge, Taylor \& Francis Group.

Woolley, H. (2008). Watch this space! Designing for children's play in public open spaces: Utah State University libraries. The AuthorJournal Compilation Blackwell Publishing LtdGeography Compass, 495-512.

Woolley, H., \& Lowe, A. (2013). Exploring the relationship between design approach and play value of outdoor play spaces. Landscape Research, 38(1), 53-74. https://doi.org/10.1080/01426397.2011.640432

Woolley, H., Armitage, M., Bishop, J., Curtis, M., \& Ginsborg, J. (2006). Going outside together: Good practice with respect to the inclusion of disabled children in primary school playgrounds. Children's Geographies, 4(3), 303-318. https://doi.org/10.1080/14733280601005666

Yantzi, N. M., Young, N. L., \& Mckeever, P. (2010). The suitability of school playgrounds for physically disabled children. Children's Geographies, 8(1), 65-78. https://doi.org/10.1080/14733281003650984

Zahra, Z., \& Moore, R. (2013). The cognitive play behavior affordances of natural and manufactured elements within outdoor preschool settings. Landscape Research, 1. http://thecela.org/wp-content/uploads/THE-COGNITIVE-PLAY-BEHAVIOR- 
AFFORDANCES-OF-NATURAL-AND-MANUFACTURED-ELEMENTS-

WITHIN-OUTDOOR-PRESCHOOL-SETTINGS.pdf 
APPENDICES 
Appendix A. Data Collection Form 
Data - Dramatic Play Affordances of Outdoor Settings for First and Second Grade Children With and Without Disabilities

$$
\text { Date: }
$$

Observer.

Weather:

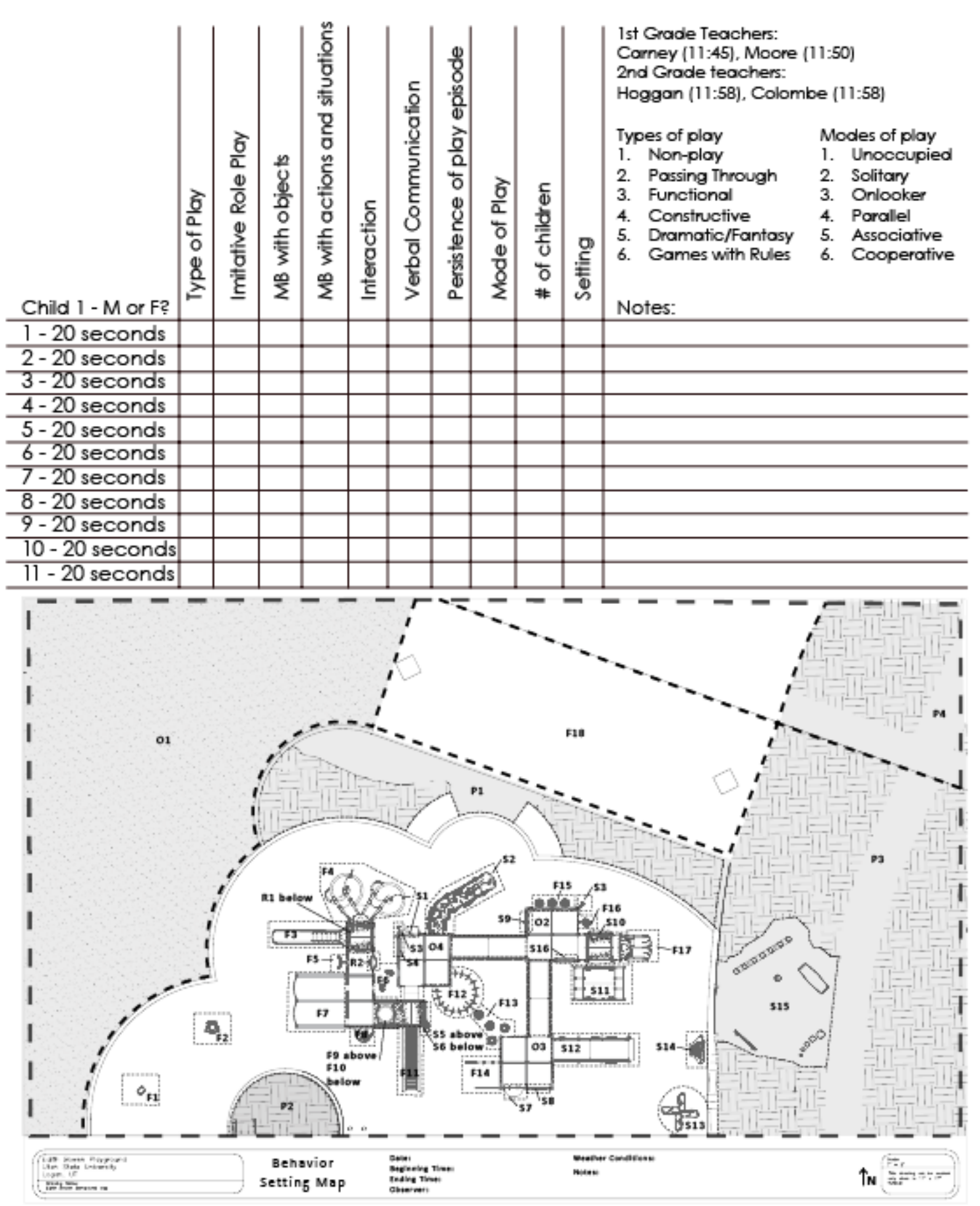


Data - Dramatic Play Affordances of Outdoor Settings for First and Second Grade Children With and Without Disabilities Date: Observer:

Weather:

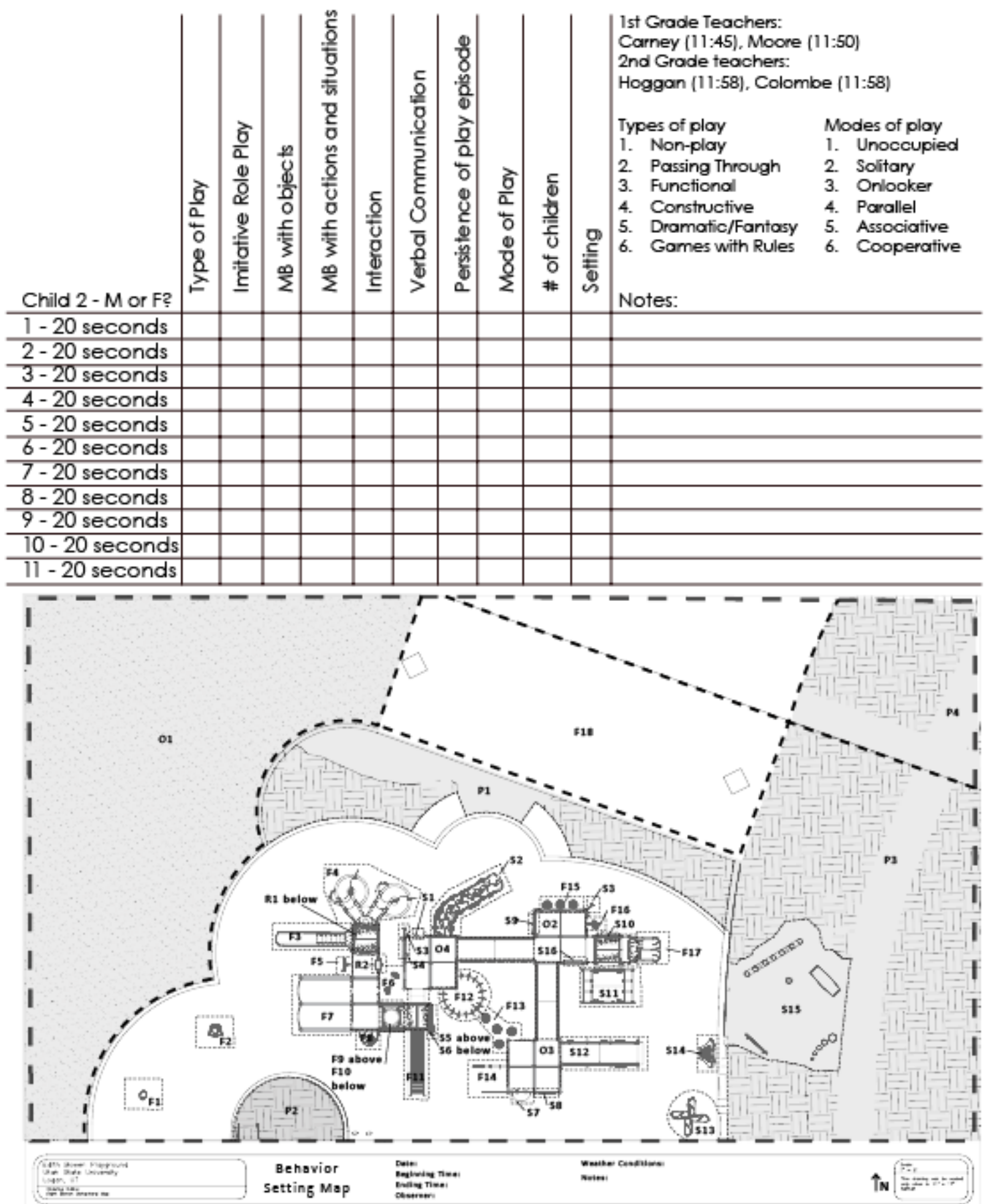


Data - Dramatic Play Affordances of Outdoor Settings for First and Second Grade Children With and Without Disabilities Date: Observer:

Weather:

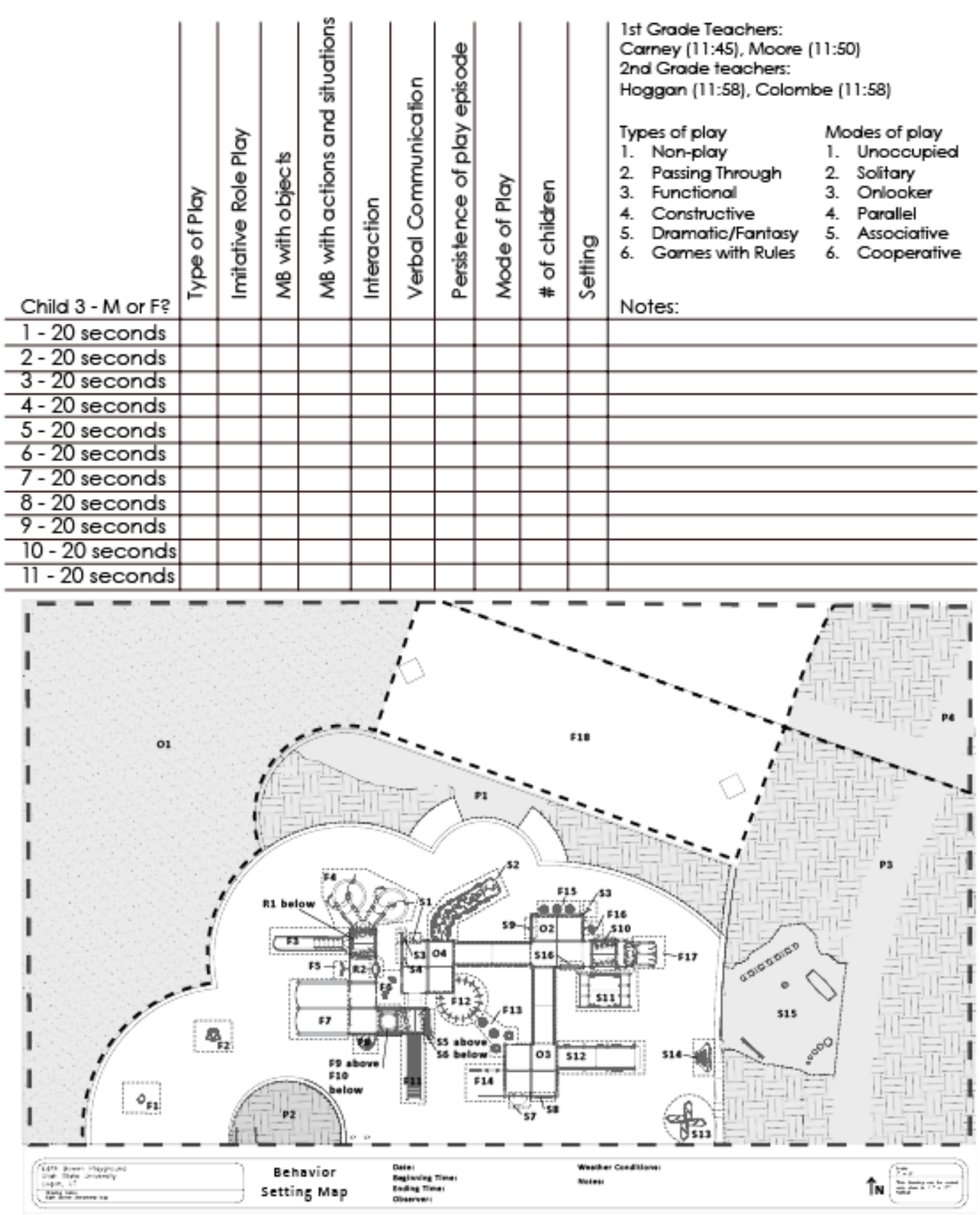


Appendix B. Data Collection Defined Measures 


\section{Types of Play}

1. Non-play (N): Child is not involved in any of the above play. Examples of non-play include watching others between activities, sitting, and talking about non-player-related topics or teacher-assigned tasks.

2. Passing through (T): Child passes through space without interacting with the setting other than to travel through.

3. Functional (F): Repetitive muscle movements, including running, climbing, splashing, jumping, riding a bike, and spinning.

4. Constructive (C): Child's activities are goal-oriented. Activities include building blocks or climbing to the top of a structure, etc.

5. Dramatic/Fantasy (D): Child takes on an imaginary role, using objects to represent something imaginary. Includes children playing house or pretending to be animals, etc.

6. Games with Rules (G): Child plays games with rules. Games with universal rules include tag, dodgeball, hide-and-go-seek, etc..

\section{Types of Dramatic Play}

Imitative role-play. A child engages in self-referenced role-play using imitative vocalizations or actions; he/she becomes a character other than himself/herself in another context.

Make-believe with objects. A child uses verbal declaration, movements, and/or a substitute object (which is not a replica of the actual object) to represent a real object in a play episode. Make-believe with actions and situations. A child uses verbal declarations to substitute for actions or to describe a situation to further the play episode.

Interaction. There are at least two children collaborating to develop or maintain a play scene. This is other-referenced role-play, in which a child commands, explains, offers play props, or gestures to peer(s) with the intent that the peer(s) will listen and use his/her suggestions to build the play episode.

Verbal communication. There is verbal dialogue between play partners within a play scene. Either a child speaks as a role-played character or speaks for an auxiliary character represented by an object.

Persistence of play episode. A child remains in an imaginary framework to support continuance of a play episode. The child may undertake multiple roles, but he/she follows a definite theme. There is some elaboration or repetition. Interruption may take place, as long as the child returns to the original theme.

\section{Modes of Play}

1. Unoccupied (U): Observing, not playing

2. Solitary (S): Playing alone

3. Onlooker (O): Observes w/out participating

4. Parallel (P): Playing side-by-side

5. Associative (A): Unorganized activity, no coordination

6. Cooperative (C): Organized w/specific roles 
Appendix C. Data Collection Map for Playground 


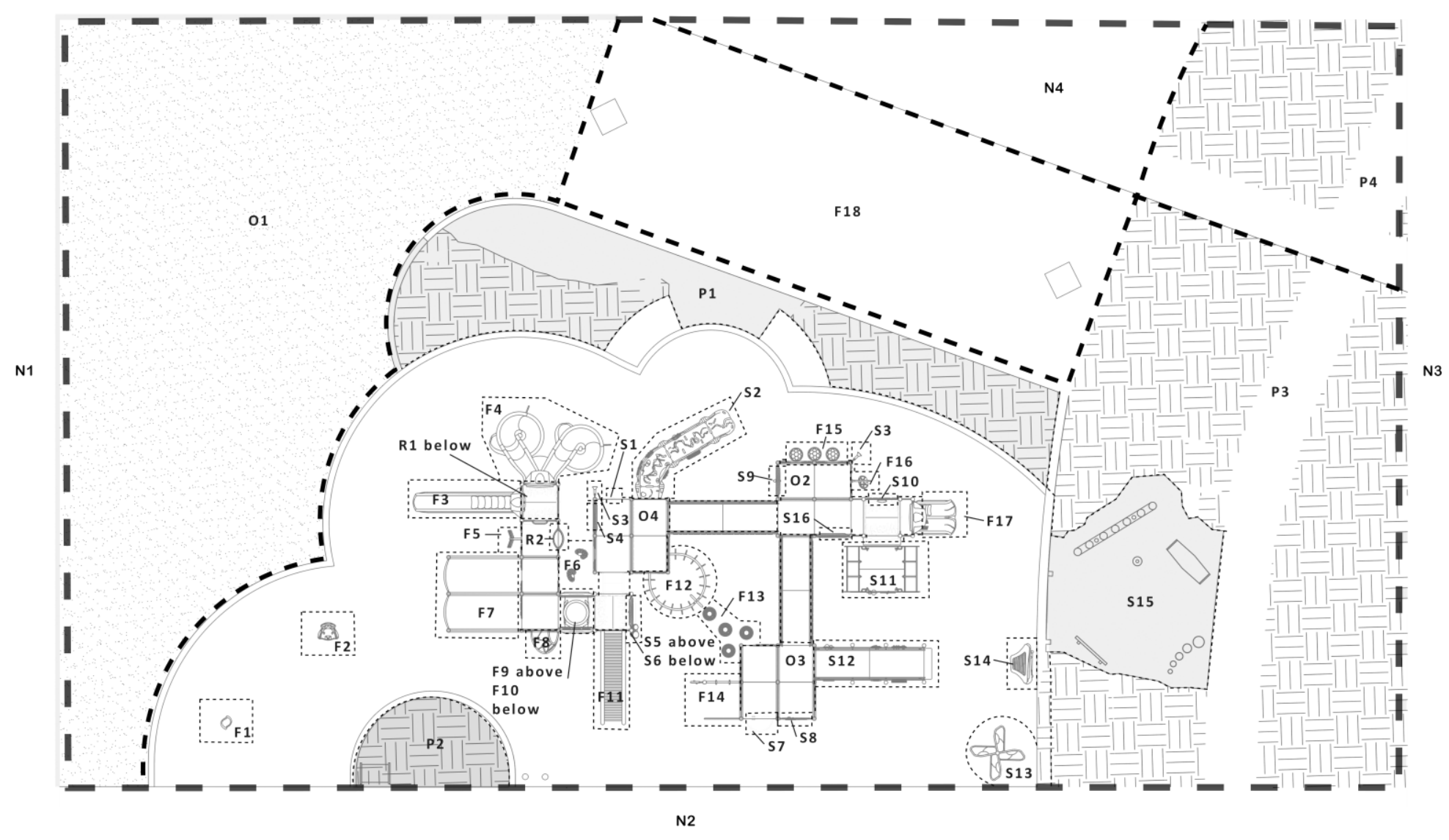


Appendix D. Data Collection Key 
5 Sensory Play

1 Telescope

2 sensory climber up \& Down

3 Talk Tube

4 Frog slide puzzle

5 kinetic spinner

6 Bongos

7 Gizmo Panel

8 Sensory wave Panel

9 sun Blosson Double

10 Thunder Ring

11 Sensory Wave Rock $N$ Raft

12 Sensory wave Ramp

13 shadow Play Area

14 Cantata chines

15 Music Area

16 Music Panel

R Rest/Activity Areas

1 Decorated Table and Benches

2 seat panel

P plantings

1 - 4 Planted Beds

o open Areas

1 Grass Hill

2 - 4 play structure surface
F Functional play

1 rilted whirlwind seat

2 sensory wave seat

3 zip slide

4 spiral slide

5 stego climber

6 sprout climber

7 Ropes Course

8 Erratic climber

9 Arch Bridge

10 straight crawl Tube

11 Roller slide

12 Loop Ladder

$13 \mathrm{X}$-pod step

14 Gymnastics Area

15 Hex pod step

16 spiral climber

17 Rumble \& Roller zip slide

18 Basketbal1 court

others

N1 Area west of playground - open grassy area, mound and trees

N2 Area south of playground - concrete area with four-square, and concrete dividers, next to building

N3 Area east of playground - concrete area, next to building, with tables and snall planted areas

N4 Area north of playground - area contains concrete slab with statues and an open grassy area sounding

ARD Around the playground, multiple settings used

AF2 Area around setting $\mathrm{F} 2$

To2 Top of setting 02

uo3 under setting 03 
Appendix E. Parental Consent Form 
Informed Consent

\section{Do Inclusive Playground Design Practices Support Beneficial Play Behaviors?}

\section{Purpose}

Your child is invited to participate in a research study conducted by Dr. Keith Christensen, an Associate Professor in the Department of Landscape Architecture and Environmental Planning at Utah State University. The purpose of this research is to better understand whether the design of the new playground at the Edith Bowen Laboratory School (EBLS) supports beneficial play behaviors and/or increased dramatic play between children with and without disabilities.

This form includes detailed information on the research to help you decide whether to participate in this study. Please read it carefully and ask any questions you have before you agree to participate.

\section{Procedures}

Your child's play on the new EBLS playground may be observed during lunch recess during this school year. The children will be observed to record the type of dramatic play (role-play, make-believe, interaction, etc.), mode of play (solitary, cooperative, etc.), and length of dramatic play interactions (persistence) children engage in within different areas of the playground.

The researcher will be comparing these measures between children with and without disabilities, some of which are indicated by whether your child has an Individualized Education Plan (IEP). If you agree to allow your child's playground activities to be observed, the researchers will also collect the IEP designation category for your child (autism, specific learning disability, speech or language impairment, etc.). During observation the researcher will also record the IEP designation category of the child engage in dramatic play. No information, such as your child's name, will be shared or documented other than the IEP category.

Of course your child's participation is voluntary and confidential. Approximately 98 students (grades 1 through 2) will participate in the study.

Risks

Participation in this study has minimal risk, meaning that the risks are no higher than those you encounter in everyday activities. The foreseeable risk is some loss of anonymity with respect to your child's IEP status. In_order.to minimize this risk, the researchers will only document IEP categories. The observations do not require personal identifying information which could be linked to IEP categories.

\section{Benefits}

There is no direct benefit to you from participation in this study. Although participation in this study may indirectly benefit you through changes in the design of future playgrounds to better support beneficial play behaviors. More broadly, this study will help the researchers leam more about the types of playground environments which support play between children with and without disabilities.

\section{Confidentiality}

The information collected is from observations of playground activities and identified IEP designation categories. The researchers will make every effort to ensure that the information observed and identified as part of this study remains confidential. Your child's identity (name, image, or personal description) will not be retained for or revealed in any publications, presentations, or reports resulting from this research study. 
It is unlikely, but possible, that others (Utah State University, state, or federal officials) may require us to share the information we obtain from the study to ensure that the research was conducted safely and appropriately. We will only share information if law or policy requires us to do so. If the researchers learn that your child has been subject to abuse, state law requires that the researchers report this behavior to the authorities.

\section{Voluntary Participation}

Your child's participation in this research is completely voluntary. If you agree to allow their participation now and change your mind later, you may withdraw at any time by contacting the researcher. If you decide not to participate, the services you receive from EBLS will not be affected in any way.

\section{IRB Review}

The Institutional Review Board (IRB) for the protection of human research participants at Utah State University has reviewed and approved this study. If you have questions about the research study itself, please contact the Principal Investigator at 435 797-0507 or keith.christensen(@usu.edu. If you have questions about your rights or would simply like to speak with someone other than the research team about questions or concerns, please contact the IRB Director at (435) 797-0567 or irb@ $\underline{\text { usuedu. }}$

Keith Christengen

Principal Investigator

(435) 797-0507; keith.christensen@usu.edu

\section{Informed Consent}

If you are willing to allow us to observe your child's playground activities and have their IEP designation category, if applicable, identified as part of this study, please click HERE and provide your name. If you do not want us to include observations of your child's playground activities in this study or have their IEP designation category identified, you do not need to take further action.

Please be sure to retain a copy of this form for your records. Thank you. 